\title{
Communicative facework in marital dissolution and post- dissolution processes
}

Brandi N. Frisby

West Virginia University

Follow this and additional works at: https://researchrepository.wvu.edu/etd

\section{Recommended Citation}

Frisby, Brandi N., "Communicative facework in marital dissolution and post-dissolution processes" (2010). Graduate Theses, Dissertations, and Problem Reports. 3107.

https://researchrepository.wvu.edu/etd/3107

This Dissertation is protected by copyright and/or related rights. It has been brought to you by the The Research Repository @ WVU with permission from the rights-holder(s). You are free to use this Dissertation in any way that is permitted by the copyright and related rights legislation that applies to your use. For other uses you must obtain permission from the rights-holder(s) directly, unless additional rights are indicated by a Creative Commons license in the record and/ or on the work itself. This Dissertation has been accepted for inclusion in WVU Graduate Theses, Dissertations, and Problem Reports collection by an authorized administrator of The Research Repository @ WVU.

For more information, please contact researchrepository@mail.wvu.edu. 
Communicative Facework in Marital Dissolution and Post-dissolution Processes

\author{
Brandi N. Frisby
}

Dissertation submitted to the College of Arts and Sciences

at

West Virginia University

in partial fulfillment of the requirements

for the degree of

Doctor of Philosophy

in

Communication Studies

Melanie Booth-Butterfield, Ph.D., Chair

Megan R. Dillow, Ph. D

Matthew M. Martin, Ph.D.

Keith A. Weber, Ed.D.

Richard T. Walls, Ph.D.

Department of Communication Studies

Morgantown, West Virginia

2010

Keywords: face threat, facework, divorce, emotion, well-being, post-divorce relationships, turning points, attachment, hurt 


\section{ABSTRACT \\ Communicative Facework in Marital Dissolution and Post-dissolution Processes \\ Brandi N. Frisby}

Divorce affects nearly 24,000 adults (U.S. Bureau of the Census, 2008) and one million children yearly (Amato, 2000), often with negative consequences for those who are involved (Amato, 2000; Kiecolt-Glaser \& Newton, 2001). Unlike previous research which focused on predictors of divorce, this dissertation ( 2 studies) focused on the communicative processes that occur when divorce is initiated and in turning points which comprise the interactions in post-divorce relationships. In study one, participants $(N=69)$ reported on the conversation where the decision to divorce was made, the face threats and facework which were communicated during that conversation, and the individual and relational outcomes associated with that conversation. Results indicate that the divorce conversation is indeed face threatening, that face threats play an integral role in the emotions experienced, and the participants' affect and attachment to the former spouse in the post-divorce relationship. In study two, participants $(N=165)$ reported on postdivorce turning points that they perceived as either positive or negative, the face threats and facework in that turning point, and individual and relational outcomes. Results indicate that negative turning points were perceived as most face threatening, while positive turning points were perceived to have higher levels of facework practiced. Further, the face threats and facework which emerged in the post-divorce turning points continued to influence emotions and the post-divorce relationship. However, the face threats and facework in turning points differed from the conversation where the divorce decision was made in that face threats and facework contributed to the individuals' levels of stress and well-being. Considered together, facework appears to be salient communicative strategy with the potential to alleviate some of the negative consequences associated with divorce and post-divorce interactions. 


\section{Table of Contents}

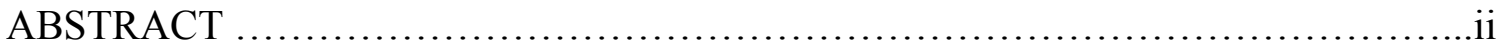

ACKNOWLEDGEMENTS ...................................................vii

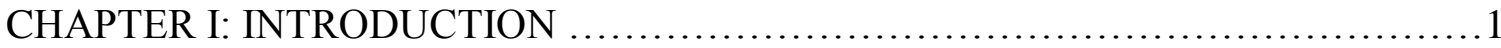

Theoretical Framework ................................................4

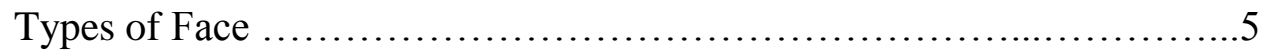

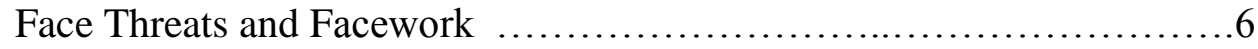

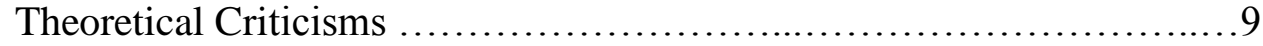

Relationship Dissolution .................................................. 11

Deciding to Dissolve ..............................................13

The Dissolution Message .....................................15

Affect During Divorce .....................................17

Reactions to the Dissolution Message ........................17

The Post-dissolution Relationship .................................19

Turning Points in Post-dissolution Relationships ..............21

Affect and Well-being Following Divorce ....................25

Sources of Negative Impacts on Individuals ...................28

Facework in Dissolution Processes .......................................29

Face Threats When Deciding to Dissolve ............................30

Facework in Dissolution Messages .......................... 31

The Post-Dissolution Relationship ................................33

The Nature of the Post-Dissolution Relationship ................33

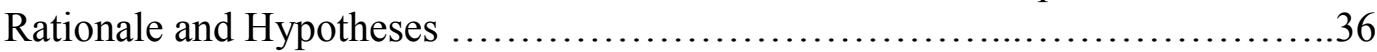

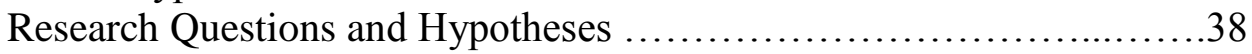

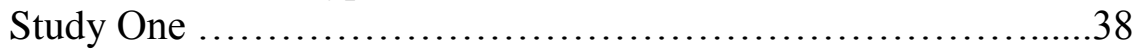

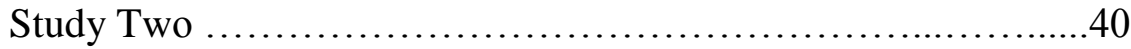

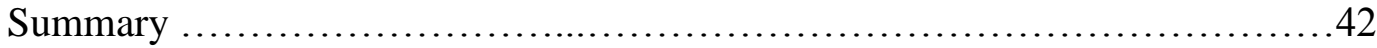

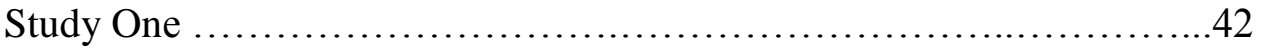

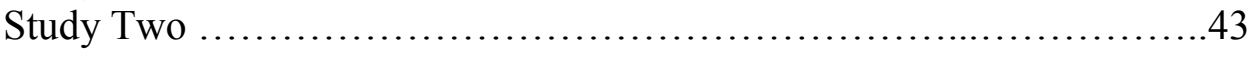

CHAPTER II: METHOD .................................................44

Study One ............................................................44

Participant Recruitment ...........................................44

Participants .......................................................44

Analysis of Dyads ..............................................46

Final Participant Sample ..........................................47

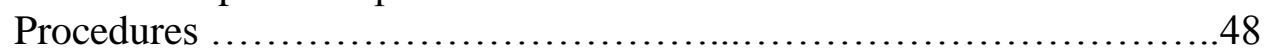

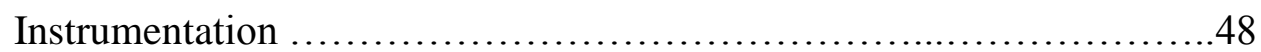

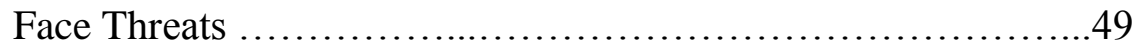

Facework .............................................49

Conflict ..............................................50 
Caring ....................................................... 50

Hurt ...................................................... 50

Emotion ................................................... 51

Well-being .............................................. 51

Current Relationship ........................................52

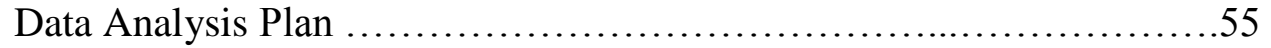

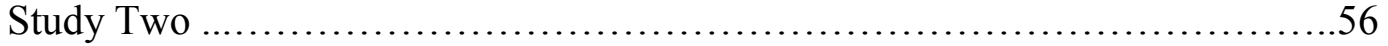

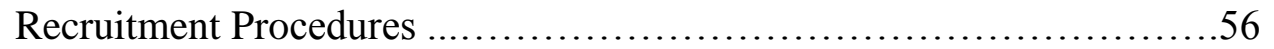

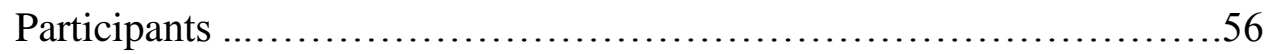

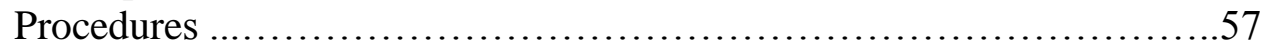

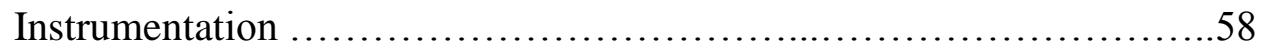

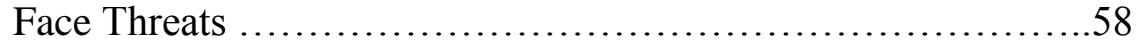

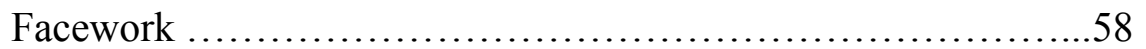

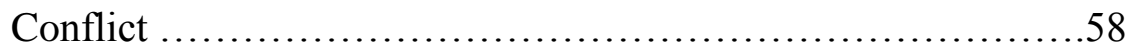

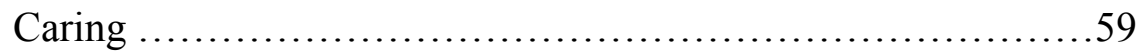

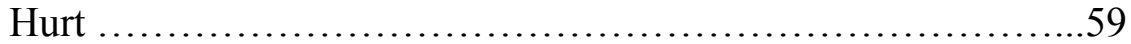

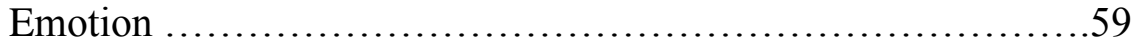

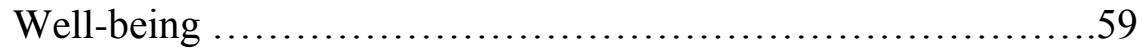

Current Relationship .....................................60

Data Analysis Plan .................................................62

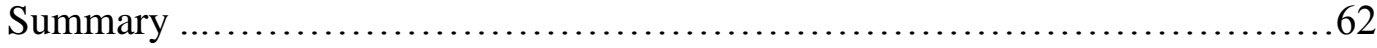

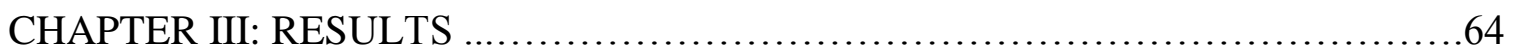

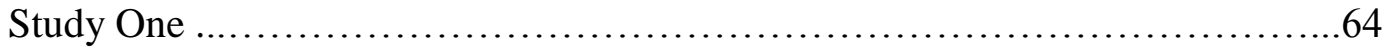

Preliminary Data Analyses ........................................64

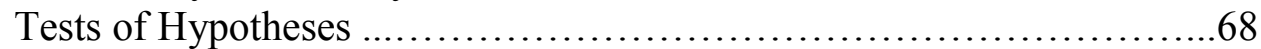

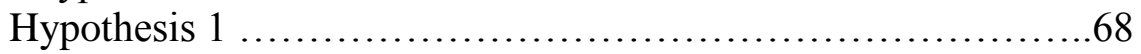

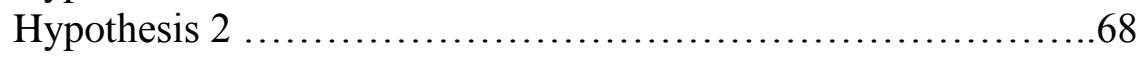

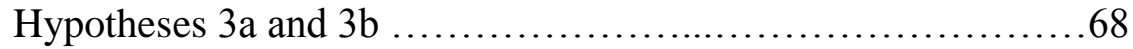

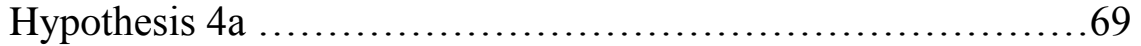

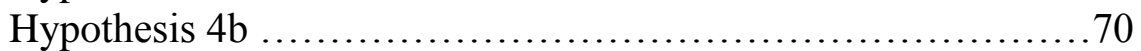

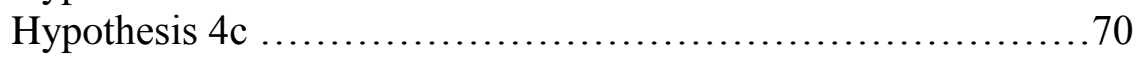

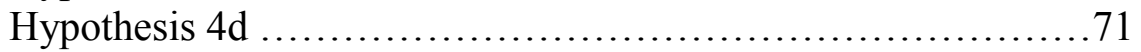

Post Hoc Analyses ....................................... 71

Study One Summary .................................................

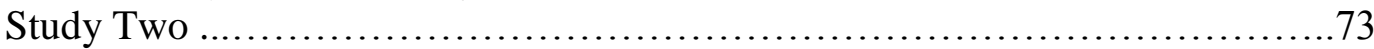

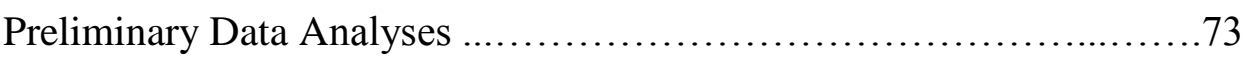

Turning Points ....................................................... 74

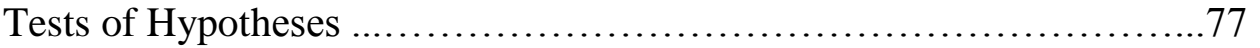

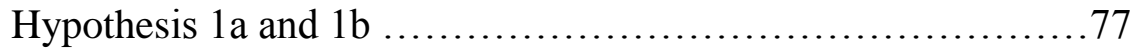

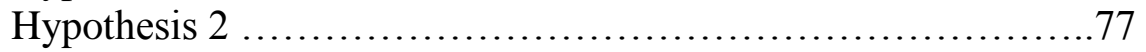

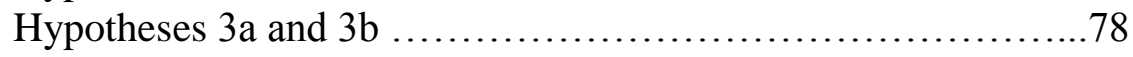

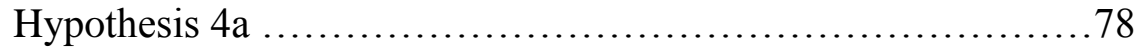

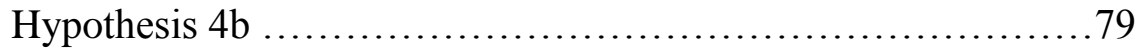

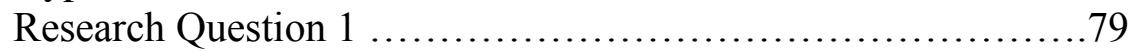




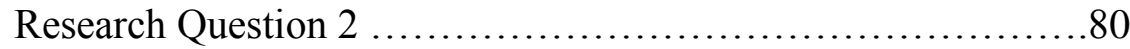

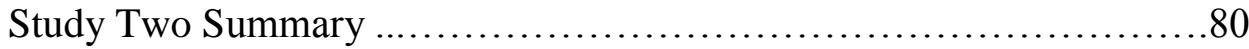

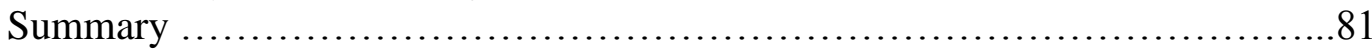

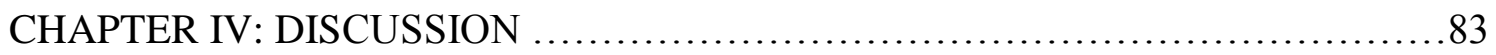

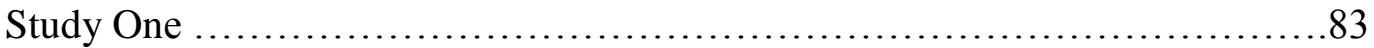

Face Threats and Facework in the Divorce Conversation ................83

Impact of the Divorcee's Role in the Divorce Decision ...................85

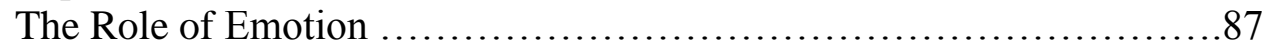

Divorce and Well-being ........................................... 89

The Impact on Post-divorce Relationships ..............................99

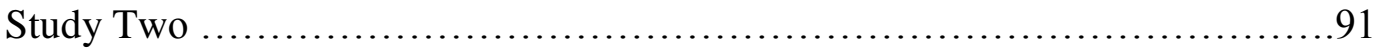

Face Threats and Facework in Post-divorce Turning Points ..............91

Impact of Divorcee's Role on Post-divorce Turning Points .................92

The Role of Emotion ................................................93

Post-divorce Relationships and Well-being ..............................94

The Impact on Post-divorce Relationships ...........................95

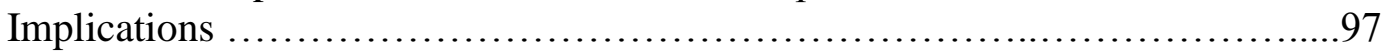

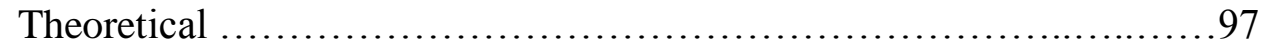

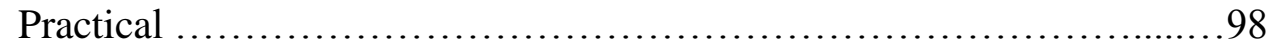

Limitations ..................................................... 100

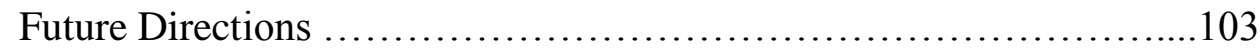

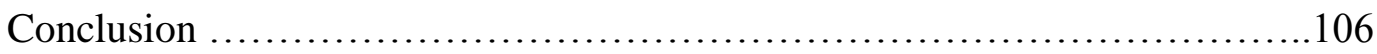

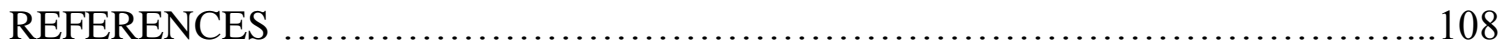

APPENDICES

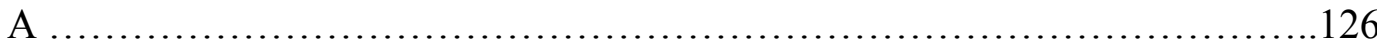

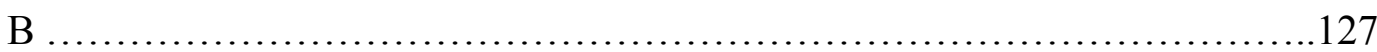

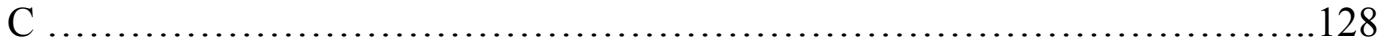

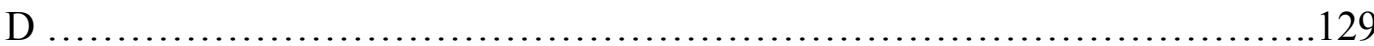

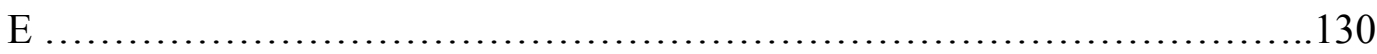

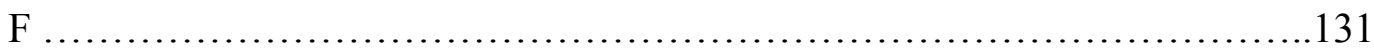

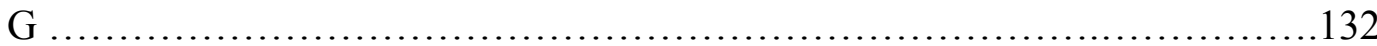

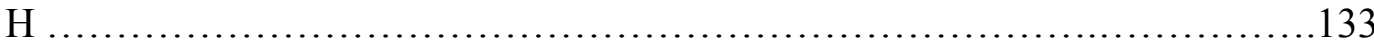

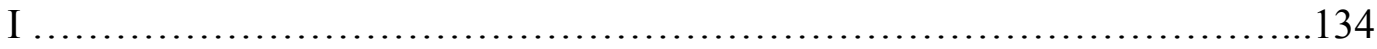

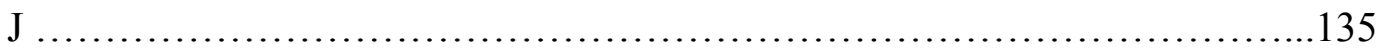

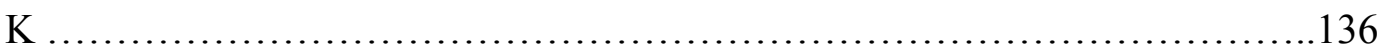

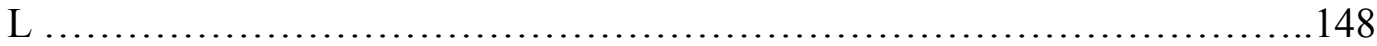




\section{LIST OF TABLES AND FIGURES}

Table 1. Study One Descriptive Statistics .....................................54

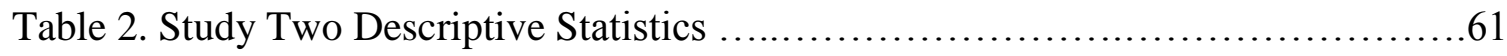

Table 3. Correlation Matrix of Study One Variables ................................67

Table 4. Correlation Matrix of Study Two Variables ............................... 76 


\section{ACKNOWLEDGEMENTS}

This dissertation would not have been possible without the invaluable guidance I have received during my academic career and without those who have been a part of my professional development. At the forefront of this guidance and professional development is my advisor Melanie Booth-Butterfield. She has always pushed me to think about the

"big picture." Her support and wisdom go above and beyond this dissertation, through the knowledge I have gained from her about being a professional, a professor, a researcher, and a colleague. I am thankful that I had Melanie as a mentor during my time at West Virginia University.

I am lucky enough to have an entire team of people who provided me with the skills and support I needed to complete this dissertation: Dr. Matthew Martin, Dr. Megan Dillow, Dr. Keith Weber, and Dr. Richard Walls. Thank you for the unique perspectives that each of you brought to this committee and for the opportunity to work with you in other capacities. You each provided me with your interest, time, opinions, knowledge, and suggestions which helped bring this dissertation to fruition. I appreciate all that you have done with me and for me.

Although not a part of my dissertation experience, I would like to acknowledge some additional influences on my education, Dr. Russell Proctor, Dr. Wendy Nichols, Dr. Laura O’Hara, Dr. Glen Stamp, and Dr. Scott Myers. Each of these individuals represent a different phase in my academic career which led me to where I am now. Dr. Proctor, thank you for sparking my interest in the field of communication. Wendy, thank you for your role in helping me to realize what I wanted to do after my undergraduate degree. Dr. O’Hara, thank you for helping me to continue learning about my primary interest, 
romantic relationships, and for advising my first major research project. Dr. Stamp, thank you for encouraging me to explore my doctoral options and your continued interest in my progress. Dr. Myers, thank you for setting high expectations and helping me to work toward reaching them.

Finally, this dissertation came to be because of some very important people in my personal life. My parents, Gary and Stacey, always encouraged me to be independent, to work hard, and to value education. It is because of them, and their belief in me, that I desired to continue my education and pursue my $\mathrm{PhD}$. They have provided me with everything I have needed to succeed. I would also like to thank my sister Erica, and my grandparents, who also provided love, support, and motivation to me throughout my entire education, and most of all, during my time here at West Virginia University. I have several friends I would like to acknowledge, for their support and enduring friendship: Kim, Margo, Kelly, Robin, Laura, Andrea, and Abbie. Additionally, I was blessed with colleagues and officemates, who I also consider friends, who have shared in this process with me, providing all of the love, support, and inspiration that a family provides. Last, I would like to thank Joe, for his unwavering love, support (emotional and technical), and patience, over both time and distance, while I pursued my personal goals. I am eternally grateful to my professors, family, friends, and Joe. 


\section{Chapter One}

\section{Introduction}

Within the primary adult relationship of marriage, spouses are important and irreplaceable (Cutrona \& Suhr, 1994; Kiecolt-Glaser \& Newton, 2001; McKenry \& Price, 1991; Weintraub \& Wolf, 1983). Yet in 2008, approximately 23,346 individuals experienced divorce (U.S. Bureau of the Census, 2008). Despite the importance spouses place on one another, it is evident that even marriage is not always a permanent union. The U.S. Department of Health and Human Services (2002) reports approximately onethird of first marriages end in divorce within ten years, and $50 \%$ of all first marriages will experience divorce at some point in the lifespan (Braver, Shapiro, \& Goodman, 2006). Moreover, individuals who remarry have a greater chance of experiencing divorce again (Amato, 2000). In a study of divorce across three different countries, Bodenmann et al. (2007) found that ineffective interpersonal communication was a primary reason cited for divorcing a spouse. Importantly, ineffective interpersonal communication may continue to plague couples during the divorce process. Amato argued that divorce is the most traumatic situation, and has the furthest reaching implications, of all life events.

Although romantic relationships can be a source of happiness (Demir, 2008), they are often a source of hurt (Bachman \& Guerrero, 2006). Relationship termination is a frequently occurring and particularly dreaded source of hurt, one which has the potential to be deleterious for the individuals involved (Baxter, 1982, 1983; Leary, 2001). The stressful and traumatic nature of divorce (Albrecht, 1980) fundamentally alters the relationship between former spouses and impacts the social network, the familial network, and any children the couple may have (T. D. Afifi \& McManus, 2006; Milardo, 
1987; Terhell, Broese van Groenou, \& Tilburg, 2004). In fact, over one million children are involved in divorce processes every year, with the potential to experience multiple divorces as their parents remarry and then, divorce again (Amato, 2000). Ahrons (1980) argued that the relationship between former spouses is the foundation on which the entire restructuring of the family is based after divorce. As partners adapt to the changes elicited by divorce, communication plays an essential role in the process (T. D. Afifi \& McManus, 2006).

Divorce has both immediate and long term consequences for the divorcees. Individuals who have experienced separation and rejection from a romantic partner physiologically and psychologically may experience grief similar to those who have lost a loved one through death (Archer \& Fisher, 2008). Divorced individuals experience greater physical, mental, and emotional problems than those who remain married (Amato, 2000; Kiecolt-Glaser \& Newton, 2001). Furthermore, despite the popular belief that time heals (Lucas, 2005), divorcees experience deteriorated physical and psychological conditions for years following marital termination (T. D. Afifi \& Hamrick, 2006; Kitson, 1982).

It is imperative to study the divorce process because of the impact divorce has on others outside of the failing marriage (e.g., children, in-laws; Ferguson, 2004; Serewicz, 2006). For example, children also experience immediate and long term consequences as a result of parental divorce. In the period immediately following divorce, children cope with losing extended family members, losing contact with a parent, suffering academically, feeling caught between parents, experiencing social, behavioral, and emotional problems, and experiencing changes in discipline and financial support 
(Amato, 2000, Barber \& Demo, 2006; Hetherington \& Kelly, 2002; Schrodt \& T. D.

Afifi, 2007). In the long term, children from divorced families are more likely to experience multiple family transitions as their parents remarry and then divorce again, are at greater risk to divorce in their own marriages, engage in risky sex, suffer from depression, pessimism, poorer communication skills, lower relationship satisfaction, and negative attitudes toward romantic relationships (Amato, 2000; Bartell, 2006;

Hetherington \& Kelly, 2002). Thus, communication that occurs during dissolution and post-dissolution processes influences multiple individuals, relationships, and the wellbeing of all who are directly, and indirectly, involved. The well documented impact and negative outcomes of divorce on those involved speaks to the importance of understanding more about ways to alleviate the negativity of the event, in order to begin addressing the detrimental psychological, emotional, and physiological consequences that divorcees experience.

Some successful research efforts have moved toward skills training to improve marital communication and to prevent divorce (Gottman, 1994; Hawkins, Blanchard, Baldwin, \& Fawcett, 2008; Markman, Floyd, Stanley, \& Storaasli, 1988). More recently, communication skills training for the co-parental relationship following the divorce has become important (Whitehurst, O'Keefe, \& Wilson, 2008). Both marital and co-parental training programs largely focus on conflict and conflict management in dissolution and post-dissolution stages. Amato (2000) argued that the results of divorce can be positive when problems between the divorcing partners are resolved effectively. Although effective conflict management may enhance perceptions of successful dissolution, other communication skills should play an important role in dissolution and post-dissolution 
renegotiation. For example, strategic facework, or the protection of the former spouses' identity and feelings when requesting a divorce, when defining the post-divorce relationship, and when collaborating to raise children may contribute to perceptions of effective divorce and post-divorce communication. Practicing facework in the divorce process may reduce face threats, and thereby reduce conflict between the individuals. Face sensitive divorce talks may also maintain the face of each divorcee to his/her social networks and families setting the stage for a more amicable termination event and later readjustment. Therefore, the purpose of the current studies was to examine the practice of facework in divorce. Facework was examined at several points throughout the divorce process including the conversation in which the divorce decision is finalized, positive turning points in the post-divorce relationship, and negative turning points in the postdivorce relationship. Communicative facework was further examined for its impact on stress, ongoing attachment to the spouse, and the general affect toward, and type of, postdivorce relationship.

\section{Theoretical Framework}

Goffman (1967) defined face as the "positive social value a person effectively claims for himself' (p. 5). Through communication, individuals portray this constructed self to others and seek support for this identity from others. Individuals believe that their identity, or face, is important to them and will work to have that identity accepted (Cupach \& Metts, 1994). This identity is comprised of two faces. Within every interaction, both faces are presented (i.e., positive and negative). Consequently, both faces have the potential to be either supported or threatened. Specifically, both the sender and receiver possess a positive and negative face, and both may experience threat to their 
own positive and negative face. While presenting face and experiencing face threat, senders and receivers can simultaneously threaten and support their interaction partner's face.

Ideally, interactants will communicate in ways which maintain the faces of all parties involved (Goffman, 1967). Individuals may possess a protective orientation which is focused on protecting the face of the conversation partner or a defensive orientation which is focused on protecting their own face (Goffman). A defensive orientation is characterized by individuals' concern for themselves and their own face, even at the expense of others' face. Conversely, individuals with a protective orientation will display more concern for the face of the partner and attempt to protect the face of the interaction partner, even at the expense of their own face. Scholars have used Goffman's conceptualization of face as a foundation for theoretical advancement, expanding on the notion of face and communicative strategies which support or threaten one's face.

\section{Types of Face}

Two specific types of face are considered; positive face is the desire for approval, closeness, solidarity, and liking while negative face is a need to experience autonomy and freedom from imposition (Holtgraves, 2001). In a different approach, Lim and Bowers (1991) conceptualized three types of face. In Lim and Bower's (1991) conceptualization of face, negative face still exists as a concern for autonomy. However, positive face is partitioned into two different types, an affiliative face and a competence face. Affiliative face can be understood as the desire for closeness and social approval, and competence face involves the approval of the abilities and skills which are possessed. As Goffman (1967) notes, communication between individuals does not always support the affiliative, 
autonomy, or competence needs of their partner. When individuals do not perceive that their identity is supported, they experience face threats, and when senders realize that they are threatening the face of another, they may attempt to temper the perceived face threat and practice facework (Goffman). Additionally, the one who experiences face threat will often attempt to respond to this face threat using facework.

\section{Face Threats and Facework}

Communicative behaviors which are contradictory to the self-identity an individual holds, denying or attacking the positive or negative face of that individual is labeled a face threatening act (FTA). FTAs deny affiliative needs, reduce perceptions of autonomy, or minimize the recognition of competence in some domain. The perception of a face threat is dependent upon a variety of factors including power, degree of imposition, social distance, and emotion (Brown \& Levinson, 1987; Goffman, 1967) in that the power and social distance of the person communicating the face threat impacts an individual's perception of the imposition and resulting emotion. Awareness of face and subsequent efforts to reduce threats to face have been labeled facework. Divorcing couples may communicate in ways which protect their own, their partners', or both individuals' faces. By that same token, communication during divorce may include FTAs and elicit corrective facework to address face threats. During the divorce process, individuals may feel that they were incompetent in the relationship, no longer liked, or that they do not have a choice, all of which may increase face threat. Their former partner, however, may try to reduce these feelings by focusing on their positive qualities or including them in the divorce decision (i.e., practicing facework), while simultaneously dissolving the relationship. 
Several typologies of facework have contributed to a new understanding of the process of face. For example, Cupach and Metts (1994) described facework as either preventative or corrective. Similar to Goffman's (1967) avoidance strategy, preventative facework is utilized to avoid threatening face. For example, individuals who want to divorce may not initially ask for the divorce at all, to avoid face threat for either partner. Corrective facework is utilized following a face threat, and is an attempt to repair perceived damage to an individual's face. For example, a divorcing couple may still support their former spouses' face by allowing them autonomy throughout the process, or showing approval of them as a parent. Additionally, a former spouse may practice corrective facework by admitting some responsibility and guilt, and thus, incurring face threat for the divorce.

Consistent with their conceptualization of three types of face, Lim and Bowers (1991) delineated three types of facework to enhance or protect both positive and negative face needs. Solidarity facework appeases an individual's affiliative needs, approbation facework assures the receivers that they are perceived as competent, and tact facework is employed to respect an individual's autonomy. Of particular interest to the current studies are the facework strategies of solidarity, approbation, and tact.

Solidarity, approbation, and tact have been examined in a variety of contexts including friendship, instructional settings, and the workplace (Agne \& White, 2004; Kerssen-Griep, Hess, \& Trees, 2003; Kerssen-Griep, Trees, \& Hess, 2008; Wagoner \& Waldron, 1999). In previous research on friends and acquaintances in group work, participants who perceived that their relationship was intimate and equal used more overall facework including solidarity, approbation, and tact (Lim \& Bowers, 1991). 
When relationships were perceived as equal but not intimate, only tact was enacted (Lim \& Bowers). Of the three types of facework, Wagoner and Waldron (1999) reported that solidarity was used most often overall in organizations. The presence of any type of facework generally enhances positive outcomes including relationship satisfaction, student motivation, student involvement (Agne \& White, 2004; Kerssen-Griep et al., 2003). It is unclear however which, if any, facework strategies will be used during divorce given the tumultuous state of intimacy, equality, and satisfaction between the divorcing spouses (Albrecht, 1980; Amato, 2000; Hetherington \& Kelly, 2002).

Craig, Tracy, and Spisak (1986) argued that the facework strategies can co-occur in interactions. However, few studies have examined facework strategies as they occur together. A notable exception (e.g., Wagoner \& Waldron, 1999), addressed the complexity of facework in interactions by coding for nine, instead of three, categories of facework. Specifically, the interactions could demonstrate more than only solidarity, approbation, or tact. The three categories of facework were combined to create a coding scheme which would apply when multiple types of facework were utilized in interactions between supervisors and employees (e.g., solidarity/approbation, approbation/tact/solidarity). The authors concluded that this study supported and extended facework theories by considering the complexity of co-occuring multiple faces and facework strategies, and demonstrating that solidarity appeared to be a universally effective type of facework.

More recently, Kerssen-Griep et al. (2008) developed a scale to measure the types of facework, allowing more than one type to occur in any given interaction between students and instructors. Further work on the facework scale indicated that approbation 
and solidarity were practiced using general positive face support, while tact was only used in negative face support. That is, only two types of facework emerged: positive face support and negative face support. Given the complexity of divorcing and post-divorce relationships, multiple faces may be threatened and multiple facework strategies may be utilized. However, the negative affect associated with divorce may hinder the use of facework strategies by either the sender or the receiver of the divorce messages. Instead, divorce may be a context in which face threat occurs, and facework is not practiced. However, the existence of face threats in divorce, and subsequent facework which can detract from face threats, have not been explored. The exploration of these constructs in a frequently occurring, and often negative, context will inform and extend theoretical frameworks including face and facework.

\section{Theoretical Criticisms}

Facework theories have undergone several revisions and improvements based on scholarly criticisms. Craig et al. (1986) made three suggestions for future research which focus on the complexity of face threat and facework in interaction. First, they suggested that messages can contain more than one politeness strategy, and that researchers should examine the multiple forms of politeness in a message. Second, any message may serve multiple functions. More specifically, a message may be designed to attend to multiple faces at once. Thus, both positive and negative face should be simultaneously considered. Finally, Craig and colleagues argued that both sender and receiver should be considered active in the communication process, in that they can threaten face, experience face threat, and practice facework simultaneously. To summarize, both partners can experience positive and negative face threat, and design messages to threaten, and 
support, both positive and negative face in any given interaction. Of particular interest to the current investigation, Kunkel, Wilson, Olufowote, and Robson (2003) noted that both partners in dissolution events experience threats to positive and negative face. Although threats to both faces can occur, this phenomenon has only been explored in the workplace (Wagoner \& Waldron, 1999) and in the classroom (Kerssen-Griep et al., 2003; KerssenGriep et al., 2008). The occurrence of multiple types of facework has not been explored in relation to the dissolution process, and warrants further attention. The dissolution process involves the loss of close relationship, and face threat in close relationships may be more salient than in relationships with co-workers or classmates.

An additional critique of research in facework concerns the exclusion of emotion. Goffman's (1967) original discussion of face included emotion as an integral component. Despite this early recognition of emotion in the process of face and facework, little research has actually examined emotion as a response to face threat. More recently, scholars have begun to make links between face and emotion. For example, Cupach and Carson (2002) examined emotions associated with positive and negative face threat in relational complaint situations. Both types of face threat predicted negative emotion, with negative face threat being the strongest predictor of embarrassment, anxiety, and depression. Similarly, Francis (1997) found that emotion was inseparable from identity. To the extent that face is a construction of, and evaluation of, an individual's identity, emotion will be linked to the face threats experienced.

The two current studies took the theoretical criticisms into consideration and built upon the advancements of recent work in facework and dissolution research (e.g., Cupach \& Carson, 2002; Kerssen-Griep et al., 2008; Metts, 1992). To summarize, the two 
current studies examined both types of face threat (i.e., positive and negative), and both types of facework (i.e., positive and negative), were examined as experienced by both the sender and the receiver of the dissolution message. Finally, emotional reactions were incorporated to provide a more complete picture of the implications of divorce, face threat, and facework.

Divorce offers a particularly salient context in which to study each of these ideas. Pinker (2007) argued that politeness is used to "lubricate" interpersonal events (p. 439). Facework manifests in relational interactions, and may be especially pertinent in difficult interpersonal situations. Arguably, relationship dissolution is one of the most hurtful and face-threatening interpersonal events (Baxter, 1982; Kunkel et al., 2003). Thus, the need for "lubrication" may become more necessary in more difficult situations such as relationship dissolution.

\section{Relationship Dissolution}

Individuals will encounter a plethora of diverse negative events throughout their lifespan. Most perceive relational dissolution, along with infidelity and extradyadic flirting, as the most negatively valenced and emotionally painful events when compared to other hurtful events (Bachman \& Guerrero, 2006). A breakup, infidelity, or extradyadic flirting may be more emotionally painful because it implies a problem with the individual or the relationship. The implied problem, or suggested failure in the relationship, is potentially harmful to the self image of a partner. Partners who are on the receiving end of these painful events may not feel competent, liked, or approved of if their partner is ending the relationship or seeking a relationship elsewhere. Perceptions that they are not competent, liked, or approved of lead to perceived face threat. Given the 
importance of one's face, this may contribute to the feelings of hurt, and other negative consequences.

Negative experiences resulting from relationship dissolution can range from hurt feelings to mental, emotional, and physiological damage. Leary, Springer, Negel, Ansell, and Evans (1998) reported that the main cause of hurt feelings in romantic relationships was the perception of relational devaluation. Relational devaluation is the belief that one partner does not find the relationship desirable, or value the relationship, to the same extent as the other relational partner (Leary et al., 1998). Dissolution messages may convey a similar devaluation message, that the dissolution initiator does not value the relationship in the same way as their partner. Thus, a message which communicates a lack of relational value may be face threatening to the receiver. A partner who experiences feelings of devaluation are equally likely to feel that they are not relationally competent, approved of, or even liked in the relationship, bringing positive face to the forefront in the interaction. Moreover, in the case of divorce, the message may be perceived as devaluing the individual, the relationship, the marriage, and even the family. A devaluation of the relationship or the individual may serve as the catalyst for facework to be practiced in response to the devaluation and accompanying face threat. The dissolution of a relationship may be expected, inevitable, and even positive, but how that relationship ends becomes crucial in understanding the consequences which result from the dissolution process.

Duck (1982) argued that dissolution is a process rather than an event. In fact, Lee (1984) found that the average relationship dissolution of pre-marital couples extended over 30 weeks, suggesting a gradual dissolution process. Given the legal barriers, 
financial consequences, religious ramifications, and upheaval of the children involved in many marriages, this process may extend over a longer period of time for marital couples. This research is interested in discovering more about the divorce and post-divorce communication process. Specifically, the two studies investigated communication that occurred during the decision to divorce and turning points described as significant by the divorcees following the divorce. A significant event in the divorce process is the actual decision to dissolve, and the communication of that decision to the partner.

\section{Deciding to Dissolve}

The decision to dissolve, which occurs before the decision has been communicated to the partner, has been described by Clark and Lebeff (1986) as relational deterioration, or the realization that the relationship would eventually dissolve. It is during this time that contemplation of the overall relationship quality and desire to continue the relationship are considered by one, or both, of the partners. The consideration of dissolution is motivated by a perceived problem in the relationship which drives the decision-making process. The problems described by participants conceptually overlap with implicit and explicit relational rules (e.g., provide support). The divorce may be considered a perceived problem or motivating factor in the larger process of divorce and in choosing to participate in a post-divorce relationship (PDR). Individuals report that dissolution occurs as a result of a relationship rule, or rules, being violated (Baxter, 1986). Specifically, individuals who dissolve their relationships report desiring more autonomy, perceiving a lack of similarity to their partner, not receiving the expected support, feeling that the communication was not sufficiently open, experiencing unfaithful behavior or infidelity, not spending enough time together, 
inequity between partners, and lacking romance in the relationship (Banks, Altendorf, Greene, \& Cody, 1987; Baxter, 1986; Cody, 1982; Levine \& Fitzpatrick, 2005). These relationship problems can gradually become apparent in the relationship or individuals may experience a critical incident, which is the immediate presentation of a relational problem which triggers the decision to dissolve (Baxter, 1984). Banks et al. (1987) reported that the reason for the relationship deterioration was an antecedent in the dissolution strategy selection process. Moreover, the reason behind the dissolution and the dissolution strategy are influential in the negotiated post-dissolution relationship. That is, the deterioration of a relationship contains elements which, subsequently, influence communication with the partner about the dissolution.

An individual's consideration of the state of the relationship is the antecedent to the actual dissolution event which then often involves both partners. The couple may engage in a discussion, or series of discussions, concerning the actual dissolution decision and event. Scholars have examined and found significant overlap in dissolution strategy typologies (Metts, 1992). Existing dissolution strategy typologies are conceptually similar to the face threats and facework in each dissolution strategy. Baxter (1984) argued that the strategies for dissolving a relationship vary based several dimensions such as the onset of problems, the decision to exit, initiating dissolution actions, reactions to the breakup, ambivalence, and repair attempts. Strategy selection will subsequently determine the specific messages used to dissolve the relationship. Similarly, in divorce, the onset of problems, decision to divorce, reactions, and repair attempts should play a role in the message used to dissolve the marriage. 
The Dissolution Message. The dissolution message is a smaller, specific component of the larger dissolution strategy. Two of Baxter's (1984) dimensions pertain to the actual dissolution message, or in other words, the message used to communicate termination to the partner in the relationship. First, the dissolution message differs in regard to unilateral or bilateral desires to terminate the relationship. Unilateral dissolution, or termination of a relationship which is independently initiated, occurs most frequently in close relationships (Baxter, 1982). Bilateral termination denotes a mutual agreement to end or renegotiate the relationship. Second, termination messages differ on the extent to which they are direct or indirect. Direct strategies are more frequently employed when dissolving relationships which are close or ruined by external factors (e.g., infidelity, Baxter, 1984; Clark \& Lebeff, 1986). Unilateral and direct strategies are used most often to dissolve a relationship, and unilateral and direct strategies are posited to be the most face threatening.

Baxter (1982) found that partners are more direct in their dissolution messages when they report being close with the partner. However, Baxter (1983) reported a degree of indirectness in her study which allowed participants to "ease out of the relationship without losing face" (p. 98). When indirect strategies are utilized, there is also a greater chance for reconciliation attempts (Baxter, 1984), which may indicate that indirect messages are less effective in completely dissolving the relationship. An indirect message may communicate a lack of finality or confidence in the decision, encouraging the receiver of the indirect dissolution message to pursue believe the relationship is not over or attempt to repair the relationship. Despite the desire to terminate a relationship, both dating and married individuals identify it as a difficult situation to approach and execute, 
and in some cases the thought of terminating a relationship hindered them from actually delivering the dissolution message (Cupach \& Metts, 1986). It is important to note that the dissolution strategy research has primarily focused on undergraduate romantic relationships (e.g., Banks et al., 1987; Baxter, 1982). The constraints that are imposed on married couples (e.g., children, financial, religion) may influence the messages which are used to terminate a relationship differently.

Baxter and Bullis (1986) identified relational dissolution as a negative turning point in interpersonal relationships. Despite the negativity of the event, dissolution was positively correlated with the amount of relational talk which occurred. That is, even though the relationship was dissolving, partners engaged in more communication about the relationship. Partners often exert communicative effort in the dissolution process to convey the message in an appropriate and effective way (Baxter \& Bullis, 1986). The partners may discuss the cause of dissolution or how to renegotiate the relationship following the dissolution (Duck, 1982). Senders report that in some cases they attempt to terminate the relationship in ways that will be less traumatic for the receiver, such as using positive tone or providing justification (Cody, 1982). Dissolving a relationship in this way may enhance perceptions that the initiator still cares about the receiver of the message. If receivers interpret messages as congruent with their preferences, beneficial to them, or exhibiting caring for them, they may not experience the same adverse effects following dissolution. Senders may consider their own and their partner's face during the dissolution, and receivers may evaluate messages differently based on the extent to which their face is protected or threatened. The extent to which a message is considered face threatening or face supporting will elicit emotional responses, which then influence 
communicative exchanges.

Affect During Divorce. Hackney and Ribordy (1980) examined emotions across couples who were happily married, attending counseling, deciding to divorce, and who had finalized the divorce at least six months prior. They found that the experience of negative emotions rose sharply for individuals during the counseling (i.e. distress) phase. This high level of negativity was maintained during the decision to divorce and throughout the divorce process. Only six to twelve months after the divorce did negative emotions eventually decline. Although this study does not explain why the negative emotions were high at each of these points, it was suggested that the reality and seriousness of the marital problems contributed to the negative emotions during counseling, and that the hurt, shock, and adjustment during the divorce process were influential factors. Hetherington and Kelly (2002) reported that the person who is left, or the receiver of the divorce message, experienced greater negative emotion than the one who initiated the divorce. The receiver may be surprised by the decision, desire a different outcome, or take the decision personally, setting them up for a more difficult adjustment and coping period. Taken together, these findings suggest that the loss of a close, personal relationship triggers strong emotions, and that although the experience is different, both dissolution message senders and receivers experience intense emotions. The emotions appear to persist throughout the process, and even continue after the divorce.

Reactions to the Dissolution Message. Although one individual may initiate the dissolution, both participate in the dissolution process. Upon delivery of the dissolution message in which the receiver is informed of the sender's decision to end the romantic 
relationship or marriage, the partner may accept the decision, resist the dissolution attempt, and even offer relational repair attempts (Baxter, 1984; Buchanan, O'Hair, \& Becker, 2006). Sutter and Martin (1998) found that when verbal aggression was employed by one partner in dissolution, the verbally aggressive behavior was reciprocated. Reciprocity of communicative behavior may vary based on the reason for dissolution, whether it is a unilateral or bilateral decision, relationship closeness, and based on the interpretation of the messages being exchanged. Similar to verbal aggression, although unexplored, other message qualities may also be reciprocated in dissolution events. For example, if one partner uses face support in the divorce conversation, showing concern for the message receiver, the message receiver may also respond in a more positive way, enacting face support. Conversely, a partner who does not support the face of the receiver may be offensive, upsetting, or insulting, eliciting angry or defensive responses which also do not support the face of the partner.

The reciprocity of communicative behaviors in the dissolution conversation, whether positive or negative, influences any renegotiation process following the dissolution. For example, the strategic use of facework to reduce face threats may be reciprocated by partners. Likewise, a defensive orientation, or concern only for oneself, may also be matched during the dissolution process. Thus, the two current studies garner information from (a) both perspectives in the divorce and (b) from several relational events that comprise the dyadic process. This information assists researchers and practitioners in understanding the simultaneous occurrence of face threat, facework, and potential reciprocity of face threats and facework across relationships and contexts. These behaviors may continue to manifest in the post-dissolution relationship as the former 
couple struggles to fully dissolve or redefine the relationship.

\section{The Post-dissolution Relationship}

Continuing relationships between former spouses are common (Goldsmith, 1980;

Lewis, Wallerstein, \& Johnson-Reitz, 2004). An interpersonal connection, feelings of guilt, obligation, and continuing attachment can be the driving forces behind post-divorce relationships (Weiss, 1975). Ahrons and Wallisch (1987) reported that the $80 \%$ of former spouses were moderately to highly interactive with one another following divorce at one year and three year interviews, and that their conversations concerned their shared children. Forty percent of participants reported that if they had no children, they would still desire a friendship with their former spouse. Further, Goldsmith (1980) reported that divorcees even continued to interact in topic areas which did not revolve around children, and that they still maintained a friendship. In fact, some divorcees reported that they desired to spend more time together with the former spouse than they currently spent together. Despite the continuing relationship, for couples with children or without chidren, $75 \%$ of the divorcees report that their continuing relationship with the former spouse is conflictual (Goldsmith, 1980).

Negative conflict patterns and poor conflict management have often been cited as a cause for divorce (Rodrigues, Hall, \& Fincham, 2006; Rogge, Bradbury, Hahlweg, Engl, \& Thurmaier, 2006). Both during the divorce and after, opportunities arise for individuals to engage in negotiating conflict as well. Indeed, Christensen and Shenk (1991) found that divorcing couples had less constructive communication, more conflict, and more interaction avoidance than either non-distressed or distressed couples. Scholars have noted that in conflict, there are face concerns which contribute to the way conflict is 
managed, and that perceived face threats can escalate a conversation into a conflict episode (Brew \& Cairns, 2004; Cupach \& Metts, 1994; Oetzel, Ting-Toomey, Yokochi, Masumoto, \& Takai, 2000). Thus, the face threats which occur during the divorce conversation and the post-divorce relationship challenge the individuals' autonomy, approval, and closeness with the former spouse, eliciting unproductive conflict behaviors.

Scholars are in general agreement that post-dissolution dating and marital relationships have been neglected due to the difficulty in gaining access to the population, the inability to study dissolution as a natural progression, and the assumption that relational dissolution is the end of the relationship (Busboom, Collins, Givertz, \& Levin, 2002; Kellas, Bean, Cunningham, \& Cheng, 2008; Weber, 1998). It is difficult to gain access to dissolved couples because divorce is often an unpleasant experience which couples do not wish to relive or discuss, and those who are included in such research are self-selected, may be biased, and unbalanced in their accounts (Weber). Dissolution is not a condition that can be realistically manipulated or captured in a laboratory environment. Finally, while dissolution may be the end of the relationship for some individuals, others redefine their relationships. Estimates of those deciding to persist in another type of relationship range from 50\%-80\% (Ahrons \& Wallisch, 1987; Dailey, Pfiester, Borae, Beck, \& Clark, 2009; Goldsmith, 1980), making it difficult to obtain samples of dissolved couples who all redefine themselves in a homogenous way. Instead of conceptualizing couples as completely together or completely dissolved, some scholars have worked to delineate the post-dissolution relationship trajectories in both pre-marital and marital relationships and have noted that each trajectory experiences a variety of outcomes (Ahrons, 2007; Graham, 1997; Kellas et al., 2008; Lannutti \& Cameron, 2002). 
Turning Points in Post-dissolution Relationships. Turning points are relational events which are associated with changes in the relationship, either positive or negative (Baxter \& Bullis, 1986). Turning points were originally conceptualized as an important tool for examining the communication occurring in relational development (Baxter \& Bullis), however, other research has also employed turning points to examine positive and negative relationship changes in deteriorating and dissolved relationships (e.g., Baxter, 1984; Graham, 1997). This line of research has emphasized the communication in relationships, illuminating changes in commitment, satisfaction, metacommunication, emotional disruption, adjustment, and relational talk (Baxter \& Bullis, 1986; Graham, 1997; Kellas et al., 2008). Analysis of turning points has further been utilized to construct relational trajectories, providing a visual representation of the processes individuals experience over time.

In pre-marital relationships, Kellas et al. (2008) discovered four post-dissolution trajectories: linear trajectory, upward progression trajectory, decline trajectory, and turbulent trajectory. First, the linear trajectory is characterized by communication, commitment, and satisfaction that is relatively unchanging. This trajectory may manifest in post-dissolution relationships where former partners remain friends or reconcile so that the relationship is comparable to that which existed prior to dissolution. Second, the upward progression trajectory indicates an increase in commitment and satisfaction over time. Similar to the linear progression, upward progression individuals may redefine themselves as friends or reconcile. However, the relationship has become more positive, as opposed to remaining the same, showing improvements in communication, commitment, and satisfaction. Third, the decline trajectory is represented by the gradual 
decrease in commitment and contact over time. In this trajectory, the couple remains close immediately following the dissolution, but eventually the relationship fades. Finally, the turbulent trajectory represents individuals who experience sharp inclines and declines in the commitment felt toward the former partner. These couples feel strongly toward one another, whether positively or negatively, as they simultaneously experience desires to be close and then separate. Although Kellas et al. (2008) examined important changes in outcomes associated with turning points (i.e., commitment, satisfaction, emotional disruption, and adjustment), questions remain about the actual communicative acts which comprise each turning point. Although understanding dating relationships and their demise is important, it can not be assumed that these same trajectories and postrelationship changes would manifest in post-divorce relationships, as Cupach and Metts (1986) identified the relationships as fundamentally different in dissolution.

In marital dissolution, Graham (1997) identified five post-divorce trajectories: gradual progress, disrupted progress, sustained adjustment, disjointed erratic cycle, and eventual deterioration. In the gradual progress trajectory, the former spouses improved their relationship, eventually obtaining what they would describe as a well-functioning relationship. Disrupted progress begins with positive expectations for a post-dissolution relationship (PDR). However, that expectation is interrupted with a negative event such as seeing the former spouse with a new partner. Sustained adjustment is a trajectory where there is a continued commitment to the former spouse, and this commitment remains stable. Disjointed erratic cycles were characterized by extreme ups and downs in commitment and both positive and negative turning points between the former spouses. Finally, the eventual deterioration begins high in commitment, similar to the disrupted 
progress trajectory. However, it then gradually declines over time. Similar to Kellas et al. (2008), Graham examined a relational outcome (i.e., commitment), and thus, the PDR turning points can be further understood through an investigation including communicative components such as face threat and facework at positive and negative turning points.

Ahrons and Wallisch (1987) classified divorced couples into five categories ranging from friendship to the elimination of all contact between the spouses. The categories include perfect pals, cooperative colleagues, angry associates, fiery foes, and dissolved duos. Perfect pals are described as friends who are amicable in all aspects of their lives. Cooperative colleagues are only cooperative as parents, but do not deal with one another in other interpersonal aspects of their lives and do not experience frequent or severe conflict. Angry associates are characterized as hostile, and limit their interactions with one another to avoid conflict because when they do interact they experience conflict over every aspect of their lives (e.g., career decisions, new dating partners, financial contributions, children). Fiery foes are extremely hostile and experience great conflict in both the parental and personal realm; they do not limit their interaction, but instead engage in the frequent expression of anger. Dissolved duos have ceased all contact with one another. Ahrons $(1994 ; 2007)$ found that the likelihood of being perfect pals increases with time since the divorce event.

It is important to note that in four of the five trajectories found by Graham (1997) and four of the five classifications reported by Ahrons (1994; 2007), the former spouses are still engaging in interaction with one another, whether positive or negative. Consequently, the current research was designed to elicit information about both positive 
and negative events in post-dissolution relationships. It is anticipated that the turning points will be differentiated by more than commitment and satisfaction, as previously measured (Graham, 1997). Specifically, the it is anticipated that the degree to which positive and negative face is threatened, whether positive or negative face is supported, and perceived former spouse caring, will differ between positive and negative postdissolution events.

Although dissolution has been recognized as a prevalent relational turning point, those involved in PDRs continue to experience changes (i.e., turning points) in their relationship. Each of the post-dissolution turning points (e.g., jealousy, harassment, support, forgiveness, unrequited advances, moving away) contributes to the redefinition process between former partners. For example, Kellas et al. (2008) identified romantic reconciliation as a turning point in post-dissolution relationships. Other research has focused on relational characteristics as explanatory mechanisms in understanding relationship reconciliation, post-dissolution relational factors, or communication used to initiate and respond to the reconciliation attempts (e.g., Bevan, Cameron, \& Dillow, 2003; Patterson \& Beckett, 1995). Following dissolution, there is potential for multiple reconciliations to occur, identified as an on-again/off-again relationship. Dailey et al. (2009) reported that this phenomenon is quite common, with $61 \%$ of their college student participants reporting multiple romantic relationship renewals with the same partner. Post-dissolution events (e.g., reconciliation) present additional opportunities to threaten, and protect, each relational partner's face. Dailey at al. (2009) found marked changes in communication in the PDRs. Specifically, renewing couples reported fewer positive behaviors, less commitment and satisfaction, and more negative conflict and aggression. 
Given that dissolution is not simply restricted to a decision and the end of a relationship, it is important to examine post-dissolution events for elements of face threat and facework to fully understand the entire process of dissolution. Understanding the series of events which comprise a post-divorce relationship will add insight to the communication required to negotiate PDRs and develop a deeper understanding of short and long term effects that divorce has on the former spouses. The impact of divorce and PDRs on former spouses may include changes in affect toward their former partner and an impact on the well-being of the divorcee. Additionally, the examination of affect and well-being is an important undertaking given the goals of this study to address theoretical criticisms by examining multiple faces, social judgments, and emotion in divorce and post-divorce event. Additionally, the current studies apply theory in learning about the responses and consequences of face threat.

Affect and Well-being Following Divorce. Couples work toward coping with the dissolution, adjusting, and potentially moving on from the relationship. The final outcome may influence each individual positively (e.g., Tashiro \& Frazier, 2003) or negatively (Boelen \& Reijntjes, 2009). Positive effects of dissolution include gaining a sense of independence, improving friendships, and having learned more about relationships from the experience (Tashiro \& Frazier, 2003). However, most common are negative effects which impact both the dissolution initiator and the dissolution message receiver. It is during this time that individuals attempt to make sense of the dissolution and adjust to the traumatic life changes.

Following dissolution, individuals often experience negative changes in affect, well-being, and overall functioning (Frazier \& Cook, 1993). Individuals often suffer from 
lingering effects including a loss of trust, lowered self-esteem, anxiety, increased worry about being hurt in future relationships, lowered confidence, depression, preoccupation with what others think, and negative emotions such as anger or shame when experiencing or simply recalling the dissolution event (Banks et al., 1987; Cupach \& Carson, 2002; Kam \& Bond, 2008; Leary, Koch, \& Hechenbleikner, 2001; Leary et al., 1998; Zhang \& Stafford, 2008). One emotion commonly experienced is hurt, an affective state in which one feels wronged, devalued, or emotionally injured (Fine \& Olson, 1997; Folkes, 1982; Leary et al., 1998). Messages which are perceived as hurtful can take several different forms including complaints, teasing, criticism, relational rule violations (e.g., not providing support), or interpersonal transgressions (e.g., deception) (Vangelisti, 1994; Young, 2010; Zhang \& Stafford, 2008). Relational dissolution and rejection can also lead to outcomes which are compounded in severity including substance abuse and suicide attempts (Leary et al., 2001).

The first year following divorce is often the most emotionally traumatic (Hetherington \& Kelly, 2002). The emotions experienced are complex, and multiple emotions co-occur (Sbarra \& Ferrer, 2006). Although some scholars noted a marked improvement in emotional stability, others have found that distress may occur and even increase over time, ranging from six months to four years (Hackney \& Ribordy, 1980; Hetherington \& Kelly, 2002; Weiss, 1975). Particular post-dissolution events, such as learning that the spouse is remarrying, could lead to a resurgence, or amplification of emotions (Hetherington \& Kelly, 2002; Sbarra \& Ferrer, 2006). Thus, it is important to examine the emotions associated with the divorce event, and emotions associated with post-divorce turning points, as the emotions are consequences of these events and guide 
subsequent behaviors. This study examines both positive and negative emotions as potential consequences experienced in response to a myriad of events during the process of divorce. Additionally, the current studies examine emotion as guiding factors in subsequent behaviors, communication, and decisions. Specifically, the emotions experienced as a result of divorce, or during post-divorce events, may influence the relationship that is developed and maintained after divorce.

The well-being of individuals following dissolution processes has also been linked to characteristics of the post-dissolution relationship. Masheter (1997) discussed the differences between healthy and unhealthy post-divorce relationships. The primary qualities which differentiated the relationships were preoccupation and hostility. Divorcees who were highly preoccupied with, and hostile toward, their former spouse were poorly adjusted to the divorce and experienced detrimental effects on their wellbeing. Losing the relationship completely or maintaining a negative relationship seems to compound negative outcomes. Conversely, Kellas et al. (2008) found that those who experienced the linear trajectory, or sustained a positive commitment following dissolution, were less disturbed emotionally and adjusted more successfully. Thus, improvements in the communicative behaviors of facework performance between former spouses may encourage healthier relationships and may be beneficial to the individuals and others impacted by the divorce. It is recognized that several communication skills may contribute to a successful post-divorce relationship, such as active listening, constructive communication, problem solving, and conflict management (Hawkins et al., 2008; Huber, 1983; Markman et al., 1988; Renick, Blumberg, \& Markman, 1992). Facework as a communicative strategy has been largely ignored. Conversely, face threat 
may be detrimental to the post-divorce relationship. Thus, the potential benefits and risks of face threats, and facework, in divorcing couples is unknown. To that end, this study examined face threat as a source of negative affect and poor well-being in divorcees, and facework as a source of positive affect and improved well-being in divorcees.

Sources of Negative Impacts on Individuals. Some scholars attribute the negative consequences resulting from dissolution to perceptions of having little control in the relationship outcome (Gray \& Silver, 1990). Specifically, individuals who perceive having control over the dissolution were better adjusted, less distressed, less preoccupied, and had little regret. Control in the dissolution event may conceptually be parallel to a unilateral dissolution, where one person makes the dissolution decision, assuming control, or in a bilateral decision where both attain some degree of control in the decision. Both the dissolution initiator and dissolution message receiver experience negative outcomes, but some studies suggest that the dissolution message receiver suffers to a greater extent emotionally, reporting greater grief, depression, and anxiety (Boelen \& Reijntjes, 2009; Perilloux \& Buss, 2008; Sprecher, 1994; Wilmot, Carbaugh, \& Baxter, 1985). In contrast, multiple studies have reported no differences in affect, adjustment, and well-being between the initiator and non-initiator (Kincaid \& Caldwell, 1991; Tashiro \& Frazier, 2003). Instead, the consequences of and individual reactions to relational dissolution may stem from face threat and facework differences in the relationship and the dissolution process. In other words, a face threatening interaction should produce detrimental effects for the individual and the relationship between the former spouses, while a face supporting interaction will improve the affective and relational outcomes. In times of difficult life events, and subsequent coping, participants reported that 
the former spouse was the ideal source of support during the dissolution (Chriboga, Coho, Stein, \& Roberts, 1979). The perceptions that a former spouse is an important source of supportive communication may explain the prevalence of PDRs, as former spouses seek one another to acquire the needed support (Chriboga et al.). Individuals who reported positive post-divorce relationships with their former partner also report experiencing more positive feelings, less anger, improved adjustment, and less guilt (Ahrons \& Wallisch, 1987; Isaacs \& Leon, 1988; Kitson, 1982), suggesting that those who have positive affect toward the relationship with the former spouse, and perceptions that the former spouse cares about them, cope more effectively with the divorce event. Conversely, a conflictual, hostile, or preoccupying ongoing emotional attachment to the former partner in the post-dissolution relationship is related to poor adjustment and wellbeing (Isaacs \& Leon, 1988; Masheter, 1997). Thus, the post-dissolution communication (e.g., facework) between former partners, beyond the actual dissolution event, continues to play a role in the affect, well-being, and adjustment of the dissolved partners. Specifically, the face threats, facework, and perceived partner caring should continue to influence each individual's outcomes (e.g., stress, attachment) related to the communication during, and following, the divorce. Additionally, the type of face threats, facework, and perceived spouse caring may determine the type of PDR the former spouses develop. This is important to examine because this PDR will be central to the environment which is constructed for the divorcees, and any children involved.

\section{Facework in Dissolution Processes}

Kunkel et al. (2003) argued that relational dissolution episodes are inherently face-threatening, and Cupach and Metts (1994) speculated that relational dissolution was 
the most face threatening interpersonal event that individuals experience. Previous work has labeled criticism as a face threat to the receiver's positive face, excuses as threats to speaker's negative face, and apologies as threats to speaker's positive face (Brown \& Levinson, 1987). Unilateral dissolution messages are perceived by the receiver as criticism and rejection rather than the desired approval of the individual or the relationship.

At the same time, the sender of the dissolution message may experience face threats through excuse-making or apologies for their decision during the delivery of the dissolution message. While both interactants enter the dissolution process with face wants and needs (e.g., desire to be liked, desire to have choices) and both may experience face threats (i.e., denied approval or freedom), the interactants also may adopt an orientation toward performing positive and negative facework in response to the social interaction. It is unclear whether partners are cognizant of attempts to perform facework, how this awareness impacts the perceptions of the relational dissolution event, and how the performance of facework impacts ongoing relationships and well-being. As the couple moves through the dissolution process, opportunities for facework are diverse. Although the entire divorce process may be face threatening, it is when the decision to divorce is first communicated and recognized by both partners that the face threats likely become most salient, and consequently the sender and the receiver of the messages have an important opportunity to first engage in facework.

\section{Face Threats When Deciding to Dissolve}

During the dissolution process, both senders and receivers may experience positive and negative face threats. In a unilateral relational dissolution episode, the 
initiator is ending the relationship which may imply a lack of desire for closeness, a lack of approval, or implied individual and relationship failure to the receiver of the message. In fact, the dissolution initiator may be expressing a need for autonomy and freedom from the relationship, indicating that the initiator is perceiving a negative face threat. Additionally, the sender of the dissolution message may be concerned about positive face threats due to being perceived as insensitive by the message receiver (Kunkel et al., 2003). Receivers experience the most risk to their positive face by feeling undesirable or inadequate (Kunkel et al., 2003). Moreover, receivers of a unilateral dissolution message may perceive that they have little choice in the dissolution decision, thereby experiencing threat to their own negative face. Because both partners may experience simultaneous threat to both faces, this communicative event also provides opportunities for both sender and receiver to practice facework in dissolving the relationship. That is, if the individuals desire to protect their own or their partner's face, they will enact face support in dissolution events. However, the different strategies used to dissolve may set the stage for different types, and amounts, of facework to occur, and subsequently begin the relational trajectory which will redefine the post-divorce relationship.

Facework in Dissolution Messages. Solidarity, or positive facework, allows the sender to emphasize feelings that remain between the individuals, stressing that the dissolution is not ending their affiliation with one another. When approbation is enacted, the sender will highlight the receivers' competence, paying particular attention to relational competence. Finally, the strategic use of tact may encourage perceptions of choice and decision-making power for the receiver in the dissolution process by enhancing autonomy and minimizing imposition. The current studies examined positive 
and negative face support between the former spouses to gain a deeper understanding of how facework impacts perceived caring, conflict, emotion, well-being, and how the relationship is redefined following the divorce. Such facework relates to Goffman's (1967) protective and defensive orientations, which conceptually overlap with Baxter's (1984) dissolution trajectories, making facework a useful lens through which to examine divorce.

Baxter (1984) differentiated between relational dissolution trajectories based on self-orientation or other-orientation. Specifically, self-oriented individuals dissolved the relationship in more direct and sometimes harmful ways, while other-oriented individuals dissolved the relationship in a way that provided a buffer for the receiver though protecting the identity of the partner. Taken together, protective messages and indirect dissolution strategies may be perceived as least threatening to the receiver's face when compared to more direct, defensive oriented messages. Moreover, Wilmot et al. (1985) found that indirect messages were strategically used to protect the self and the partner simultaneously. Thus, the degree to which one enacts face threatening acts in dissolution may be indicative of the partners' orientation (i.e., defensive or protective). This may alter perceptions of the relationship between the former spouses, communication decisions to threaten or support face needs, and subsequent individual and relational outcomes. The relational renegotiation process presents more opportunities for face threat to occur between the former spouses, and for the former spouses to engage in facework with one another as the redefine the relationship. 


\section{The Post-dissolution Relationship}

Post-dissolution relationships (PDRs) require communicative work to define the relationship and facilitate adjustment and renegotiation following the dissolution event. Attention to face during dissolution is should influence subsequent communication, and potentially relational redefinition following dissolution. Banks et al. (1987) found that romantic partners remained friends if the dissolution initiator used de-escalation tactics, but not when the partner used avoidance or justification to dissolve the relationship. Similarly, Busboom et al. (2002) found that when individuals dissolved romantic relationships by neglecting the partner, the post-dissolution friendship was negatively impacted. Avoidance and neglecting partners are face threatening for receivers, as they are not receiving the communicative explanation they may desire in dissolution.

Justification is face threatening to senders of the dissolution message, as senders then lose autonomy through the expectation that they have to justify their decisions. Thus, those strategies which are face threatening to either the sender or receiver of the dissolution message impact the post-divorce relationship in a negative way.

The Nature of the Post-Dissolution Relationship. Lannutti and Cameron (2002) argued that traditional research has been too narrow in conceptualizing the PDR. Instead of categorizing participants into a dichotomy which identified whether they were friends or not friends, they call for a broader examination of the PDR, allowing multiple types of PDRs to be examined. The host of PDR possibilities may also include casual friends, close friends, sexual partners, friends with desire to reconcile, thwarted reconciliation attempts, casually dating again, or even relational escalation into seriously dating, engaged, or married. The move toward constructing these relationships presents diverse 
opportunities in which face may be threatened and facework may be practiced. Thus, the studies reported here examined multiple PDR events to construct an overall picture of the face threat and facework occurring between former spouses.

Wilmot et al. (1985) found that in their sample of college student dating relationships, $61 \%$ of former partners remained friends following the dissolution. Some post-dissolution relationships extend beyond platonic friendship. Some participants reported that they still engaged in sexual activity with their former romantic partners, desired continued sexual activity, and had hope for relationship renewal which was the catalyst for continuing in a PDR (Banks et al., 1987; Foley \& Fraser, 1998; Lannutti \& Cameron, 2002). Thus, evidence exists which supports that a friendship or a sexual relationship does occur in the post-dissolution relationship, at least in college student romantic relationships. However, Schneider and Kenny (2000) found that friendships between former partners were often lower in quality when compared to friendships that had never shared a romantic past. Although PDRs between divorcees have not been examined to the same extent, similar to dating partners former spouses have shared a romantic past. However, other situational and relational differences between former dating partners and former spouses (Cupach \& Metts, 1986) will likely differentiate their post-divorce relationship from those dating couples or friendships who have dissolved.

In marital dissolution, former spouses recognized that they experienced stress and conflict as a result of the friendship with a former spouse (Goldsmith, 1980), but also found the relationship supportive. Friendship between the former spouses is common, increases parental contact for the children, and a positive relationship between the parents is also predictive of more effective communication between the parent and child (Ahrons 
\& Miller, 1993; Berman \& Turk, 1981; Goldsmith, 1980). Isaacs and Leon (1988) noted that friendship with a former spouse could be both beneficial and detrimental. A "practical" friendship between former spouses involved a relationship focused on the tasks of parenting and a "personal" friendship revolves around intimacy and closeness beyond parental duties. A "practical" friendship has been linked to improved well-being for divorcees. Although a "personal" friendship had some positive effects on well-being, it was to a lesser extent than the "practical" friendship. Miller (2009) found that divorcees still had concerns about face with their former partner, and did employ facework with the former partner. However, the face concerns reported by Miller's participants were about parental duties and abilities and hence may not be pertinent to all divorcees.

Consequently, questions still remain about the facework between former spouses, and face concerns that do not involve children.

Some dissolved relationships are redefined by the former partners multiple times. The continuing redefinition of the relationship may bring the former couple full circle by making decisions to re-enter a romantic relationship through reconciliation. In instances where reconciliation was not successful, Kellas et al. (2008) found that reconciliation attempts were perceived as a negative turning point if the romantic relationship was not mutually desired and one partner rejected the reconciliation attempt. Conversely, it was perceived as a positive turning point if it was mutually desired by both partners. Bevan et al. (2003) situated reconciliation attempts as a unique compliance-gaining interpersonal event. Requesting reconciliation is face threatening to both partners, as one must accept or reject the request and the requester becomes vulnerable in awaiting a reply. Multiple reconciliations have been noted as a frequently occurring phenomenon in college student 
dating relationships (Dailey et al., 2009). Although reconciliation attempts may be less common in post-divorce relationships, Weiss (1975) argued that divorcees will often make at least one attempt at reconciliation. Kunkel et al. (2003) noted that relational initiation, escalation, and dissolution were all face threatening events. The combination of these events would present a complex and face-threatening process. Specifically, when individuals experience divorce (i.e., dissolution) and one of the divorcees attempts to redefine the relationship as either a friendship or works to re-escalate into a romantic relationship, face threats and facework will be associated with each phase of this complex renegotiation process. However, if a former partner does not attempt to reconcile, one may feel that they are not desirable, approved of, or liked, resulting in continuing positive face threat.

\section{Rationale and Hypotheses}

The extant relationship dissolution research largely focuses on dating and college student romantic relationships (Metts, 1992). The importance of making a distinction between the dissolution of pre-marital and marital relationships became clear in a study by Cupach and Metts (1986). Cupach and Metts compared the dissolution of pre-marital and marital relationships and concluded that marital partners experienced more relational problems, attempted to repair relationships more often, and cited more reasons that deterred relationship dissolution. Moreover, the dissolution of marriage differs from that of a pre-marital relationship because of the potential impact on communication in other relationships (e.g., parent-child). Taken together, the examination of divorce as a dissolution process has important implications for individuals and relationships, and differs from the majority of the extant dissolution research. 
Duck (1982) briefly discusses the social face which is presented to the social network during the dissolution process. Specifically, he argues that breakup accounts are constructed and shared with the network such that the individuals experiencing dissolution are protective of her or his own face. However, Duck does not address the need for facework between the individuals who are dissolving and renegotiating the relationship. This is an important component to the dissolution process, as Baxter (1983) argued that relational partners do not cease to evaluate one another during de-escalation and dissolution of the relationship. Moreover, Kunkel et al. (2003) found that relationship dissolution is inherently face-threatening, and more face-threatening than either initiating or intensifying relationships. Therefore, the level of face threat associated with dissolution and post-dissolution events suggests that facework could occur at several points throughout the dissolution and post-dissolution process in response to potential face threats. However, there may be less importance placed on evaluations made by the former spouse in post-divorce because of the changing nature of the relationship. Thus, the level of possible face threat may change during, and after, the divorce. The attempts at supporting face may also change to parallel the experienced face threats (e.g., positive face support practiced when positive face threats are anticipated). What remains unclear is how the presence of, or the absence of, facework will impact other outcomes beyond the face threatening event.

These two studies were designed to accomplish several purposes. First, divorce was examined as having multiple events which comprise the process (i.e., divorce decision conversation, turning points). Second, these studies examined both dissolution initiators and receivers to provide a more complete picture of the dissolution process and 
facework performances of both partners. Third, these studies examined social judgments of face threats and facework and incorporated emotion as suggested in previous research (Craig et al., 1986; Locher \& Watts, 2005; Metts, 1992).

The goal of the two studies was to examine the perceived impact of communicating the divorce decision to a spouse on the positive and negative face of each individual involved in the dissolution of a marriage, and subsequently, the impacts of threats to positive and negative face on individual and relational outcomes. The studies examined the resulting facework associated with marital dissolution and potential renegotiation processes. Face threats, facework, perceived former spouse caring, and emotion were also examined as influential factors in the well-being of individuals, and on the nature of the post-dissolution relationship of the former couple. The first study examined perceptions of face threats and facework during the actual conversation in which the decision was made to divorce. The second study examined positive and negative events identified as significant by the participants in their post-divorce interactions with their former spouses for perceptions of face threat and facework.

In the following section, each of the two studies is briefly summarized, and the hypotheses and research questions are proposed.

\section{Research Questions and Hypotheses}

\section{Study One}

The divorce literature can broadly be categorized into two categories: a) predictors of divorce (e.g., age, infidelity) and b) outcomes of divorce (e.g., depression, coping). This study was designed to gather more information about the communication that occurs during the divorce, rather than the predictors or outcomes of divorce. The 
majority of divorce research is largely focuses on predictors of divorce and outcomes of divorce. Therefore, the limited amount of theory-driven literature on communication during divorce warrants additional scholarly attention using theory. Facework theories lend themselves to a deeper understanding of divorce communication. To that end, this study collected individual perspectives and dyadic data to more completely inform research questions.

Obtaining both perspectives about the same dissolution event has been recognized as a challenge in the dissolution research, and few studies have been successful in gathering data from both partners with few notable exceptions (Hill, Rubin, \& Peplau, 1976; Sprecher, 1994). Sprecher (1994) was able to obtain data from 47 dating couples and Hill et al. (1976) obtained data from 103 dating couples who dissolved during longitudinal research. Sprecher (1994) argued that gathering and then comparing data from both partners illuminates the complexity of the dissolution process and contributes to the understanding of the coping processes employed post-dissolution. Similarly, facework research has rarely examined the perception of both interactants, although the existence of multiple faces operating simultaneously has been recognized (Craig et al., 1986; Wagoner \& Waldron, 1999). Thus, this study examined both phenomena, dissolution and facework, from the perspectives of individuals and the perspectives of both divorced partners. Building upon two bodies of literature, face and dissolution, the following hypotheses and research question were posed:

H1: Both senders and receivers of divorce messages will perceive greater positive face threat than negative face threat.

$\mathrm{H} 2$ : $\quad$ Both senders and receivers will perceive that their partner used more 
positive face support than negative face support.

H3a: There will be a positive relationship among perceived face threat, conflict, hurt, and negative emotions.

H3b: There will be a negative relationship between perceived face threat, overall affect toward the current relationship with the former spouse, perceived former spouse caring, and positive emotions.

H4a: Participant's perceived face threat, conflict, hurt, facework, affect toward the relationship with the former spouse, ongoing attachment, and perceived former spouse caring will be associated with stress.

H4b: Participant's perceived face threat, conflict, hurt, facework, affect toward the current relationship with the former spouse, and perceived former spouse will be associated with ongoing attachment to the former spouse.

H4c: Participant's perceived face threat, conflict, hurt, facework, and perceived former spouse caring will be associated with affect toward the current relationship with the former spouse.

H4d: Participant's current relationship status with the former spouse will be predicted by perceived face threat, conflict, hurt, facework, affect toward the current relationship with the former spouse, and perceived former spouse caring.

\section{Study Two}

Following Duck's (1982) argument that dissolution is a process, study two focused on facework as it occurs at different points after divorce, extending beyond the divorce decision conversation. This study allowed for the examination of multiple post- 
dissolution events, or turning points, which comprise the renegotiation processes. Baxter (1983) argued that following dissolution, partners do not cease to interact, evaluate one another, or be concerned about identity and image issues. So, facework between the former partners may continue as they redefine the relationship. Graham (1997) identified several relational turning points which were categorized as either negative (e.g., financial hardship, parent-child problems) or positive (e.g. well-functioning family, participant remarries). Each turning point within the post-dissolution relationship will also impact the communication occurring between the former partners. Turning points may threaten one or both partners' faces and require different types, and levels, of facework to address the face threats associated with each turning point. Thus, this study examined perceived face threat, facework strategies, and perceived former spouse caring associated with turning points in post-dissolution relationships. Building upon two bodies of literature, face and dissolution, the following hypotheses were posed:

H1a: Negative turning points will elicit greater perceived positive face threat than positive turning points.

H1b: Negative turning points will elicit greater perceived negative face threat than positive turning points.

H2: Greater positive and negative face support will be perceived in negative turning points than in positive turning points.

H3a: Positive turning points will be associated with positive emotions, affect toward the current relationship with the former spouse, and perceived former spouse caring.

H3b: Negative turning points will be associated with negative emotions. 
H4a: Participant's perceived face threats, facework, emotions, affect toward the relationship with the former spouse, and perceived former spouse caring will be associated with current stress levels.

H4b: Participant's perceived face threats, facework, emotions, affect toward the relationship with the former spouse, and perceived former spouse caring will be associated with ongoing attachment to the former spouse.

RQ1: How does post-dissolution perceived face threat, facework, emotion, and perceived former spouse caring predict affect toward the current relationship with the former spouse?

RQ2: How does post-dissolution perceived face threat, facework, emotion, and perceived former spouse caring predict the current relational status with the former spouse?

\section{Summary}

The two studies presented here apply facework theories to a new context and address previous criticisms, providing a theoretical framework for the examination of divorce and post-divorce events, potentially offering valuable information to inform counseling and mediation professionals.

\section{Study One}

The aim of study one was to explore the face threats and facework which occur during the divorce decision, and how the concept of face then impacts subsequent individual and relational outcomes. Perceptions of face threat, facework, conflict, former spouse caring, emotions, and hurt during the divorce conversation were assessed as predictors of the divorcees' stress, ongoing attachment, affect toward the relationship 
with the formers spouse, and the nature, or type, of post-divorce relationship.

\section{Study Two}

Study two sought to examine face threats and facework in post-divorce turning points. Perceptions of each event (i.e., positive turning points and negative turning points) were gathered including face threats, facework, emotions, and perceived former spouse caring. Outcomes of the communicative events were gathered including stress, ongoing attachment, affect toward the relationship with the former spouse, and the nature of the relationship between the divorcees. 


\section{Chapter Two}

\section{Method}

\section{Study One}

Participant Recruitment. To participate in Study one, participants were required to be 18 years of age or older and have been divorced within the previous 2 years. The two year time frame was chosen following other research (e.g., Stephen, 1987) and to assist participants in recalling the divorce conversation. To cast the widest net, participants were recruited using snowball sampling and several avenues including divorce support groups, single parent support groups, social networking websites (e.g., Facebook), campus wide electronic announcements, professional organization announcements (e.g., CRTNET), and classroom recruitment from six different universities. Two samples were recruited through these methods including a) participants who represented one perspective of the divorced dyad and when possible b) both individuals from the same divorced dyad.

Participants. The first participant sample included 18 divorced dyads (18 males, 18 females) who ranged in age from 25 to $58(M=41.33, S D=9.64)$. Each dyad had been married for an average of 10.36 years (range $=2$ years to 26 years, $S D=8.33$ years), and divorced an average of 1.22 years prior to completing the survey (range $=1$ month to 3 years, $S D=.82$ years). In terms of current dating status, $52.7 \%$ of the participants reported that they were not currently dating, $30.6 \%$ were casually dating a new partner, $8.3 \%$ were seriously dating a new partner, $5.5 \%$ were engaged to a new partner, and one did not report their current relationship status. Geographically, the former spouses lived an average of 212.62 miles apart (range $=1$ mile to 4000 miles, $S D$ 
$=751.86$ miles). In terms of contact with the former spouse, $47.2 \%$ of participants had monthly contact, $30.6 \%$ had weekly contact, $16.7 \%$ had no contact, and two did not report on contact frequency. In terms of children, $33.3 \%$ of the participants had two children, $27.8 \%$ were child free, $16.7 \%$ had one child, $11.1 \%$ had three children, $5.6 \%$ had four children, and 5.6\% had six children. Within the divorced dyads, $41.7 \%$ of the participants shared custody, $22.2 \%$ had no custody agreement because there were no children, $18.8 \%$ reported that the biological mother had custody, $2.7 \%$ reported that the biological father had custody, and 5.5\% reported that their children were adults so no legal custody was required. It was not possible to obtain data from both perspectives in all couples, and thus, a sample of individual divorcees (i.e., non-matched) was also collected. This subset of dyads was analyzed for potential differences from the nonmatched individuals, prior to combining the samples to create total participant sample for analyses.

The second sample included divorced non-dyadic participants $(N=74,22$ males, 51 females, and 1 who did not report their biological sex) ranged in age from 20 to 58 ( $M$ $=35.32, S D=10.75$ ). Individuals had been married an average of 8.38 years (range $=1$ year to 20.25 years, $S D=8.51$ years), and divorced an average of 1.42 years prior to taking this survey (range $=1$ month to 20.25 years, $S D=2.38$ years). Five participants were outliers, and exceeded the 2 year time limit for the time since the divorce occurred, and were excluded in data analysis. In terms of current dating status, $24.3 \%$ of the participants reported that they were not currently dating a new partner, $45.9 \%$ were casually dating a new partner, $20.3 \%$ were seriously dating a new partner, $4.1 \%$ were engaged to a new partner, $2.7 \%$ were remarried to a new partner, and $2.7 \%$ did not report 
their current status. Geographically, the former spouses lived an average of 163.51 miles apart (range $=0$ miles to 3000 miles, $S D=526.82$ miles). In terms of contact with the former spouse, $28.4 \%$ had weekly contact, $23 \%$ of the participants reported that they had monthly contact, $21.6 \%$ had no contact, $12.2 \%$ had daily contact, $4.1 \%$ had yearly contact, and $6.8 \%$ selected other. Of the participants, $51.4 \%$ of the divorcees were child free, followed by $18.9 \%$ who had one child, $16.2 \%$ who had two children, $10.8 \%$ who had three children, and $2.7 \%$ who had four children. Of the participants, $52.7 \%$ had no custody agreement because the couple had no children, $17.8 \%$ reported that the biological mother had custody, $16.2 \%$ reported that they shared custody, $4.1 \%$ reported that there was no custody agreement because the children were adults, $3.1 \%$ reported that the biological father had custody, and $1.4 \%$ reported that another family member had custody, and $2.7 \%$ did not report on the custody arrangement.

Analysis of Dyads. For descriptive and interpretive purposes, the sample of matched dyads $(N=18)$ who were once married to one another were examined for potential patterns of differences from the remaining sample of divorcees in which only one former spouse completed the survey. A multiple analysis of variance (MANOVA) with sample (i.e., matched divorced dyad or single non-matched divorcee) was used as the independent variable and demographics, communicative variables, well-being, and relational variables were entered as the dependent variables, was conducted to explore these differences. Results revealed that there were significant differences [Wilk's $\Lambda=.60$, $\left.F(1,81)=2.20, p=.01 . \eta^{2}=.40\right]$. Specifically, the divorced dyad subset had been married longer $(M=14.38$ years $)$ than the non-dyadic participants $(M=7.77$ years $)$, divorced dyads had more children $(M=1.70)$ than the non-dyadic participants $(M=.84)$, 
divorced dyads were older $(M=40.74)$ than the non-dyadic participants $(M=34.82)$, divorced dyads experienced less positive face threat $(M=3.78)$ than the non-dyadic participants $(M=4.55)$, divorced dyads had less conflict during the divorce $(M=4.96)$ than the non-dyadic participants $(M=6.39)$, and former spouses within divorced dyads were seen as more caring $(M=3.77)$ than the non-dyadic participants saw their former spouses $(M=3.06)$. Overall, the matched divorcee subset was different in that their experience was more positive, characterized by less positive face threat, less conflict, and more perceived former spouse caring. Thus, the dyads and the five outliers were not included in the analyses for this study, resulting in 69 non-dyadic participants who had divorced within the past two years.

Final Participant Sample. After removal of the dyads and the five outliers, the participants ( $N=69,19$ males, 49 females, and 1 who did not report their biological sex) ranged in age from 20 to $58(M=34.34, S D=10.37)$. Individuals had been married an average of 7.79 years (range $=1$ year to 29 years, $S D=7.25$ years), and divorced an average of 1.02 years prior to taking this survey (range $=1$ month to 2 years, $S D=.64$ years). In terms of current dating status, $26.1 \%$ of the participants reported that they were not currently dating a new partner, $47.8 \%$ were casually dating a new partner, $18.8 \%$ were seriously dating a new partner, $4.3 \%$ were engaged to a new partner, $1.4 \%$ were remarried to a new partner, and $1.4 \%$ did not report their current status. Geographically, the former spouses lived an average of 128.78 miles apart (range $=0$ miles to 2300 miles, $S D=411.24$ miles). In terms of contact with the former spouse, $29.0 \%$ had weekly contact, $23.2 \%$ of the participants reported that they had monthly contact, $20.3 \%$ had no contact, $13.0 \%$ had daily contact, $4.3 \%$ had yearly contact, and $7.2 \%$ selected other. Of 
the participants, $52.2 \%$ of the divorcees were child free, followed by $18.8 \%$ who had one child, $17.4 \%$ who had two children, and $11.6 \%$ who had three children. Of the participants, $54.4 \%$ had no custody agreement because the couple had no children, $17.6 \%$ reported that the biological mother had custody, $14.7 \%$ reported that they shared custody, 4.4\% reported that there was no custody agreement because the children were adults, 4.4\% reported that the biological father had custody, and $1.5 \%$ reported that another family member had custody, and $2.9 \%$ did not report on the custody arrangement. Participants reported that they initiated the divorce $(n=41)$, their partner initiated the divorce $(n=9)$, or the divorce was a mutual decision $(n=12)$.

Procedures. Participants were instructed to contact the researcher to indicate interest in participating in the research. The survey was sent to each participant electronically, to be completed and returned to the researcher in one of three ways including a) emailing the completed survey, b) faxing the completed survey, or c) mailing the completed survey using the postal service. All returned surveys were temporarily associated with the participant's identity to allow for dyadic data matching. The survey packet included one open ended question about the divorce and nine quantitative measures including perceived face threat (i.e., positive and negative), facework (i.e., positive face support and negative face support), perceived former spouse caring, conflict, emotion, stress, ongoing attachment to the spouse, intensity of hurt, overall affect toward the current relationship with the former spouse, and demographics.

Instrumentation. The measures used in Study one are described in the following paragraphs including response scales, modifications, and descriptive statistics. Descriptive statistics for each measure are presented in Table 1. 
Face Threats. Perceived face threat was measured using a scale developed by Cupach and Carson (2002). The original scale was used to measure face threat in interpersonal complaints. It is a 14-item scale assessing both positive and negative face threats on a 7-point Likert-type scale ranging from strongly disagree (1) to strongly agree (7). Positive face threat (e.g., my partner's actions strengthened the relationship between us) was measured using ten items and had previously achieved high reliabilities ranging from .84 to $.88(M=3.95, S D=1.29$, Cupach \& Carson, 2002; Zhang \& Stafford, 2008). Negative face threat (e.g., my partner's actions took away some of my independence) was measured using four items, and had previously achieved acceptable reliabilities ranging from .68 to $.69(M=2.58, S D=1.24$, Cupach \& Carson, 2002; Zhang \& Stafford, 2008). For the purposes of this study, the scale was modified through the addition of two negative face threat items in an attempt to achieve a higher reliability (i.e., my partner's actions made me feel obligated to comply, and my partner's actions made me feel like I had no control; See Appendix A).

Facework. Facework was assessed using a modified version of the Revised Instructional Face Support Scale (Kerssen-Griep et al., 2008). The original scale measured facework in providing feedback to students, and in this study, the wording was changed to target the former spouse instead of an instructor. The items were measured on an 8-item, 7-point Likert type scale ranging from not at all (1) to very much (7) to indicate the degree to which both positive facework (e.g., made sure that he/she doesn't cast you in a bad light) and negative facework (e.g., left me free to choose how to respond) was enacted (See Appendix B). Kerssen-Griep et al. (2008) obtained an acceptable reliability of .75 for negative facework $(M=5.10, S D=1.20)$ and a reliability 
of .85 for positive facework $(M=4.90, S D=1.40)$. The reliability of negative face support was low $(\alpha=.63)$ and could not be improved through item deletion.

Conflict. Similar to Brissette and Cohen (2002), a 1-item conflict measure was utilized (See Appendix C) to assess conflict severity during the divorce conversation. Participants were asked to rate the intensity of their conflict during the divorce conversation with the former spouse using a scale ranging from Not Intense (1) to Extremely Intense (5).

Caring. Perceived former spouse caring was measured using the goodwill dimension of the Source Credibility scale (See Appendix D, McCroskey \& Teven, 1999). The scale has previously been used to examine the perceived caring of instructors, political figures, public figures (e.g., celebrity), supervisors, and interpersonal contacts (e.g., roommate, dating partner) (McCroskey \& Teven). The scale included six semantic differential items rated on a scale ranging from (1) to (7) to indicate perceived former spouse caring and goodwill (e.g., cared-did not care, sensitive-was not sensitive) about the participant's recalled divorce conversation. McCroskey and Teven obtained a high reliability of $.92(M=24.70, S D=9.60)$.

Hurt. To assess hurt, two items from Zhang and Stafford (2008; See Appendix E) were utilized. The scale was developed for use in measuring the degree of pain experienced in hurtful messages. For the first item, participants indicated the general hurtfulness of the divorce conversation on a scale ranging from not at all hurtful (1) to extremely hurtful (7). The second item referred to emotional pain, and participants rated the emotional pain caused by the divorce conversation on a scale ranging from no emotional pain at all (1) to a great deal of emotional pain (7). These two items are then 
summed together to form a composite measure of pain $(\alpha=.86, M=4.36, S D=1.49$, Zhang \& Stafford, 2008). The scale had low reliability $(\alpha=.66)$, and could not be improved because there were only two items in the measure.

Emotion. Emotion was assessed using the Positive and Negative Affect Schedule (Watson, Clark, \& Tellegren (i.e., PANAS; 1988). The scale includes ten negative affect descriptors (e.g., guilty, nervous, upset) and ten positive affect (e.g., inspired, enthusiastic, attentive) descriptors (See Appendix F). Following McCullough, Bellah, Kilpatrick, and Johnson (2001), participants indicated the degree to which they generally experienced this emotion on a 5-point Likert-type scale ranging from very slightly (1) to extremely (5). Previous reliabilities have been above .70 for positive affect $(M=33.84$, $S D=7.52$, McCullough et al., 2001; Tuccitto, Giacobbi, \& Leite, 2010) and above .70 for negative affect $(M=33.84, S D=7.81$, McCullough et al., 2001; Tuccitto et al., 2010). Tuccitto et al. recommended adding additional items to the PANAS to better capture overall affect. Consequently, three additional items were added following a study by Sbarra and Ferrer (2006) including love, anger, and sadness, and were measured using the same scale ranging from very slightly (1) to extremely (5).

Well-being. Two measures assessed well-being. First, well-being was measured using Cohen, Kamarck, and Mermelstein's (1983) Perceived Stress Scale (See Appendix G) which assessed levels of stress within the past month (e.g., In the last month, how often have you felt nervous and stressed). It is a 14-item, 5-point Likert-type scale ranging from never (0) to very often (4). Previous studies reported high reliabilities (e.g., $.86, M=23.67, S D=7.79$, Cohen et al., 1983).

Second, well-being was assessed utilizing Kitson's (1982) Attachment to Spouse 
Scale (See Appendix H). The Attachment to Spouse Scale (e.g., I find myself wondering what my ex-spouse is doing) is a 9-item 5-point Likert type scale ranging from not my feelings at all (1) to very much my feelings (5) and had previously been reliable (e.g., .80, Kitson). Kitson did not report the mean and the standard deviation of the scale.

Current Relationship. The nature of the post-divorce relationship was assessed in two ways to address the type of relationship between former spouses, and the affect toward the type of relationship. The use of two measures allowed for both a qualitative and a quantitative understanding of the relationship to be ascertained. The qualitative measure provided a description of the relationship with the former spouse on which the participant was reporting, while the quantitative measure obtained the participants' evaluation of that relationship with the former spouse.

First, affect toward the current relationship was quantitatively measured using a modified version of Andersen's (1979) Affective Learning Scales. Originally, the scales measured affect toward the instructor, course content, and taking a similar course in instructional settings. Only the scale intended to measure affect toward the instructor was modified and used. Specifically, the scale was modified to address affect toward the current relationship with the former spouse instead of affect toward the instructor. Four semantic differential four-item measures were chosen for this study reflecting affect toward the current relationship with the former spouse using the adjective pairs bad-good, valuable-worthless, unfair-fair, and negative-positive (Appendix I). Reliability coefficients for the affective learning measures have ranged from .91 to $.98(M=21.40$, $S D=7.30$, Andersen, 1979; Gorham, 1988; Teven \& McCroskey, 1997).

Second, Ahrons and Wallisch's (1987) qualitative descriptive typology (i.e., 
perfect pals, cooperative colleagues, angry associates, fiery foes, and dissolved duos) was provided to the participants, and the participants indicated which description best illustrated their current relationship with their former spouse (Appendix J). 
Table 1

Study One Descriptive Statistics

\begin{tabular}{|c|c|c|c|c|c|}
\hline Measure & Minimum & Maximum & Mean & SD & $\alpha$ \\
\hline Positive Face Threats & 13.00 & 70.00 & 45.20 & 15.47 & .91 \\
\hline Negative Face Threats & 6.00 & 38.00 & 20.18 & 8.51 & .75 \\
\hline Positive Face Support & 4.00 & 28.00 & 12.47 & 6.04 & .78 \\
\hline Negative Face Support & 4.00 & 28.00 & 16.79 & 5.93 & .64 \\
\hline Conflict & 1.00 & 9.00 & 6.13 & 2.34 & -- \\
\hline Caring & 6.00 & 37.00 & 18.75 & 8.73 & .84 \\
\hline Hurt & 5.00 & 18.00 & 11.43 & 2.87 & .68 \\
\hline Positive Emotion & 12.00 & 50.00 & 29.31 & 8.34 & .87 \\
\hline Negative Emotion & 15.00 & 69.00 & 42.52 & 10.15 & .88 \\
\hline Stress & 5.00 & 44.00 & 23.73 & 8.64 & .86 \\
\hline Attachment to Spouse & 9.00 & 41.00 & 21.04 & 6.02 & .69 \\
\hline Affect toward & 4.00 & 28.00 & 13.97 & 6.24 & .88 \\
\hline Relationship & & & & & \\
\hline
\end{tabular}


Data analysis plan. Although the purpose of this study was to gather data from both divorcees' perspectives to avoid the potential bias when only one perspective was gathered, only the non-dyadic data were utilized in the analyses. Prior to testing each hypothesis, each variable was examined for differences based on initiator status, sex, relationship length, time since the divorce, and the number of children. These preliminary analyses uncovered variables which should be controlled for in subsequent analyses, and the results are reported in the preliminary analysis section of Chapter 3.

Hypotheses one and two were examined using paired samples t-tests. Hypothesis $3 \mathrm{a}, 3 \mathrm{~b}, 4 \mathrm{a}, 4 \mathrm{~b}$, and $4 \mathrm{c}$ were tested using bivariate correlations. Hypothesis $4 \mathrm{~d}$ was examined using a discriminant analysis. A large number of statistical tests were required to test the hypotheses; thus, the $\mathrm{p}$ value was adjusted to .01 instead of .05 to minimize type I errors. 


\section{Study Two}

Recruitment Procedures. To participate in Study Two, participants were required to be 18 years of age or older and have been divorced within the past five years. The five year time frame was deemed appropriate to assist participants in recalling postdivorce events, avoid the novelty of the actual divorce so that the participant could focus on the post-divorce events instead of the divorce event, and allow time for both positive and negative post-divorce turning points to actually occur. This decision was based on extant trajectories and typologies which suggest that post-divorce relationships are more likely to develop with enough time (Ahron, 1994, 2007; Graham, 1997; Kellas et al., 2008). Participants were recruited using snowball sampling and several avenues including divorce support groups, single parent support groups, social networking websites (e.g., Facebook), campus wide electronic announcements, professional organization announcements (e.g., CRTNET), and classroom recruitment from five different universities.

Participants. Participants $(N=165,49$ males, 105 females, and 11 who did not indicate their biological sex) ranged in age from 20 to $68(M=39.53, S D=10.35)$. Each individual had been married an average of 9.89 years (range $=1$ month to 39 years, $S D=$ 8.09 years), and divorced an average of 3.06 years prior to taking the survey (range $=1$ month to 30 years, $S D=3.90$ years). In terms of current dating status, $21.8 \%$ of the participants reported that they were not currently dating a new partner, $21.8 \%$ were casually dating a new partner, $20.0 \%$ were seriously dating a new partner, $8.5 \%$ were engaged to a new partner, $21.8 \%$ were remarried to a new partner $(21.8 \%)$, and $6.1 \%$ did not report their current relationship status. Geographically, the former spouses lived an 
average of 247.81 miles apart (range $=0$ miles to 5000 miles, $S D=650.35$ miles). In terms of contact with the former spouse, $29.7 \%$ of the participants reported that they had no contact, $25.5 \%$ reported that they had monthly contact, $12.7 \%$ reported that they had weekly contact, $10.3 \%$ reported that they had daily contact, $4.8 \%$ reported that they had yearly contact, and $17 \%$ did not report how frequently they communicated with their former spouse. Of the participants, $27.9 \%$ had two children, followed by $22.4 \%$ with one child, $23.0 \%$ had zero children, $9.1 \%$ had three children, . $6 \%$ had four children, and $.6 \%$ had six children. In terms of custody agreement, $40.2 \%$ of the participants had no custody agreement because the couple had no children, $25.9 \%$ had shared custody, $21.4 \%$ reported that the biological mother had custody, $11 \%$ reported that the children were adults so no legal custody was required, and $1.2 \%$ reported that the biological father had custody $(1.2 \%)$. Participants reported that they initiated the divorce $(n=83)$, their partner initiated the divorce $(n=33)$, or the divorce was a mutual decision $(n=38)$, and 11 did not report who initiated the divorce decision.

Procedures. Those who met the criteria then contacted the researcher to indicate interest in participating. When each individual contacted the researcher, they were randomly assigned using a random numbers table to report on either a positive postdivorce turning point (e.g., forgiveness, became friends, moved on, reconciliation) or a negative post-divorce turning point (e.g., counseling, lost custody, partner remarries) and they were provided with the corresponding link to a survey hosted on SurveyMonkey. The survey included one open-ended question where participants briefly described the positive $(n=87)$ or negative post-divorce turning point $(n=78)$ to assist the participants with recall, and six quantitative measures including perceived face threat (i.e., positive 
and negative), facework (i.e., positive face support and negative face support), perceived former spouse caring, emotion, stress, ongoing attachment to the spouse, and demographics.

Instrumentation. The measures used in study one and study two were similar, however, there were fewer measures in study two. Specifically, conflict and hurt were used in study one, but not in study two. The items in study two were modified to refer to the turning point which was described by the participant, instead of the divorce conversation, as was referred to in study one. For more information on the measures, please refer to study one.

Face Threats. Perceived face threat was measured using a a 14-item scale assessing both positive and negative face threats on a 7-point Likert-type scale ranging from strongly disagree (1) to strongly agree (7) (Cupach \& Carson, 2002). For the purposes of this study, the scale was modified through the addition of two negative face threat items in an attempt to achieve a higher reliability and to address perceptions of a turning point.

Facework. Facework was assessed using a modified version of the Revised Instructional Face Support Scale (Kerssen-Griep et al., 2008). The items were measured on an 8-item, 7-point Likert type scale ranging from not at all (1) to very much (7) to indicate the degree to which both positive facework and negative facework was enacted. The scale reliability was low $(\alpha=.60)$, and it could not be improved through item deletion.

Conflict. Similar to Brissette and Cohen (2002), a 1-item conflict measure was utilized to assess conflict severity. Participants were asked to rate the intensity of their 
conflict during the divorce conversation with the former spouse using a scale ranging from Not Intense (1) to Extremely Intense (5).

Caring. Perceived former spouse caring was measured using the goodwill dimension of the Source Credibility scale (See Appendix D, McCroskey \& Teven, 1999). The scale included six semantic differential items rated on a scale ranging from (1) to (7) to indicate perceived former spouse caring and goodwill

Hurt. To assess hurt, two items from Zhang and Stafford (2008) were utilized. Participants indicated the general hurtfulness of the turning point on a scale ranging from not at all hurtful (1) to extremely hurtful (7) and the extent of emotional pain rated on a scale ranging from no emotional pain at all (1) to a great deal of emotional pain (7).

Emotion. Emotion was assessed using the Positive and Negative Affect Schedule (Watson, Clark, \& Tellegren (i.e., PANAS; 1988). The scale includes ten negative affect descriptors (e.g., guilty, nervous) and ten positive affect (e.g., inspired, enthusiastic) descriptors. Participants indicated the degree to which they generally experienced this emotion on a 5-point Likert-type scale ranging from very slightly (1) to extremely (5). Three additional items were added including love, anger, and sadness, and were measured using the same scale ranging from very slightly (1) to extremely (5).

Well-being. Two measures assessed well-being. First, well-being was measured using Cohen, Kamarck, and Mermelstein's (1983) Perceived Stress Scale which assessed levels of stress within the past month. It is a 14-item, 5-point Likert-type scale ranging from never (0) to very often (4). Second, well-being was assessed utilizing Kitson's (1982) Attachment to Spouse Scale. The Attachment to Spouse Scale is a 9-item 5-point Likert type scale ranging from not my feelings at all (1) to very much my feelings (5). 
Current Relationship. The nature of the post-divorce relationship was assessed in two ways. First, affect toward the current relationship was measured using a modified version of Andersen's (1979) Affective Learning Scales. Four semantic differential fouritem measures were chosen for this study reflecting affect toward the current relationship with the former spouse using the adjective pairs bad-good, valuable-worthless, unfairfair, and negative-positive. Second, Ahrons and Wallisch's (1987) typology (i.e., perfect pals, cooperative colleagues, angry associates, fiery foes, and dissolved duos) was provided to the participants, and the participants indicated which description best illustrated their current relationship with their former spouse. The descriptive statistics for each measure are presented in Table 2. 
Table 2

Study Two Descriptive Statistics

\begin{tabular}{|c|c|c|c|c|c|}
\hline Measure & Minimum & Maximum & Mean & SD & $\alpha$ \\
\hline Positive Face Threats & 10.00 & 70.00 & 42.33 & 20.06 & .95 \\
\hline Negative Face Threats & 6.00 & 42.00 & 19.60 & 9.97 & .82 \\
\hline Positive Face Support & 4.00 & 28.00 & 13.60 & 7.79 & .87 \\
\hline Negative Face Support & 4.00 & 28.00 & 17.42 & 6.09 & .60 \\
\hline Caring & 6.00 & 42.00 & 19.74 & 12.56 & .96 \\
\hline Positive Emotion & 11.00 & 55.00 & 31.99 & 10.51 & .88 \\
\hline Negative Emotion & 12.00 & 60.00 & 33.42 & 13.83 & .93 \\
\hline Stress & 14.00 & 47.00 & 28.51 & 7.55 & .82 \\
\hline Attachment to Spouse & 9.00 & 38.00 & 19.71 & 7.07 & .79 \\
\hline Affect toward Relationship & 4.00 & 28.00 & 14.57 & 7.00 & .92 \\
\hline
\end{tabular}


Data analysis plan. The participants were randomly assigned using a random numbers table to report on either a positive or a negative turning point, creating two groups. Prior to testing each hypothesis and research question, each variable was examined for differences based on initiator status, sex, relationship length, time since the divorce, and the number of children. These preliminary analyses uncovered variables which should be controlled for in subsequent analyses and these results are reported in the preliminary analyses section of the results in Chapter 3 . The turning points were also analyzed for differences based on whether participants reported on a positive or a negative event, and for sex differences in reporting about the turning points, and this information is reported in Chapter 3.

Hypotheses 1a through $3 \mathrm{~b}$ were explored using independent samples $t$-tests with turning point valence (i.e., positive or negative) entered as the fixed factor and positive face threat, negative face threat, positive face support, negative face support, emotion, overall affect, and perceived former spouse caring entered independently as the outcome variables. Hypothesis $4 \mathrm{a}, 4 \mathrm{~b}$, and research question 1 were examined using bivariate correlations. Last, research question 2 was explored using a discriminant analysis. A large number of statistical tests were required to test the hypotheses and examine the research questions; thus, the $\mathrm{p}$ value was adjusted to .01 instead of .05 to account for type I errors.

\section{Summary}

This chapter delineated the rationale for the methods and measures used in each study. The methods were designed to obtain information about communication during the divorce conversation and the post-divorce turning points and the impact the 
communication had on well-being and post-divorce relationships. The results of each study are discussed in Chapter Three. 


\section{Chapter Three}

\section{Results}

\section{Study One}

The purpose of study one was to understand the communication that occurs during the conversation where partners decide to divorce and the impact that this conversation has on well-being and the post-divorce relationship. Specifically, face threats, facework, perceived spouse caring, conflict, emotion, hurt, attachment to the spouse, stress, affect toward the relationship, and the nature of the relationship were examined.

Preliminary data analyses. Previous research has uncovered differences in the divorce experience based on sex (e.g., Perilloux \& Buss, 2008), an individual's role in the divorce decision (e.g., Boelen \& Reijntjes, 2009), relationship length (e.g., Shortt, Capaldi, Kim, \& Owen, 2006), time since the divorce (e.g., Kitson, 1982), and the number of children (e.g., Berman, 1985). To explore sex differences, a MANOVA was conducted with participant sex entered as the fixed factor and face threats, facework, perceived spouse caring, conflict, emotion, hurt, attachment to the spouse, stress, affect toward the relationship entered as the dependent variables. Results indicate that there were no significant differences between the sexes [Wilk's $\Lambda=.73, F(1,54)=1.33, p=$ $\left..24 . \eta^{2}=.27\right]$. Thus, sex will not be used as a control variable in future analyses.

To explore potential differences in initiator status, a MANOVA was utilized with initiator status entered as the fixed factor and face threats, facework, perceived spouse caring, conflict, emotion, hurt, attachment to the spouse, stress, affect toward the relationship were entered as the dependent variables. The MANOVA revealed a 
significant model [Wilk's $\left.\Lambda=.27, F(2,52)=2.92, p=.001 . \eta^{2}=.48\right]$. Post hoc Scheffe analyses indicate that initiation status differed in negative face support, positive face support, caring, and positive emotion. For negative face support, the sender of the dissolution messages perceived that their partners enacted significantly greater negative face support $(M=4.50)$ than either message receivers $(M=3.06)$, but neither senders nor receivers were significantly different from those who made a mutual decision in perceived negative face support $(M=4.18)$. For positive support, mutual decision makers experienced significantly greater positive face support $(M=4.40)$ than those who were the sender of the decision $(M=2.82)$, but mutual decision makers and senders did not significantly differ from receivers $(M=3.22)$ in perceived positive face support. For former spouse caring, those who made mutual decisions perceived their former spouse as significantly more caring $(M=4.25)$ than both senders $(M=2.87)$ and receivers $(M=$ 2.72), but senders and receivers did not significantly differ from one another. For positive emotion, both senders $(M=2.85)$ and those who made mutual decisions $(M=2.93)$ significantly differed from receivers $(M=1.72)$, but senders and those who made mutual decisions did not differ from one another.

Finally, to explore potential differences resulting from the length of the marriage, the time passed since the divorce, and the number of children, Pearson correlations between these demographics and face threats, facework, perceived spouse caring, conflict, emotion, hurt, attachment to the spouse, stress, affect toward the relationship were utilized. Please see Table 3 for a correlation matrix of all variables. The time passed since the divorce, the number of children between the divorcees, and the length of marriage was not related to any of the variables of interest. Given the lack of significant 
relationships between the demographics and the outcome variables, the demographics were not entered as control variables in subsequent analyses. 
Table 3

Correlation Matrix of Study One Variables

\begin{tabular}{|c|c|c|c|c|c|c|c|c|c|c|c|c|c|c|}
\hline Variable & 1. & 2. & 3. & 4. & 5. & 6. & 7. & 8. & 9. & 10. & 11. & 12. & 13. & 14. \\
\hline \multicolumn{15}{|l|}{ 1.ML } \\
\hline 2.TSD & -.07 & & & & & & & & & & & & & \\
\hline 3.NOC & $.78^{* *}$ & .24 & & & & & & & & & & & & \\
\hline 6.PS & -.22 & -.04 & -.21 & $-.78 * *$ & $-.39 * *$ & & & & & & & & & \\
\hline 7.NS &.-20 & .03 & .24 & $-.61 * *$ & $-.63 * *$ & $.47 * *$ & & & & & & & & \\
\hline 8.H & .07 & .08 & .07 & $.58 * *$ & $.38 * *$ & $-.52 * *$ & $-.39 * *$ & & & & & & & \\
\hline 12.NE &.-11 & -.01 & -.04 & $.46^{* *}$ & $.41 * *$ & $-.35 * *$ & -.28 & $.65^{* *}$ & $.39 * *$ & -.32 & $-.35 * *$ & & & \\
\hline 13.S & -.01 & .19 & .14 & .19 & .25 & -.16 & -.22 & $.33 * *$ & .21 & -.22 & -.28 & .30 & & \\
\hline 14.ATT & -.06 & .13 & -.10 & .26 & .30 & -.24 & -.29 & $.55^{* *}$ & -.26 & -.13 & -.28 & $.42 * *$ & $.62 * *$ & \\
\hline 15.AFF & -.15 & -.17 & -.02 & $-.41 * *$ & -.31 & $.41 * *$ & .23 & -.26 & -.26 & $.38 * *$ & .11 & -.16 & $-.34 * *$ & $-.32 * *$ \\
\hline
\end{tabular}

Note. Entire sample of participants $(\mathrm{N}=110) * * \mathrm{p}<.01$.

$\mathrm{ML}=$ marriage length, $\mathrm{TSD}=$ Time since divorce, $\mathrm{NOC}=$ number of children, $\mathrm{PT}=$ positive threat, $\mathrm{NT}=$ negative threat, $\mathrm{PS}=$ positive support, $\mathrm{NS}=$ negative support, $\mathrm{H}=$ hurt, $\mathrm{C}=$ conflict, $\mathrm{CA}=$ caring, $\mathrm{PE}=$ positive emotion, $\mathrm{NE}=$ negative emotion, $\mathrm{S}=$ stress, $\mathrm{ATT}=$ attachment, and $\mathrm{AFF}=$ affect 


\section{Tests of Hypotheses}

Hypothesis 1. Hypothesis 1 stated that both senders and receivers of dissolution messages would perceive greater positive face threat than negative face threat. For dissolution message senders $(n=40)$, a paired samples $t$-test indicated significantly more positive face threat $(M=4.61, S D=1.66)$ than negative face threat $(M=3.09, S D=$ $1.46) ; t(39)=7.24, p<.001$. For dissolution message receivers $(n=9)$, a paired samples t-test indicated no significant differences in positive face threat and negative face threat $t(8)=1.79, p=.11$. That is, senders experienced greater positive face threat than negative face threat and receivers experienced positive and negative face threat equally. Hypothesis 1 was partially supported.

Hypothesis 2. Hypothesis 2 predicted that both dissolution message senders and receivers would perceive that their partner employed more positive face support than negative face support. For dissolution message senders $(n=39)$, a paired samples t-test indicated significantly more negative face support $(M=4.48, S D=1.34)$ than positive face support $(M=2.77, S D=1.41) ; t(38)=-7.76, p<.001$. For dissolution message receivers $(n=9)$, a paired samples t-test indicated that there were no significant differences in perceived negative face support and positive face support $t(8)=.62, p=$ .55. That is, senders perceived that their former spouse used more negative face support than positive face support and receivers perceived that their former spouse used negative and positive face support equally. Hypothesis 2 was partially supported.

Hypothesis 3a and 3b. Hypothesis 3a predicted a positive relationship between face threat and conflict, hurt, and negative emotions. Pearson correlations indicated positive face threat was significantly correlated to conflict $(r=.60, p=.01)$, hurt $(r=.59$, 
$p=.01)$, and negative emotions $(r=.46, p=.01)$ in the predicted direction. Pearson correlations indicate that negative face threat was significantly correlated to conflict $(r=$ $.46, p=.01)$, hurt $(r=.38, p=.01)$, and negative emotion $(r=.41, p=.01)$, in the predicted direction. Thus, hypothesis 3a was supported; positive and negative face threats are both directly and positively correlated to the hurt, conflict, and negative emotions present during a divorce conversation.

Hypothesis $3 \mathrm{~b}$ predicted a negative relationship between face threat and affect toward the relationship, spouse caring, and positive emotions. Pearson correlations indicate that positive face threat is significantly correlated to affect toward the relationship $(r=-.41, p<.01)$ and spouse caring $(r=-.69, p<.01)$ in the predicted direction, but was not significantly correlated with positive emotion $(r=-.15, p>.01)$. Pearson correlations indicate that negative face threat is significantly related to spouse caring $(r=-.49, p<.01)$ and positive emotion $(r=-.33, p<.01)$ in the predicted direction, however negative face threat was not significantly correlated to affect toward the current relationship $(r=-.31, p<.01)$. Thus hypothesis $3 b$ was partially supported, in that positive face threat and negative face threat were significantly and negatively correlated with perceived former spouse caring. Positive face threat was significantly and negatively correlated to affect toward the relationship but not positive emotion, while negative face threat was significantly correlated to positive emotion, but not to affect toward the relationship.

Hypothesis 4a. Hypothesis 4a asserted that face threats, conflict, hurt, facework, affect toward the relationship with the former spouse, ongoing attachment, and former spouse caring would be associated with current stress levels of the participant. Pearson 
correlations indicated that only hurt $(r=.33, p<.01)$ ongoing attachment $(r=.62, p<$ $.01)$, and affect toward the relationship $(r=-.34, p<.01)$ were significantly and positively correlated with stress. The remaining variables were not significantly associated with stress: positive face threat $(r=.19, p>.01)$, negative face threat $(r=.25$, $p>.01)$, conflict $(r=.21, p>.01)$, positive face support $(r=-.16, p>.01)$, negative face support $(r=-.22, p>.01)$, affect $(r=-.16, p>.01)$, and spouse caring $(r=-.22, p<.01)$. Thus, higher levels of hurt and ongoing attachment, and lower levels of affect were associated with participants' current stress. Hypothesis $4 \mathrm{a}$ was partially supported.

Hypothesis 4b. Hypothesis $4 \mathrm{~b}$ asserted that face threats, conflict, hurt, facework, affect toward the relationship with the former spouse, and former spouse caring would be associated with ongoing attachment to the former spouse. Pearson correlations indicated that only hurt $(r=.55, p<.01)$, affect toward the relationship $(r=-.32, p<.01)$, and negative emotion $(r=.42, p<.01)$ were associated with ongoing attachment. The remaining variables were not associated with ongoing attachment: positive face threat ( $r$ $=.26, p>.01)$, negative face threat $(r=.30, p>.01)$, conflict $(r=-.26, p>.01)$, positive face support $(r=-.24, p>.01)$, negative face support $(r=-.29, p>.01)$, and spouse caring $(r=-.13, p<.01)$. That is, when hurt and negative emotions are higher, or affect toward the relationship is lower, participants experience greater ongoing attachment to the spouse . Hypothesis $4 \mathrm{~b}$ was partially supported.

Hypothesis 4c. Hypothesis 4c predicted that face threats, conflict, hurt, facework, and former spouse caring would be associated with affect toward the current relationship with the former spouse. Pearson correlations indicated that only positive face threats ( $r=$ $-.41, p<.01)$, positive face support $(r=.41, p<.01)$, and spouse caring $(r=.38 p<.01)$ 
were significantly correlated to affect toward the current relationship. The remaining variables were not associated with affect toward the current relationship: negative face threat $(r=-.31, p>.01)$, conflict $(r=-.26, p>.01)$, hurt $(r=-.26, p>.01)$, negative face support $(r=.23, p>.01)$, and spouse caring $(r=-.13, p<.01)$. That is, when positive face threats are higher, positive face support is higher, or perceived spouse caring is higher, then affect toward the relationship is more positive. Hypothesis $4 \mathrm{c}$ was partially supported.

Hypothesis 4d. Hypothesis 4d predicted that face threats, conflict, hurt, facework, and former spouse caring would predict the nature of the current relationship between the former spouses. A discriminant analysis with the nature of the relationship as the dependent variable, and face threats, conflict, hurt, facework, and former spouse caring as independent variables indicated that this combination of variables could not accurately predict which type of relationship existed between the former spouses (i.e., perfect pals, cooperative colleagues, angry associates, fiery foes, and dissolved duos), $\left[\Lambda=.55, \chi^{2}\right.$ (28, $\mathrm{N}=62)=32.81, p=.24$. Hypothesis $4 \mathrm{~d}$ was not supported.

Post Hoc Analyses. In light of the results for hypotheses 3a and 3b, a series of Fisher's z-tests were used to assess the differences in the strength of the relationships between positive/negative face threat and conflict, negative emotion, hurt and spouse caring. Despite the apparent strength of the relationships, Fisher's z-test revealed that positive face threat and negative face threat correlations with conflict were not significantly different $(z=1.12, p>.05)$, that positive and negative face threat correlations with hurt were not significantly different $(z=1.59, p>.05)$, and that positive and negative face threat correlations with negative emotion were not significantly 
different $(z=.35, p>.05)$.However, the relationships between positive and negative face threat and perceived former spouse caring were significantly different $(z=-1.79, p<.05)$, with positive face threat and perceived former spouse caring exhibiting a significantly stronger negative correlation $(r=-.69, p<.01)$ than negative face threat $(r=-.49, p<$ .01). That is, the conflict, hurt, and negative emotion are similar when positive or negative face threat occurs. However, the perception of former spouse caring is more negative when positive face is threatened than when negative face is threatened.

\section{Study One Summary}

The results of study one illuminate the impact of face threats and face support on the divorcing couple and the individual, influencing their perceptions and relationships with one another following divorce. Divorce, as an event, is face threatening for both the sender and the receiver, and is especially threatening to the positive face of senders. Despite the threats to positive face, senders believed that they were receiving negative face support. Face threats were associated with perceptions of conflict in the relationship, hurt experienced, perceived caring, and the emotions during the divorce event.

Interestingly, the communicative variables were not associated with the participants' stress levels, and suggested instead that stress was related to hurt, ongoing attachment, and affect toward the relationship. However, the affect toward the post-divorce relationship was associated with communicative variables. Specifically, positive face threats, positive face support, and perceived spouse caring in a divorce conversation played a role in negotiating a relationship that former spouses felt positively toward. The examination of the post-divorce relationship continued with the investigation presented in study two. 


\section{Study Two}

The purpose of study two was to investigate the communicative events that transpired following a divorce, focusing on both positive and negative events and their impact on well-being and the nature of the post-divorce relationship. Specifically, face threats, facework, emotion, affect toward the relationship, former spouse caring, stress, ongoing attachment to the spouse, and the current relationship between divorcees were examined.

Preliminary Data Analyses. Similar to study one, the preliminary analyses explored sex, the role in the decision process, relationship length, time since the divorce and the number of children as potential covariates. To explore sex differences, a MANOVA was utilized with participant sex entered as the fixed factor and face threats, facework, perceived spouse caring, conflict, emotion, hurt, attachment to the spouse, stress, affect toward the relationship entered as the dependent variables. Results indicate that there were no significant sex differences [Wilk's $\Lambda=.43, F(1,52)=.98, p=.47 . \eta^{2}=$ .19]. Thus, sex will not be used as a control variable in subsequent analyses.

To explore potential differences in initiator status, a MANOVA was utilized with initiator status entered as the fixed factor and face threats, facework, perceived spouse caring, conflict, emotion, hurt, attachment to the spouse, stress, affect toward the relationship were entered as the dependent variables. The MANOVA revealed a nonsignificant model when using the adjusted $\mathrm{p}$ value of .01 for significance, [Wilk's $\left.\Lambda=.81, F(2,50)=1.80, p=.03 . \eta^{2}=.34\right]$. Thus, there were no differences in the variables of interest based on how the divorce decision was made.

Last, to explore potential differences resulting from the length of the marriage, the 
time passed since the divorce, and the number of children, Pearson correlations between these demographics and face threats, facework, perceived spouse caring, conflict, emotion, hurt, attachment to the spouse, stress, affect toward the relationship were utilized. Please see Table 4 for a correlation matrix of all variables. The length of the marriage was only significantly related to the number of children between the divorcees $(r=.53, p=.01)$ and was not significantly related to any of the variables under study. The time passed since the divorce was significantly related to positive emotion $(r=.35, p$ $=.01)$ and negative face support $(r=.21, p=.01)$. The number of children between the divorcees was significantly related to negative face threat $(r=.20, p=.01)$. Thus, the time since the divorce had passed and the number of children between divorcees will be utilized as control variables in subsequent analyses which include positive emotion, negative face support, and negative face threat as outcome variables. Given the lack of significant relationships among the demographics and the outcome variables, these demographics were not entered as control variables in subsequent analyses.

Turning Points. Participants were randomly assigned to report on positive postdivorce turning points $(n=87)$ and negative post-divorce turning points $(n=78)$. When reporting on positive turning points, participants wrote accounts of the event ranging from 1 to 213 words $(M=53.59, S D=44.17)$ to describe the turning point. Positive turning points included events such as celebrating a child's graduation, showing support at a funeral, mourning the loss of a shared pet together, and realizing that the anger was no longer a salient part of their relationship (See Appendix K for all positive turning points described by participants). There were no significant sex differences in how much the participants wrote about the turning point event $[t(81)=-.94, p=.35]$. For negative 
turning points, participants wrote accounts of the negative events randing from 2 to 686 words $(M=65.90, S D=107.75)$ to describe the turning point. Negative turning points included events such as custody disputes, domestic violence charges, the former spouse ceasing communication with the child(ren), and when former partners began dating a new partner (See Appendix L for all negative turning points described by participants). There were no significant sex differences in how much the participants wrote about the turning point event $[t(69)=-1.29, p=.20]$. The responses were examined for significant differences in how much participants wrote about positive and negative turning point, and no significant differences were found $[t(163)=-.98, p=.35]$. Last, the responses were examined for significant differences in how much participants wrote based on their decision status (i.e., they initiated the divorce decision, their partner initiated the decision, the partners decided together). An ANOVA revealed that there were no significant differences $F(2,153)=.24, p=.78$, in how much decision initiators $(M=62.49)$, decision receivers $(M=67.72)$, and mutual decision makers $(M=54.23)$ wrote in their turning point descriptions. 
Table 4

Correlation Matrix of Study Two Variables

\begin{tabular}{|c|c|c|c|c|c|c|c|c|c|c|c|c|}
\hline Variable & 1. & 2. & 3. & 4. & 5. & 6. & 7. & 8. & 9. & 10. & 11. & 12. \\
\hline \multicolumn{13}{|l|}{ 1.ML } \\
\hline 2.TSD & .07 & & & & & & & & & & & \\
\hline 3.NOC & $.53^{* *}$ & .17 & & & & & & & & & & \\
\hline 4.PT & .01 & -.07 & .12 & & & & & & & & & \\
\hline 5.NT & .03 & -.04 & .20 & $.63^{* *}$ & & & & & & & & \\
\hline 6.PS & -.09 & .10 & -.11 & $-.80 * *$ & $-.47 * *$ & & & & & & & \\
\hline 7.NS & -.09 & .21 & -.13 & $-.73 * *$ & $-.69 * *$ & $.70 * *$ & & & & & & \\
\hline 8.PE & -.04 & $.35^{* *}$ & -.04 & $-.46 * *$ & $-.29 * *$ & $.53 * *$ & $.53 * *$ & & & & & \\
\hline 9.NE & .03 & -.16 & .07 & $.63^{* *}$ & $.53 * *$ & $-.61 * *$ & $-.61 * *$ & $-.39 * *$ & & & & \\
\hline 10.CA & -.12 & .05 & -.13 & $-.78 * *$ & $-.46^{* *}$ & $.87 * *$ & $.65^{* *}$ & $.57 * *$ & $-.60 * *$ & & & \\
\hline 11.S & -.05 & -.17 & -.01 & .05 & $.34 * *$ & -.05 & -.13 & .00 & .25 & -.07 & & \\
\hline 12.AFF & -.02 & .05 & -.11 & $-.61 * *$ & $-.33 * *$ & $.62 * *$ & $.49 * *$ & $.32 * *$ & $-.47 * *$ & $.62 * *$ & -.17 & \\
\hline 13. ATT & .04 & -.15 & .04 & .10 & $.24 * *$ & -.16 & -.19 & -.09 & .34 & -.12 & $.49 * *$ & $-.26 * *$ \\
\hline
\end{tabular}

Note. Participants $(N=165) * * p<.01$.

$\mathrm{ML}=$ marriage length, $\mathrm{TSD}=$ Time since divorce, $\mathrm{NOC}=$ number of children, $\mathrm{PT}=$ positive threat, $\mathrm{NT}=$ negative threat, $\mathrm{PS}=$ positive support, NS = negative support, $\mathrm{H}=$ hurt, $\mathrm{CA}=$ caring, $\mathrm{PE}=$ positive emotion, $\mathrm{NE}=$ negative emotion, $\mathrm{S}=$ stress, $\mathrm{AFF}=$ affect 


\section{Tests of Hypotheses}

Hypothesis 1a and 1b. Hypothesis $1 \mathrm{a}$ and $1 \mathrm{~b}$ asserted that negative turning points would elicit greater perceived positive and negative face threat than positive turning points. Results of an independent samples t-test with the turning point type entered as the fixed factor and positive and negative face threat entered as the dependent variables revealed that there were significant differences in positive face threat $[t(137)=-6.83, p<$ $.01]$ and in negative face threat $[t(147)=-5.84, p<.01]$. Specifically, negative turning points were more threatening to positive face $(M=5.22)$ than positive turning points $(M$ $=3.20)$. Similarly, negative turning points were more threatening to negative face $(M=$ 4.05) than positive turning points $(M=2.61)$. That is, negative turning points are more threatening to both positive and negative face than positive turning points, providing support for hypothesis $1 \mathrm{a}$ and $1 \mathrm{~b}$.

Hypothesis 2. Hypothesis two predicted that more positive and negative facework would be perceived in negative turning points than in positive turning points. Results of an independent samples t-test with turning point type entered as the fixed factor and positive and negative face support entered as the dependent variables revealed that the turning points significantly differed in positive face support $[t(149)=6.72, p<$ $.01]$ and in negative face support $[t(147)=7.13, p<.01]$. Specifically, more positive face support $(M=4.29)$ was utilized in positive turning points than in negative turning points $(M=2.42)$. More negative face support $(M=5.05)$ was also enacted in positive turning points than negative turning points $(M=3.51)$. That is, participants perceived more positive and negative face support to be enacted in positive turning points than in negative turning points. Thus, hypothesis two was not supported. 
Hypothesis 3a and 3b. Hypothesis 3a predicted that positive turning points would be associated with significantly more positive emotion, affect toward the current relationship with the former spouse, and perceived former spouse caring than negative turning points, while hypothesis $3 \mathrm{~b}$ predicted that negative turning points would be associated with significantly more negative emotion than positive turning points. Independent samples t-tests with turning points entered as the fixed factor and emotion, affect, and caring entered as the dependent variables were conducted. For positive emotion, positive and negative turning points were significantly different $[t(134)=6.61$, $p<.01]$, with positive turning points being associated with significantly more positive emotion $(M=3.34)$ than negative turning points $(M=2.39)$. For negative emotion, positive and negative turning points were significantly different $[t(135)=-7.58, p<.01]$, with negative turning points being associated with significantly more negative emotion $(M=3.50)$ than positive turning points $(M=2.23)$. For affect toward the current relationship with the former spouse, positive and negative turning points were significantly different $[t(150)=4.02, p<.01]$, with positive turning points being associated with significantly higher affect toward the current relationship with the former spouse $(M=4.14)$ than negative turning points $(M=3.04)$. For perceived former spouse caring, positive and negative turning points were significantly different $[t(145)=8.30, p$ $<.01$ ], with positive turning points being associated with significantly more perceived former spouse caring $(M=4.40)$ than negative turning points $(M=2.03)$. Hypotheses $3 \mathrm{a}$ and $3 b$ were supported.

Hypothesis 4a. Hypothesis 4a asserted that face threats, facework, emotions, affect toward the relationship with the spouse and perceived former spouse caring would 
be associated with current stress levels. Pearson correlations indicated that only negative face threat was related to stress $(r=.34, p<.01)$. The remaining variables were not associated with stress: positive face threat $(r=.05, p>.01)$, positive face support $(r=-$ $.05, p>.01)$, negative face support $(r=-.13, p<.01)$, positive emotion $(r=.00, p<.01)$, negative emotions $(r=.25, p<.01)$, affect toward the relationship $(r=-.17, p<.01)$, and spouse caring $(r=-.07, p<.01)$. That is, higher levels of negative face threat in postdivorce turning points are associated with current stress levels of participants. Hypothesis 4a was partially supported.

Hypothesis 4b. Hypothesis $4 \mathrm{~b}$ stated that face threats, facework, emotions, affect toward the relationship with the spouse and perceived former spouse caring would be associated with ongoing attachment to the spouse. Pearson correlations indicated that ongoing attachment was significantly correlated with negative face threat $(r=.24, p<$ $.01)$, negative emotion $(r=.34, p<.01)$, and affect toward the relationship $(r=-.26, p<$ .01). The remaining variables were not significantly related to ongoing attachment: positive face threat $(r=.10, p>.01)$, positive face support $(r=-.16, p>.01)$, negative face support $(r=-.19, p>.01)$, positive emotions $(r=-.09, p>.01)$, and perceived caring $(r=-.12, p>.01)$. That is higher levels of negative face threat, higher levels of negative emotion, and low affect toward the relationship are associated with ongoing attachment. Hypothesis $4 \mathrm{~b}$ was partially supported.

Research question 1. The first research question inquired about how perceived face threats, facework, emotion, and former spouse caring would be associated with the affect toward the relationship. Pearson correlations indicated that affect toward the relationship was significantly correlated with positive face threat $(r=-.61, p<.01)$, 
negative face threat $(r=-.33, p<.01)$, positive face support $(r=.62, p<.01)$, negative face support $(r=.49, p<.01)$, positive emotion $(r=.32, p<.01)$, and negative emotion $(r=-.47, p<.01)$, but was not significantly related to spouse caring $(r=.62, p>.01)$. That is, face threats and negative emotions are related to lower affect for the relationship with the spouse. Conversely, face support and positive emotions are positively related to higher affect toward the relationship with the spouse.

Research question 2. The second research question inquired about how perceived face threats, facework, emotion, and former spouse caring would predict the nature of the current relationship. A discriminant analysis with the nature of the relationship as the dependent variable, and face threats, conflict, hurt, facework, and former spouse caring as independent variables indicated that this combination of variables could accurately predict which type of relationship (i.e., perfect pals, cooperative colleagues, angry associates, fiery foes, and dissolved duos) the former spouses had $40.4 \%$ of the time $\left[\Lambda=.58, \chi^{2}(28, N=114)=59.20, p=.001\right]$. There was one significant discriminant function, which accounted for $74 \%$ of the variance, and included positive face threat $(.85, \mathrm{p}<.01)$, positive face support $(-.88, \mathrm{p}<.01)$, and perceived former spouse caring $(-.88, \mathrm{p}<.01)$. That is, face threatening and uncaring events with the spouse during the divorce conversation allows for participants to be correctly classified into the type of post-divorce relationships $40.6 \%$ of the time.

Study two summary. The findings from this study begin to delineate the impact of face threats and facework in post-divorce turning points between former spouses. Overall, negative turning points were perceived as more face threatening, and positive turning points were perceived as events where more facework was demonstrated. Positive 
turning points were associated with positive emotions, higher affect toward the relationship with the former spouse, and more perceived caring from the former spouse. Negative turning points were associated with negative emotions. Negative face threats were associated with the stress and ongoing attachment the divorcees experienced. Both communicative and emotional variables were associated with the affect toward the relationship with the former spouse. Specifically, face threats, facework, and emotion were associated with the affect divorcees reported. Positive face threats, positive facework, and former spouse caring allowed for individuals to be correctly classified over $40 \%$ of the time into one of five post-divorce couple types. However, the types of relationships were not equally represented: perfect pals $(n=26)$, cooperative colleagues $(n=49)$, angry associates $(n=29)$, fiery foes $(n=8)$, and dissolved duos $(n=41)$.

\section{Summary}

This chapter reported the results from two studies. Study one investigated how face threats and facework in divorce decision conversations were related to relationships between the former spouses, and individual well-being including stress, affect toward the relationship with the spouse, the nature of the relationship, emotions, and ongoing attachment. The results of study one emphasize the importance of communication in ending, and renegotiating, relationships between former spouses. Study two examined face threats and facework as associated with significant turning points between former spouses, after the divorce was finalized, for the impact on individual stress, affect toward the relationship with the spouse, the nature of the relationship, emotions, and ongoing attachment. The results of study two begin to illuminate the importance of examining events beyond the divorce, as the post-divorce events were important factors in relational 
and individual well-being. The final chapter discusses the findings in detail, offers potential explanations for the findings, suggests practical applications of the results, as well as delineates study limitations and future direction for research. 


\section{Chapter Four}

\section{Discussion}

Divorce is a naturally occurring face threatening event with potentially negative outcomes for the divorcees. The aim of the two studies presented here was to examine an event where former spouses had a conversation about the decision to divorce, and postdivorce turning points, for the influence of face threats and facework on individual wellbeing and relational perceptions. The two investigations presented here uncover the impact of communication, specifically, on the outcomes which have the potential to be beneficial, or detrimental, to the divorcee, children of divorce, and the larger social network. Taken together, the two studies highlight the salience of communication and emotion in divorce and post-divorce events, influencing stress, attachment, affect, and the type of post-divorce relationship which develops. First, study one will be discussed, including the face threats and face work associated with the divorce conversation, the role in the divorce decision, emotional responses, individual outcomes, and relational outcomes. Second, study two will be discussed, including the face threats and facework associated with post-divorce turning points, the role in the divorce, emotional responses, individual outcomes, and relational outcomes. Additionally, the discussion examines theoretical and practical implications, limitations, and future directions for research.

\section{Study One}

\section{Face Threats and Facework in the Divorce Conversation}

Participants in study one described a divorce conversation where they perceived that the final decision to divorce was determined. Kunkel et al. (2003) argued that both initiators and receivers of dissolution messages were prone to experience face threat in 
termination of dating relationships. Kunkel et al. suggested that those who initiate the decision are concerned about being perceived as insensitive or uncaring, while receivers of the dissolution message are concerned about gaining approval, liking, closeness, and being perceived as relationally competent. It was expected that the decision to divorce may be even more face threatening because of the marital connection which differentiates spouses from dating romantic partners (Cupach \& Metts, 1986). The decision to divorce can be difficult for senders, and hurtful for receivers, and this may be a significant relational turning point in which both would experience face threats.

The divorce conversation was indeed face threatening. Although both positive and negative face threats occurred, positive face threats were most salient to initiators, providing partial support for hypothesis 1. Both Kunkel et al. (2003) and Cupach and Carson (2002) reported that individuals reported higher negative face threat in termination and in relational complaint situations. In this study, initiators and receivers did not significantly differ in their perceived face threat. Although senders and receivers may have different face concerns, the data supports the notion that face threats are simultaneously occurring for both interactants. It was expected in this study that face threats would impact the receiver as the divorce message communicated relational devaluation, when in fact there were no differences based on the role a partner played in the divorce conversation.

Contrary to expectations in hypothesis 2 , divorce initiators perceived that their partners practiced greater negative face support than positive face support. This is initially puzzling, because participants reported experiencing greater positive face threat, thus, creating a need and opportunity for positive face support to be practiced. However, 
participants reported negative facework was being enacted in the divorce conversation. Kunkel et al. (2003) found that termination was a greater threat to negative face in scenario research, but Kunkel and colleagues did not assess the facework associated with the termination event. If greater negative face threat is indeed occurring in real termination events, as suggested in Kunkel et al.'s scenario research, former spouses may employ more negative facework in response to the perceived negative face threat. When energy is expended to protect the negative face, less effort is exerted to protect the positive face. It is possible, yet unexplored, whether this pattern is unique to the divorce conversation, or may manifest in interactions between former spouses after the divorce is final. Moreover, these face and identity vulnerabilities and responses to threats may hinge on one's role in the face threatening event.

\section{Impact of Divorcee's Role in the Divorce Decision}

The individual's role in the divorce decision influenced their perception of the divorce conversation. The divorcee's role in the divorce decision revealed a pattern which placed the divorcees on a recognizable continuum ranging from mutual divorce decisions (i.e., bilateral) to divorce message receivers (i.e., unilateral receivers). Specifically, those who engaged in mutual divorce decisions reported more positive outcomes including greater positive face support, perceptions that their spouse was caring, and had more positive emotions. Senders of dissolution messages only benefitted in that they experienced greater negative face support. These findings support Erbert and Floyd's (2004) assertion that face threats are more salient for receivers. Thus, in divorce conversations, being the receiver of a divorce message was the least advantageous role to play in the decision making process. Receivers experienced less overall face support, 
experienced less positive emotions, and perceived their former spouse as uncaring. A partner's role in the divorce decision may be indicative of power which influences communicative exchanges and relational perceptions.

Previous research discusses the role of power in face threats (e.g., Baxter, 1984; Craig et al., 1986; Lim \& Bowers, 1991). Perceptions of relational power are often explained by the principle of least interest (Waller, 1937), and Sprecher and Felmlee (1997) reported that an imbalance of power is evident in decision making. That is, a receiver of a message which initiates divorce, or a unilateral dissolution message, may perceive that they are powerless in the decision process and may become painfully aware that their partner is the least interested in that relationship. Gray and Silver (1990) noted that responses to termination depended on the level of control a partner had in the break up. That is, senders and those who have partial control (i.e., mutual decision makers) in the decision to dissolve do experience differences when compared to those who have no control (i.e., receiver).

Interestingly, in this study, the initiators, receivers, and mutual decision makers did not significantly differ on any of the outcome variables (i.e., stress, ongoing attachment, post-divorce relationship). Regardless of the role in the divorce decision, participants were similar in stress, ongoing attachment to the spouse, affect toward the relationship, and perception of the relationship type they had with their former spouse. Despite the appearance that a mutual decision may be most beneficial, individuals who engage in a bilateral decision are still as likely to experience outcomes which are similar to those who initiate or receive the divorce message, outcomes which may be either positive or negative. This suggests that the negative outcomes of divorce can be attributed 
to another cause, such as the communication occurring, not the role as sender or receiver of the divorce decision message. It was expected that face threats and facework would be an important alternative source to consider in explaining the outcomes from divorce because of their relationships to identity, emotion, and relational outcomes. To that end, additional hypotheses and research questions assessed the relationships between face threats, facework, and emotion.

\section{The Role of Emotion}

Divorce has been labeled a hurtful, emotional, and traumatic event (Albrecht, 1980; Amato, 2000; Hetherington \& Kelly, 2002). Despite suggestions to include emotion in face threat and facework research (Craig et al., 1986; Locher \& Watts, 2005; Metts, 1992), few studies have linked face threat to emotion. Recently, KennedyLightsey (2010) found that positive face threat also elicited greater negative emotional responses including anger and frustration. In the current study, and consistent with Hypothesis 3a, face threats were also related to negative emotions, suggesting that a face threatening divorce event elicits negative emotional reactions. This finding supports the need to further incorporate emotion into face threat and facework research.

Hurt has been conceptualized as one type of negative emotion (Fine \& Olson, 1997; Folkes, 1982; Leary et al., 1998). The divorce conversation may be equated with a hurtful message, and hurtful messages have also been associated with negative emotions (Cupach \& Carson, 2002; Zhang \& Stafford, 2008). Consistent with Cupach and Carson, negative face threat had a stronger relationship with negative emotions, and consistent with Zhang and Stafford, positive face threat was more strongly associated with hurt. Although positive face threat is occurring, it does not appear that divorcees perceive their 
former spouses as practicing positive face support. Given the greater positive face threat in the divorce event, and the lack of positive face support in divorce conversations, face threat should be considered a potential source of the hurt associated with divorce.

Thus far, research has focused on negative emotional responses to face threat (Cupach \& Carson, 2002; Kennedy-Lightsey, 2010; Zhang \& Stafford, 2008). In light of research which suggested that some individuals experience positive reactions to divorce events (e.g., Tashiro \& Frazier, 2003), this study included positive emotions as a potential response to face threats. In partial support of hypothesis $3 \mathrm{~b}$, negative face threats were significantly and negatively related to positive emotions, but positive face threats were not related to positive emotions. That is, as negative face threats are reduced more positive emotions occur. One of the positive outcomes of divorce suggested by Tashiro and Frazer was personal growth and freedom. This may be indicative of reduced negative face threat, or gaining autonomy and independence from the relationship, resulting in a positive emotional reaction.

During the divorce conversation, negative facework was inversely related to negative emotions, and negative facework was positively associated with positive emotions. These findings suggest that facework alleviates negative emotions and enhances positive emotions. Additionally, positive facework was more strongly associated with reducing the hurt felt in divorce conversations. Facework detracts from the face threats which are posed to a partner, and may enhance perceptions of caring in the communicative event. That is, positive facework decreased negative emotions and hurt experienced in the divorce conversation and increased perceptions that the partner was caring in the interaction. Although positive and negative facework did not elicit 
positive emotions in the divorce conversation, overall, positive facework seems to be most critical when attempting to avoid hurting a partner and avoiding negative emotional reactions.

\section{Divorce and Well-Being}

Divorce is assumed to be an inherently stressful event which brings changes to family structure, financial stability, parenting responsibilities, and romantic connections (Ahrons, 1980; Amato, 2000; Barber \& Demo, 2006; Hetherington \& Kelley, 2002). This study did not find that face threats and facework occurring during the divorce decision were associated with stress as predicted in hypothesis 4a. Plummer \& Koch-Hattem (1986) found that the severity of the divorce contributed to stress, however, other factors were influential as well, including social network, income changes, family stressors (e.g., child leaving home, illness, relocation). It is plausible that other factors are important to consider during the divorce conversation. However, high levels of hurt and ongoing attachment were associated with stress, as was low affect toward the relationship.

High hurt and low affect toward the relationship were related to ongoing attachment (i.e., hypothesis 4b). Ongoing attachment was conceptualized by Kitson (1982) as rumination, disbelief, disinterest in life, guilt, and feelings of not getting over the former spouse, and is considered a negative outcome. High levels of hurt, a negative emotion, and low affect toward the current relationship, or a generally negative evaluation of the relationship, may operate as fodder for negative reflective behavior. Specifically, and consistent with the conceptualization of ongoing attachment, the partner may be ruminating. Rumination has been linked to vengefulness, less life satisfaction, less forgiveness, maladaptive coping, and higher negative affect (Garnefski \& Kraaij, 
2009; McCullough, Bellah, Kilpatrick, \& Johnson, 2001). Thus, ongoing attachment may hinder the ability for partners to move on and progress in effectively coping with the divorce.

\section{The Impact on Post-Divorce Relationships}

In partial support of hypothesis $4 c$, low positive face threats, high positive face support, and high levels of former spouse caring were related to affect toward the relationship. Avoiding face threats, supporting positive face, and portraying care in the relationship are all communicative tactics that a former spouse may utilize. The communicative variables may be indicative of overall affect toward the individual, rather than the affect toward the relationship. That is, a divorcee may still find their spouse to be valuable, good, positive, and fair because of the way the former spouse communicates with them or any shared children. If the partner is being sensitive to positive face needs, showing approval and liking, these communicative strategies would likely lead to a higher affect for the relationship or the spouse. On the other hand, the affect one feels toward the partner or the relationship likely guides the way in which the participant communicates with the former spouse. Taken together, reducing face threats, providing face support, and demonstrating caring will enhance the affect and the communication occurring between former spouses.

Ahrons and Wallisch's (1987) typology determined that there are five types of post-divorce couples: perfect pals, cooperative colleagues, angry associates, fiery foes, and dissolved duos. In study one, communicative, emotional, and perceptual variables could not correctly classify individuals into these five post-divorce couple types. Importantly, it appears that the communication which occurs during the conversation 
where partners decide to divorce is not helpful in understanding, and making predictions about, the post-divorce relationship, contrary to expectations in hypothesis $4 \mathrm{~d}$. Instead, it may be events which comprise the post-divorce relationship which have the ability to more accurately classify couples.

\section{Study Two}

\section{Face Threats and Facework in Post-divorce Turning Points}

Because spouses seldom cease all contact after divorce (Ahrons \& Wallisch, 1987; Goldsmith, 1980), it is necessary to explore the communication in post-divorce interactions because the post-divorce relationship continues to impact the divorcees, their children, and extended familial network. Graham $(1997,2003)$ identified turning points for former spouses after the divorce was final and examined communication and relational outcomes including dialectical tensions and changes in commitment associated with positive and negative turning points. The current study extends such research on post-divorce turning points by examining communicative differences in face threats, facework, emotion, and hurt in positive and negative turning points. The current study further extends this work through the addition of new relational outcomes including stress, ongoing attachment, affect toward the relationship, and the type of relationship which developed between the former spouses.

As expected in hypotheses 1a and 1b, negative turning points were perceived as more threatening to both positive and negative face. Contrary to hypothesis 2 , positive turning points were perceived as more supportive for both positive and negative face. Only Miller (2009) has reported on post-divorce face concerns, and revealed that the concerns primarily revolved around the children and parental duties. Although not all of 
the participants in this study had children with the former spouse, no differences were found based on the existence of children. Consistent with Baxter's (1983) argument, former spouses do not cease to evaluate one another or worry about their former spouse's evaluation of them. The turning points which did not involve children were also face threatening, as face concerns include both relational (e.g., liking) and practical concerns (e.g., children). Thus, post-divorce interactions are creating opportunities for face threat and facework to occur for both co-parents and child-free divorcees. Further, face threats and facework may be useful in differentiating between positive and negative turning points beyond the changes in commitment initially explored by Graham (1997). The picture becomes more complex, however, as the role in the divorce decision as a sender, receiver, or in making a mutual decision together impacted perceptions of the divorce event and subsequent interactions.

\section{Impact of Divorcee's Role on Post-divorce Turning Points}

Although the role of the divorcee in the divorce decision was differentiated on several variables, this role did not continue to manifest in differences in the post-divorce relationship. The divorce conversation is an event which is distinct in purpose and may have occurred up to five years ago in study two. The role in the divorce decision may be overshadowed by the turning point events which are more recent and which happen to meet other goals (e.g., negotiate child care, boundaries). This provides some evidence that it is the events which occur post-divorce, rather than the divorce itself which are important to understanding the aftermath of divorce. 


\section{The Role of Emotion}

After the divorce, and consistent with hypothesis $3 \mathrm{a}$, positive turning points were associated with positive emotions. When couples are able to interact in a civil, and even friendly way, then they have greater potential to experience the positive outcomes discussed by Tashiro and Frazer (1993). Positive turning points may serve as a catalyst to decrease rumination and grant forgiveness, improving the overall relationship between the spouses and providing opportunities to experience positive emotions toward one another. This extends research which focused on changes in commitment in turning points and post-divorce trajectories (Graham, 1997), as emotion can now be associated with turning points and relational trajectories following divorce.

Conversely, negative post-divorce turning points are associated with hurt and negative emotion, providing support for hypothesis $3 \mathrm{~b}$. This is not surprising because negative post-divorce turning points were threatening to both positive and negative face, and the least overall facework was practiced by former spouses. DeGarmo and Kitson (1996) found that that a unique stressor for divorcees is continued interaction with the spouse. This continued source of negativity and hurt, particularly in divorces where children eternally link the spouses (Ahrons, 1980), potentially act as a reminder of the divorce event and relationship loss. DeGarmo and Kitson (1996) argued that negative events disrupt the identity and shape future interpretations and communicative exchanges. The divorce may be an initial source of identity disruption through face threats, but continued interaction provide additional opportunities to threaten face and further change a partner's identity. However, the continuing interaction should be examined more closely, as negative turning points may continue to disrupt identity and 
negatively impact adjustment when compared to positive turning points.

In post-divorce turning points, both positive and negative facework decreased negative emotions and enhanced positive emotions. Positive and negative facework were highly correlated $(r=.70)$, suggesting some overlap in the practice of facework.

Although positive and negative face support address entirely different identity concerns, they are likely co-occuring and serving multiple functions. For example, a former spouse may provide negative face support, granting autonomy, which may simultaneously suggest to the partner that they approve of their abilities to make autonomous decisions, supporting positive face. However, it may be that the perception of facework is framed through another communicative mechanism, with only one of the facework frames (i.e., either positive or negative facework) emerging as salient in an interaction, as partners perceived significantly more negative face support in both studies. The most salient frame, as perceived by the receiver of the facework, impacts subsequent emotional outcomes.

\section{Post-Divorce Relationships and Well-being}

In post-divorce turning points, negative face threats were associated with divorcees' stress levels, in partial support of hypothesis 4a. Post-divorce events include those difficult times of changing family structure, financial struggle, parenting responsibilities, and entering new romantic relationships are stress inducing. Plummer and Koch-Hattem (1986) noted that things other than the divorce itself contributes to stress, which may explain the importance of the communication during post-divorce interactions which emerged in this study. Additionally, post-divorce turning points happen chronologically later than the divorce, and the recency of the turning point is 
more influential in stress than the earlier divorce, affecting stress either positively or negatively.

Miller (2009) reported that divorcees experienced two primary negative face threats following divorce, facing autonomy constraints when parenting (e.g., seeing their children on certain days, finding childcare) and being replaced by the former spouse's new romantic partner. Certain events can be stress inducing, such as sharing custody, having restricted visitation, struggling to locate and retain child care, presenting the divorce to the social network, entering the dating world again, and explaining the situation to their children which can elicit negative emotions, create autonomy barriers, and increase face-threatening circumstances for the newly single partners. However, the number of children (i.e., 0-6) did not impact the face threats experienced by the divorcees, suggesting that the face threat may indeed be attributed to the evaluations of the individual, or relationship, as competent, autonomous, liked, or approved.

In partial support of hypothesis $4 \mathrm{~b}$, negative face threat, negative emotion, and affect toward the relationship with the former spouse were related to ongoing attachment to the spouse. When former spouses are engaging in turning points which are evaluated as face threatening and eliciting negative emotions, then an individual may engage in negative coping through unhealthy ongoing attachment and rumination to the former spouse. This ongoing attachment (i.e., rumination, disbelief) promotes low affect toward the relationship, as a source of hurt and negative emotion.

\section{The Impact on Post-Divorce Relationships}

Research question 1 inquired about the impact of communication and emotion on affect toward the current relationship with the former spouse. Perceived face threats, 
facework, and emotion were related to affect toward the relationship. Similar to study one, the communicative variables may be predictive of overall affect toward the individual, rather than the affect toward the relationship. That is, even in post-divorce events, a divorcee may still find their spouse to be valuable, good, positive, and fair because of the way the former spouse communicates with them in negotiating the postdivorce relationship. Specifically, the former spouse may continue to be sensitive to face needs and demonstrate caring, which then leads to a higher affect for the relationship.

Research question 2 further probed the post-divorce relationship. In study two, participants could again be correctly classified into these five post-divorce couple types approximately $40 \%$ of the time. Again, positive face threat, positive facework, and perceived spouse caring during post-divorce turning points increased the ability to predict the type of post-divorce relationship between former spouses by $20 \%$. Interestingly, the same three variables emerged as predictors in both studies (i.e., during the divorce decision and during post-divorce turning points). Positive face threat, positive facework, and former spouse caring are important communicative and relational variables to developing a deeper understanding of the post-divorce relationship, despite the event on which participants are reporting (i.e., positive turning points, negative turning points). Thus, these variables should be considered in other contexts and relational events.

The ability to identify the type of post-divorce relationship that divorcees will have and the affect which will exist between former spouses has important practical and clinical implications. For example, targeted efforts can be made with those couples who are likely to comprise the negative, conflictual relationships (i.e., angry associated, fiery foes, and dissolved duos) in post-divorce mediation and co-parenting classes. Targeted 
efforts to assist those with negative outcomes will impact divorcees, children of divorcees, and the extended family network.

\section{Implications}

\section{Theoretical}

The goals of this study were to apply facework theories to the divorce literature. In applying facework theories to the divorce context, a number of theoretical concerns were also addressed including the potential for simultaneous face threats to occur for both senders and receivers in recalled events, the ability of communicative messages to serve multiple functions, and the inclusion of emotion as an important factor in face and facework.

Craig et al. (1986) suggested that research should examine simultaneous threats to both faces and to both interactants. Some have responded to this suggestion (KerssenGriep et al., 2003; Kerssen-Griep et al., 2008; Kunkel et al., 2003; Wagoner \& Waldron, 1999), examining simultaneous face threats in dating relationship termination, the workplace, and in the classroom. The two current studies also respond to this suggestion, examining positive and negative face threat from the role of divorce message initiator and receiver, finding that initiators and receivers experience both positive and negative face threat and receivers experienced greater negative face threat. Further, this extends research on facework and the examination of simultaneous face threats into two new contexts: the divorce conversation and the post-divorce relationship.

Craig et al. (1986) also argued that face threats and facework can serve multiple functions. Some of the findings in the two studies support the notion that the same message may serve to efficiently, but politely, end the marriage. The goals associated 
with each function should be examined more closely to understand how these diverse goals may create a barrier or facilitate goal achievement. Specifically, to efficiently end the marriage the goal may be to reduce reconciliation attempts, to reinforce that the relationship is different from the marriage, and to reduce ongoing attachment. At the same time, this divorce message may be delivered in a face-saving or supportive way in order to promote a positive post-divorce relationship, reduce negative emotions, and prevent hurt in the former spouse. It is possible that the two strategically co-occur in a multifunctional message during the divorce decision, efficiently ending the marriage but avoiding permanent damage to the relationship which may persist following the divorce.

Emotion has been considered an important variable for inclusion in the theoretical framework of face and identity (Francis; 1997; Goffman, 1967). Only recently have researchers begun to systematically incorporate emotion into face research (Cupach \& Carson, 2002; Kennedy-Lightsey, 2010). This research examined divorce, an inherently emotional event (Frazier \& Cook, 1993; Hetherington \& Kelly, 2002), and found that face threats and facework, both communicative variables, were associated with the emotions experienced. Because emotions guide subsequent communication, it is important then for researchers to continue to include emotion to fully understand processes and communicative exchanges in divorced and post-divorce dyads.

\section{Practical}

The results from these studies also offer practical findings which can be applied in both clinical and lay settings. When considering divorce, or when in distress, it is not uncommon for couples to seek help. Prior clinical efforts of divorcing and divorced couples have focused on expressing feelings, active listening, constructive 
communication, destructive communication, expectations, relational maintenance, problem solving, team-building, re-evaluating beliefs, and conflict management (Hawkins et al., 2008; Huber, 1983; Markman et al., 1988; Renick, Blumberg, \& Markman, 1992). However, facework has been largely ignored in relational education courses. It is possible that facework operates at a different level than each of the communication skills which are currently included in educational programs. Specifically, facework may be a concept which subsumes each of these skills, such that effective listening, constructive communication, problem solving, and conflict management are beneficial because they communicate face support to the spouse. Incorporating facework into skills training as a communication tactic which can be attained, and refined, should be utilized during the divorce process, in the post-divorce relationship, and when building and maintaining a co-parenting relationship.

Renick et al. (1992) argued that most couples do not seek treatment until significant relational problems are already occurring. That is, these couples are already at a significant risk for divorce. While some scholars find it fruitful to attempt to prevent the divorce (e.g., Renick et al.), it may be more practical to focus on skills which serve a dual function, improve communication to prevent divorce or communication which will make the divorce decision and post-divorce relationship go more smoothly. Promoting face supporting communication can help to alleviate the negative outcomes associated with divorce, and in fact, enhance positive outcomes such as positive affect toward the former spouse and the development of positive post-divorce relationships.

More recently, courts have begun to mandate skills training for divorced parents, to enhance the co-parental relationship and improve the post-divorce transition for 
children of divorcees (McKenry, Clark, \& Stone, 1999; Whitehurst et al., 2008). The current co-parenting education programs focus largely on managing conflict, understanding the children's emotions, communicating with the former spouse, communicating with the child, and instructing the parents to avoid putting the child into loyalty conflicts (McKenry, 1999). The results of study two continue to suggest that facework would be an important skill to incorporate into co-parenting and post-divorce relationship education programs. Face threats in post-divorce communication were associated with stress and negative ongoing attachment. Therefore, reducing face threats in the post-divorce relationship should assist the divorcees in coping with stress and emotionally divorcing the partner. Further, face threats and facework helped to identify couples who are likely to develop a certain type of post-divorce relationship. Those who have experienced high positive face threat, low positive face support, and perceived the former spouse as low in caring during the divorce process may need to be targeted more than those couples with low face threat, high positive face support, and caring former spouses. This targeted process should help clinicians to administer more specific counseling and co-parenting classes to enhance the post-divorce relationship for those who need it most.

\section{Limitations}

The findings of this study should be interpreted in light of the inherent limitations. These limitations should also serve as a foundation in the design of future studies in face threats, facework, and divorce. The primary limitations involve the sample, measurement issues, methodological issues, and the inability to make causal claims.

First, the samples in study one and study two were largely female, with $63 \%$ and 
$64 \%$ being female, respectively. Additionally, the sample was relatively small given the number of people who are affected by divorce every year. Even smaller is the matched dyad subset. In general the dyadic subset of matched former spouses had more positive experiences in the divorce conversation. Future samples of divorcees should be inclusive of both sexes, a larger more representative sample, and work toward attaining matched dyads which are also more similar to the general divorce population. This may be achieved through collaboration and recruitment through support groups, mediation services, or co-parenting education programs. Additionally, larger samples and matched dyads may be obtained with incentives for participation in research on divorcees.

Second, to fully understand the simultaneous face threats experienced, and the facework performed by both interactants in the same communicative event, participants need to complete self and other-reports of face threat and facework. The utility of self and other-report research was recognized prior to the studies being conducted, concern for participant fatigue was considered, as the survey already included 92 items, with only self-report measures included. The studies included here should be considered an exploratory application of facework theories to divorce and post-divorce events, and as such, should be expanded upon in future research to gather self and other-reports.

Third, there were some methodological and measurement limitations. The emotion measure included a wide range of validated emotions, however, it is not an exhaustive list of emotions that were potentially felt by the participants. Additionally, this study examined well-being of the divorcees, and the indicators of well-being included stress and ongoing attachment, also not an exhaustive list of potential well-being indicators. A continuing problem in face threat and facework research is the low 
reliability of negative face threat in the current studies and in previous studies (e.g., Cupach \& Carson, 2002; Zhang \& Stafford, 2008). It is plausible that negative face threat is more difficult to measure due to varying perceptions of autonomy, freedom, and imposition. The low reliability associated with negative face threat may explain the mixed findings across previous studies and the two current studies. Adding additional items in the current studies did slightly improve the reliability; however, the measure should continue to be refined. It may be more appropriate to develop face threat measures specific to the context or relationship being examined, to more fully capture the negative face threats which are relevant. Although the length of the marriage and the length of the time since the divorce did not impact the outcome variables, study two did not inquire about the time since the post-divorce turning point occurred. The time since the turning point occurred would allow researchers to develop a detailed trajectory of positive and negative post-divorce events, and may influence the perceptions of the event being reported on by the participants.

Last, it is not possible to make causal claims. Although, the results provide insight into the relationships between these variables, and allow scholars to speculate about potential causes of emotions and outcomes, further research should be conducted which explores the actual causes, as opposed to the potential causes. However, methodologically the data would need to be longitudinal, experimental, and account for other intervening variables to more clearly delineate the causes of emotions, hurt, stress, affect, and ongoing attachment to the spouse, which are problems noted in previous research (Busboom et al., 2002; Kellas et al., 2008; Weber, 1998). The limitations provide opportunities for future research to further develop this line of research, and 
additional ideas for future directions also emerged from the current studies.

\section{Future Directions}

The findings presented here represent an exploratory effort in understanding the impact of face threat and facework in the divorce and post-divorce process. Face threats and facework were indeed contributing factors in individual well-being and relational (re)definition outcomes. Given the apparent influence of face threats and facework, future research should work toward developing a deeper understanding of the divorce process using this theoretical framework. Future research should examine face needs of former spouses, the reason for the divorce, how divorcees enact face with their social networks and children, face threats and facework as continuing patterns after marriage, nonverbal components of facework, the impact of face threats and facework on relational beliefs and attitudes, and the examination of skills training in facework for divorcees.

Erbert and Floyd (2004) found that individuals possessed trait like face needs, and that these needs impacted how the expression of affection influenced the perceived severity of the face threat. Further, Erbert and Floyd suggested that face needs may influence the perception of facework which accompanies the face threats. The divorcees' trait face needs should then impact their perception of face threats, facework, and guide their subsequent responses to the divorce including emotions, hurt, conflict, and the type of relationship the divorcees develop. If indeed, face needs are a trait-like construct, then a pattern of interpretation should emerge for face threats and facework, and this pattern would continue even in the post-divorce relationships and significant turning points between the former spouses.

Although divorce is a highly face threatening event, it is evident that not all 
divorces are the same. One differentiating factor may be the reason a divorcee provides for desiring divorce. Couples cite that they dissolve because of infidelity, ineffective interpersonal communication, and partner faults, among other reasons (e.g., W. A. Afifi, Falato, \& Weiner, 2001; Bodenmann et al., 2007; Cody, 1982). In a study of terminating dating relationships, Frisby, Booth-Butterfield, and Malachowski (2010) found that terminating because of infidelity was significantly more face threatening than other termination reasons including long distance, changed feelings, lack of trust, and poor communication. Further, W.A. Afifi et al. (2001) found that the method of discovering infidelity from a third-party source was the most damaging. That is, the reason for divorcing which is likely communicated during the divorce conversation can threaten positive and negative face differently. Given the impact of face on outcomes in the two studies which comprise this dissertation and the predictive abilities of face in individual and relational outcomes, future research should examine the reason for the decision to divorce as it impacts the face threats and facework performed during the divorce decision conversation.

The studies presented here focused on face between the former spouses. Duck (1982) suggested that former relational partners also worked to construct stories which were face preserving to share with their social network. While the divorce is face threatening, individuals may find it more face threatening to admit their perceived individual or relational faults through a failed marriage to others outside of the union. The fear of experiencing face threat with the social network may impact the seeking of social support and the type of relationship which is negotiated with the former spouse. Miller (2009) found that the face concerns after divorce were often related to parenting 
duties, and individuals worked to protect their parental face. This may indirectly influence the well-being of the individual, and the co-parenting relationship. Second, the way in which parents discuss divorce with their children should also include elements of face, as the parent works to protect their own face, and simultaneously either protect or threaten the face of the former spouse. The orientation one takes toward facework (i.e., protective or defensive, Goffman, 1967), should then manifest in the divorce accounts disclosed to the social network and the children.

Isaacs and Leon (1988) found that post-termination communication patterns were often continuations of the communicative patterns that happen prior to termination, especially for conflict patterns. The face threats and facework examined here were those which occurred during the divorce conversation, and in post-divorce turning points. It was assumed that the face threats and facework were occurring because of the nature of the events (i.e., divorce or turning point). However, the face threats and facework may also be consistent with those patterns which emerged, and persisted, throughout marriage. The couples may have fallen into a cycle of face threats and facework performance in previous conflict and marital turning points, which are simply repeating patterns after divorce. The patterns may also encourage reciprocity of behaviors. Sutter and Martin (1998) found that in termination, verbal aggression was reciprocated and is a face-saving technique. It is possible that during divorce, a face attack is delivered in the form of verbal aggression, and reciprocity of face attacks may be less taxing than performing corrective or preventative facework. Understanding more about these reciprocating and continuing patterns will illuminate additional communicative differences in the context of divorce and post-divorce relationships. 
Previous research has alluded to the importance of nonverbal communication in enhancing perceptions facework (e.g., Trees \& Manusov, 1998). At its most basic, the verbal messages in the divorce conversations are similar (e.g., "I want a divorce"), however, many were perceived differently. This is relevant to Craig et al.'s (1986) suggestion to examine social judgments instead of linguistic qualities, as nonverbal communication will contribute to a social judgment. It would be fruitful to separate the verbal and nonverbal messages used to request, or receive a request for, divorce. For example, measures of immediacy, affection given, touch avoidance, and other nonverbal behaviors could be included in future research on face threats in divorce messages and post-divorce turning points.

Finally, the results here provide evidence that incorporating facework into skills training may be beneficial to spouses who are considering divorce and to those who are former spouses. Recent work (Young, 2010; Young et al., 2008) suggests that despite the hurtful message being communicated, care in delivering the messages does impact the perceptions of the partner and interaction, and especially when taking the relationship type into consideration. Thus, in marital couples who are distressed or already divorced, the "packaging" of the messages may influence the perceived face threat and facework which occurs. Message delivery is a skill which can be targeted, and improved for the divorcees.

\section{Conclusion}

Face threats and facework have been largely overlooked in relational termination events, and entirely overlooked in the divorce process. The two current studies begin to delineate the impact of face threat and facework in divorce and post-divorce events, and 
provide evidence that these are important components to consider when attempting to understand the source of hurt, emotions, affect, ongoing attachment, and the renegotiation of post-divorce relationships. With divorce impacting approximately 23,346 adults (U.S. Bureau of the Census, 2008) and over one million children (Amato, 2000) yearly, is important to address the negative impact of divorce events. In these two studies, face threats and facework influenced the experience of individuals in the divorce process. It affected how partners related to one another and how they responded to life stressors in interpersonal relationships. Specifically, face threats and facework shaped emotional reactions, evaluations of the post-divorce relationship, individual well-being, and the type of relationship which develops between former spouses. Through the knowledge gathered here, it appears necessary to integrate the study of face threats and facework in future divorce research, and more importantly, into future divorce counseling, mediation, and skills training. Face is a salient concern in all relationships, but especially in the most important, and irreplaceable relationship, the marriage (Cutrona \& Suhr, 1994; KiecoltGlaser \& Newton, 2001; McKenry \& Price, 1991; Weintraub \& Wolf, 1983), and remains critical in the post-divorce relationship. 


\section{References}

Afifi, T. D., \& Hamrick, K. (2006). Communication processes that promote risk and resiliency in postdivorce families. In M. A. Fine and J. H. Harvey (Eds.), Handbook of divorce and relationship dissolution (pp. 435-456). New York: Taylor \& Francis.

Afifi, T. D., \& McManus, T. (2006). Investigating privacy boundaries: Communication in post-divorce families. In K. Floyd and M. T. Morman (Eds.), Widening the family circle: New research on family communication (pp. 171-187). Thousand Oaks, CA: Sage.

Afifi, W. A., Falato, W. L., \& Weiner, J. L. (2001). Identity concerns following a severe relational transgression: The role of discovery method for the relational outcomes of infidelity. Journal of Social and Personal Relationships, 18, 291- 308. doi:10.1177/0265407501182007

Agne, R. R., \& White, C. H. (2004). The nature of facework in discussion of everyday problems between friends. Southern Communication Journal, 70, 1-14. doi:10.1080/10417940409373308

Ahrons, C. R. (1980). Redefining the divorced family: A conceptual framework. Social Work, 25, 437-441.

Ahrons, C. R. (1994). The good divorce: Keeping your family together when your marriage comes apart. New York: Harper Collins.

Ahrons, C. R. (2007). Family ties after divorce: Long-term implications for children. Family Processes, 46, 53-65. doi:10.1111/j.1545-5300.2006.00191.x

Ahrons, C. R., \& Miller, R. B. (1993). The effect of the postdivorce relationship on 
paternal involvement: A longitudinal analysis. American Journal of Orthopsychiatrics, 63, 441-450. doi: 10.1037/h0085043

Ahrons, C. R., \& Wallisch, L. S. (1987). The relationship between former spouses. In D. Perlman \& S. Duck (Eds.), Intimate relationships (pp.269-296). Thousand Oaks, CA: Sage Publications.

Albrecht, S. L. (1980). Reactions and adjustments to divorce: Differences in the experiences of males and females. Family Relations, 29, 59-68. doi: $10.2307 / 583717$

Amato, P. R. (2000). The consequences of divorce for adults and children. Journal of Marriage and the Family, 62, 1269-1287.

Andersen, J. F. (1979). Teacher immediacy as a predictor of teaching effectiveness. In D. Nimmo (Ed.), Communication yearbook 3 (pp. 543-559). New Brunswick, NJ: Transaction Books.

Archer, J., \& Fisher, H. (2008). Bereavement and reactions to romantic rejection: A psychobiological perspective. In M. S. Stroebe, R. O. Hansson, H. Schut, \& W. Stroebe (Eds.), Handbook of bereavement research and practice (pp. 349-371). Washington, DC: American Psychological Association.

Bachman, G. F., \& Guerrero, L. K. (2006). Relational quality and communicative responses following hurtful events in dating relationships: An expectancy violations analysis. Journal of Social and Personal Relationships, 23, 943-963. doi: $10.1177 / 0265407506070476$

Banks, S. P., Altendorf, D. M., Greene, J. O., \& Cody, M. J. (1987). An examination of relationship disengagement: Perceptions, breakup strategies, and outcomes. The 
Western Journal of Speech Communication, 51, 19-41.

Barber, B. L., Demo, D. H. (2006). The kids are alright (at least, most of them): Links between divorce and dissolution and child well-being. In M. A. Fine and J. H. Harvey (Eds.), Handbook of divorce and relationship dissolution (pp. 435-456). New York: Taylor \& Francis.

Bartell, D. S. (2006). Influence of parental divorce on romantic relationships in young adulthood: A cognitive-developmental perspective. In M. A. Fine and J. H. Harvey (Eds.), Handbook of divorce and relationship dissolution (pp. 435-456). New York: Taylor \& Francis.

Baxter, L. A. (1982). Strategies for ending relationships: Two studies. The Western Journal of Speech Communication, 46, 223-241.

Baxter, L. A. (1983). Relationship disengagement: An examination of the reversal hypothesis. The Western Journal of Speech Communication, 47, 85-98.

Baxter, L. A. (1984). Trajectories of relationship disengagement. Journal of Social and Personal Relationships, 1, 29-48. doi:10.1177/0265407584011003

Baxter, L. A. (1986). Gender differences in the heterosexual relationship rules embedded in break-up accounts. Journal of Social and Personal Relationships, 3, 289-306. doi:10.1177/0265407586033003

Baxter, L. A., \& Bullis, C. (1986). Turning points in developing romantic relationships. Human Communication Research, 12, 469-493. doi:10.1111/j.14682958.1986.tb00088.x

Berman, W. H., \& Turk, D. C. (1981). Adaptation to divorce: Problems and coping strategies. Journal of Marriage and the Family, 43, 179-189. doi:10.2307/351428 
Bevan, J. L., Cameron, K. A., \& Dillow, M. R. (2003). One more try: Compliancegaining strategies associated with romantic reconciliation attempts. Southern Communication Journal, 68, 121-135. doi:10.1080/10417940309373255

Bodenmann, G., Charvoz, L., Bradbury, T. N., Bertoni, A., Lafrate, R., Giuliani, C., et al. (2007). The role of stress in divorce: A three-nation retrospective study. Journal of Social \& Personal Relationships, 24, 707-728. doi:10.1177/0265407507081456.

Boelen, P. A., \& Reijntjes, A. (2009). Negative cognitions in emotional problems following romantic relationship break-ups. Stress and Health, 25, 11-19. doi:10.1002/smi.1219

Braver, S. L., Shapiro, J. R., \& Goodman, M. R. (2006). Consequences of divorce for parents. In M. A. Fine and J. H. Harvey (Eds.), Handbook of divorce and relationship dissolution (pp. 435-456). New York: Taylor \& Francis.

Brew, F. P., \& Cairns, D. R. (2004). Styles of managing interpersonal workplace conflict in relation to status and face concern: A study with Anglos and Chinese. The International Journal of Conflict Management, 15, 27-56.

Brissette, I., \& Cohen, S. (2002). The contribution of individual differences in hostility to the associations between daily conflict, affect, and sleep. Personality and Social Psychology Bulletin, 28, 1265-1274. doi: 10.1177/01461672022812011

Brown, P., \& Levinson, S. C. (1987). Politeness: Some universals in language usage. University of Cambridge: Great Britain.

Buchanan, M. C., O’Hair, D., \& Becker, J. A. H. (2006). Strategic communication during marital relationship dissolution: Disengagement resistance strategies. 
Communication Research Reports, 23, 139-147.

doi:10.1080/08824090600796351

Busboom, A. L., Collins, D. M., Givertz, M. D., \& Levin, L. A. (2002). Can we still be friends? Resources and barriers to friendship quality after romantic relationship dissolution. Personal Relationships, 9, 215-223. doi:10.1111/1475-6811.00014

Chiriboga, D. A., Coho, A., Stein, J. A., \& Roberts, J. (1979). Divorce, stress, and social supports: A study in helpseeking behavior. Family Processes, 3, 121-135.

Christensen, A., \& Shenk, J. L. (1991). Communication, conflict, and psychological distance in nondistressed, clinic, and divorcing couples. Journal of Consulting and Clinical Psychology, 59, 458-463. doi:10.1037/0022-006X.59.3.458

Clark, R. E., \& Lebeff, E. E. (1986). Ending intimate relationships: Strategies of breaking off. Sociological Spectrum, 6, 245-267.

Cody, M. J. (1982). A typology of disengagement strategies and an examination of the role intimacy, reactions to inequity, and relational problems play in strategy selection. Communication Monographs, 49, 148-170. doi:10.1080/03637758209376079

Cohen, S., Kamarck, T., \& Mermelstein, R. (1983). A global measure of perceived stress. Journal of Health and Social Behavior, 24, 385-396. doi:10.2307/2136404

Craig, R. T., Tracy, K., \& Spisak, F. (1986). The discourse of requests: Assessment of a politeness approach. Human Communication Research, 12, 437-468. doi:10.1111/j.14682958.1986.tb00087.x

Cupach, W. R., \& Carson, C. L. (2002). Characteristics and consequences of interpersonal complaints associated with perceived face threat. Journal of Social 
and Personal Relationships, 19, 443-462. doi:10.1177/0265407502019004047

Cupach, W. R., \& Metts, S. (1986). Accounts of relational dissolution: A comparison of marital and non-marital relationships. Communication Monographs, 53, 311-334. doi:10.1080/03637758609376146

Cupach, W. R., \& Metts, S. (1994). Facework. Thousand Oaks, CA: Sage.

Cutrona, C. E., \& Suhr, J. A. (1994). Social support communication in the context of marriage: An analysis of couples' supportive interactions. In B. R. Burleson, T. L.

Albrecht, \& I. G. Sarason (Eds.), Communication of social support: Messages, interactions, relationships, and community (pp. 113-135). Thousand Oaks, CA, US: Sage.

Dailey, R. M., Pfiester, A. Borae, J., Beck, G., \& Clark, G. (2009). On-again/off-again dating relationships: How are they different from other dating relationships? Personal Relationships, 16, 23-47. doi:0.1111/j.1475-6811.2009.01208.x

DeGarmo, D. S., \& Kitson, G. C. (1996). Identity relevance and disruption as predictors of psychological distress for widowed and divorced women. Journal of Marriage and Family, 58, 983-997.

Demir, M. (2008). Sweetheart, you really make me happy: Romantic relationship quality and personality as predictors of happiness among emerging adults. Journal of Happiness Studies, 9, 257-277. doi:10.1007/s10902-007-9051-8

Dillard, J. P., Wilson, S. R., Tusing, K. J., \& Kinney, T. A. (1997). Politeness judgments in personal relationships. Journal of Language and Social Psychology, 16, 297325. doi:10.1177/0261927X970163003

Duck, S. (1982). A topography of relationship disengagement and dissolution. In S. Duck 
(Ed.), Personal relationships 4: Dissolving personal relationships. New York: Academic Press.

Duthler, K. W. (2006). The politeness of requests made via email and voicemail: Support for the Hyperpersonal Model. Journal of Computer-Mediated Communication, 11, 500-521. doi:10.1111/j.1083-6101.2006.00024.x

Erbert, L. A., \& Floyd, K. (2004). Affectionate expressions as face-threatening acts: Receiver assessments. Communication Studies, 55, 254-270.

Ferguson, N. (2004). Children's contact with grandparents after divorce. Family Matters, 67, 36-41.

Fine, M. A., \& Olson, K. A. (1997). Anger and hurt in response to provocation: Relationship to psychological adjustment. Journal of Social Behavior and Personality, 12, 325-344.

Foley, L., \& Fraser, J. (1998). A research note on post-dating relationships: The social embeddedness of redefining romantic couplings. Sociological Perspectives, 41, 209-219.

Folkes, V. S. (1982). Communicating the reasons for social rejection. Journal of Experimental Social Psychology, 18, 235-252. doi:10.1016/0022-1031(82)90052$\mathrm{X}$

Francis, L. E. (1997). Ideology and interpersonal emotion management: Redefining identity in two support groups. Social Psychology Quarterly, 60, 153-171. doi: $10.2307 / 2787102$

Frazier, P. A., \& Cook, S. W. (1993). Correlates of distress following heterosexual relationship dissolution. Journal of Social and Personal Relationships, 10, 55-67. 
doi:10.1177/0265407593101004

Frisby, B. N., Booth-Butterfield, M., \& Malachowski, C. C. (2010). Perceived face threats and perceived facework in romantic relationship dissolution episodes. Unpublished manuscript.

Garnefski, N., \& Kraaij, V. (2009). Cognitive coping and psychological adjustment in different types of stressful life events. Individual Differences Research, 7, 168181.

Goffman, E. (1967). Interaction ritual. Garden City, NY: Anchor Books.

Goldsmith, J. (1980). Relationships between former spouses: Descriptive findings. Journal of Divorce, 4, 1-20.

Gorham, J. (1988). The relationship between verbal teacher immediacy behaviors and student learning. Communication Education, 37, 40-53.

doi:10.1080/03634528809378702

Gottman, J. (1994). What predicts divorce? The relationship between marital processes and marital outcomes. Hillsdale, NJ England: Lawrence Erlbaum Associates, Inc.

Graham, E. E. (1997). Turning points and commitment in post-divorce relationships. Communication Monographs, 64, 350-368. doi:10.1080/03637759709376428

Graham, E. E. (2003). Dialectical contradictions in postmarital relationships. The Journal of Family Communication, 3, 193-214. doi:10.1207/S15327698JFC0304_3

Gray, J. D., \& Silver, R. C. (1990). Opposite sides of the same coin: Former spouses' divergent perspectives in coping with their divorce. Journal of Personality and Social Psychology, 59, 1180-1191. doi:10.1037/0022-3514.59.6.1180

Grice, H. P. (1975). Logic and conversation. In P. Cole \& J. L. Morgan (eds.), Syntax \& 
Semantics Vol. 3: Speech acts. New York, NY: Academic Press.

Hackney, G. R., \& Ribordy, S. C. (1980). An empirical investigation of emotional reactions to divorce. Journal of Clinical Psychology, 36, 105-110. doi:10.1002/1097-4679(198001)36:1<105::AID-JCLP2270360107>3.0.CO;2-C

Hawkins, A. J., Blanchard, V. L., Baldwin, S. A., Fawcett, E. B. (2008). Does marriage and relationship education work? A meta-analytic study. Journal of Consulting and Clinical Psychology, 76, 723-734. doi:10.1037/a0012584

Hetherington, E. M., \& Kelly, J. (2002). For better or for worse: Divorce reconsidered. New York: Norton.

Hill, C. T., Rubin, Z., \& Peplau, L. A. (1976). Breakups before marriage: The end of 103 affairs. Journal of Social Issues, 32, 137-168.

Holtgraves, T. (2001). Politeness. In W.P. Robinson \& H. Giles (Eds.) The new handbook of language and social psychology. West Sussex, England: John Wiley and Sons Ltd.

Holtgraves, T., \& Yang, J. (1992). Interpersonal underpinnings of request strategies: General principles and differences due to culture and gender. Journal of Personality and Social Psychology, 62, 246-256. doi:10.1037/0022-3514.62.2.246

Huber, C. H. (1983). Feelings of loss in response to divorce: Assessment and intervention. Personnel and Guidance Journal, 61, 357-361.

Isaacs, M. B., \& Leon, G. (1988). Divorce, disputation, and discussion: Communication styles among recently separated spouses. Journal of Family Psychology, 1, 298311. doi: $10.1037 / \mathrm{h} 0080457$

Kam, C. C., \& Bond, M. H. (2008). Role of emotions and behavioural responses in 
mediating the impact of face loss on relationship deterioration: Are Chinese more face-sensitive then Americans? Asian Journal of Social Psychology, 11, 175-184. doi: 10.1111/j.1467-839X.2008.00254.X

Kellas, J. K., Bean, D., Cunningham, C., \& Cheng, K. Y. (2008). The ex-files: Trajectories, turning points, and adjustment in the development of postdissolutional relationships. Journal of Social and Personal Relationships, 25, 2350. doi:10.1177/0265407507086804

Kennedy-Lighsey, C. D. (2010). Recognizing contributions: Face-support and face-threat influences students' emotional and communicative responses. Communication Research Reports, 27, 20-29. doi:10.1080/08824090903526588

Kerssen-Griep, J., Hess, J. A., \& Trees, A. R. (2003). Sustaining the desire to learn: Dimensions of perceived facework related to student involvement and motivation to learn. Western Journal of Communication, 67, 357-381.

Kerssen-Griep, J., Trees, A. R., \& Hess, J. A. (2008). Attentive facework during instructional feedback: Key to perceiving mentorship and an optimal learning environment. Communication Education, 57, 312-332. doi:10.1080/03634520802027347

Kiecolt-Glaser, J. K., \& Newton, T. L. (2001). Marriage and health: His and hers. Psychological Bulletin, 127, 472-503. doi:10.1037/0033-2909.127.4.472

Kincaid, S. B., \& Caldwell, R. A. (1991). Initiator status, family support, and adjustment to marital separation: A test of an interaction hypothesis. Journal of Community Psychology, 19, 79-88. doi:10.1002/1520-6629(199101)19:1<79

Kitson, G. C. (1982) Attachment to the spouse in divorce: A scale and its application. 
Journal of Marriage and the Family, 44, 379-393. doi:10.2307/351547

Kunkel, A. D., Wilson, S. R., Olufowote, J., \& Robson, S. (2003). Identity implications of influence goals: Initiating, intensifying, and ending romantic relationships. Western Journal of Communication, 67, 382-412.

Lannutti, P. J., \& Cameron, K. A. (2002). Beyond the breakup: Heterosexual and homosexual post-dissolutional relationships. Communication Quarterly, 50, 153170.

Leary, M. R. (2001). Toward a conceptualization of interpersonal rejection. In M. R. Leary (Ed.) Interpersonal rejection. New York: Oxford Press.

Leary, M. R., Koch, \& Hechenbleikner, N. R. (2001). Emotional responses to interpersonal rejection. In M. R. Leary (Ed.) Interpersonal rejection. New York: Oxford Press.

Leary, M. R., Springer, C., Negel, L., Ansell, E., \& Evans, K. (1998). The causes, phenomenology, and consequences of hurt feelings. Journal of Personality and Social Psychology, 74, 1225-1237. doi:10.1037/0022-3514.74.5.1225

Lee, L. (1984). Sequences in separation: A framework for investigating endings of the personal (romantic) relationship. Journal of Social and Personal Relationships, 1, 49-73. doi:10.1177/0265407584011004

Levine, T., \& Fitzpatrick, S. L. (2005). You know why; the question is how? Relationships between reasons and methods in romantic breakups. Paper presented at the annual meeting of the International Communication Association, New York, NY.

Lewis, J. M., Wallerstein, J. S., \& Johnson-Reitz, L. (2004). Communication in divorced 
and single-parent families. In A. L. Vangelisti (Ed.) Handbook of family communication (pp. 197-214). Mahwah, NJ, Lawrence Earlbaum Associates.

Lim, T. S., \& Bowers, J. W. (1991). Facework: Solidarity, approbation, and tact. Human Communication Research, 17, 415-450. doi:10.1111/j.1468-2958.1991.tb00239.x

Locher, M. A., \& Watts, R. J. (2005). Politeness theory and relational work. Journal of Politeness Research: Language, Behavior, Culture, 1, 9-33. doi:16125681/05/001_0009

Lucas, R. E. (2005). Time does not heal all wounds: A longitudinal reaction of adaptation to divorce. Psychological Science, 16, 945-950.

Markman, H. J., Floyd, F. J., Stanley, S. M., \& Storaasli, R. D. (1988). Prevention of marital distress: A longitudinal investigation. Journal of Consulting and Clinical Psychology, 56, 210-217. doi:10.1037/0022-006X.56.2.210

Masheter, C. (1997). Healthy and unhealthy friendship and hostility between ex-spouses. Journal of Marriage and the Family, 59, 463-475. doi:10.2307/353483

McCroskey, J. C., \& Teven, J. J. (1999). Goodwill: A reexamination of the construct and its measurement. Communication Monographs, 66, 90-103. doi:10.1080/03637759909376464

McCullough, M. E., Bellah, C. G., Kilpatrick, S. D., \& Johnson, J. L. (2001). Vengefulness: Relationships with forgiveness, rumination, well-being, and the big five. Personality and Social Psychology Bulletin, 27, 601-610. doi: $10.1177 / 0146167201275008$

McKenry, P. C., Clark, K. A., \& Stone, G. (1999). Evaluation of a parent education program for divorcing parents. Family Relations, 48, 129-137. 
doi: $10.2307 / 585076$

McKenry, P. C., \& Price, S. J. (1991). Alternatives for support: Life after divorce - A literature review. Journal of Divorce and Remarriage, 15, 1-19. doi:10.1300/J087v15n03

Metts, S. (1992). The language of disengagement: A face-management perspective. In T. L. Orbuch (Ed.), Close relationship loss: Theoretical perspectives. New York: Springer.

Milardo, R. M. (1987). Changes in social networks of women and men following divorce. Journal of Family Issues, 8, 78-96. doi:10.1177/019251387008001004

Miller, A. E. (2009). Face concerns and facework strategies in maintaining postdivorce coparenting and dating relationships. Southern Communication Journal, 74, 157173. doi:10.1080/10417940802516842

Oetzel, J. G., Ting-Toomey, S., Yokochi, Y., Masumoto, T., \& Takai, J. (2000). A typology of behaviors in conflicts with best friends and relative strangers. Communication Quarterly, 48, 397-419.

Park, H. S. (2008). The effects of shared cognition on group satisfaction and performance: Politeness and efficiency in group interaction. Communication Research, 35, 88-108. doi:10.1177/0093650207309363

Patterson, B. R., \& Beckett, C. S. (1995). A re-examination of relational repair and reconciliation: Impact of socio-communicative style on strategy selection. Communication Research Reports, 12, 235-240.

Perilloux, C., \& Buss, D. M. (2008). Breaking up romantic relationships: Costs experienced and coping strategies deployed. Evolutionary Psychology, 6, 164- 
181.

Pinker, S. (2007). The evolutionary social psychology of off-record indirect speech acts. Intercultural Pragmatics, 4, 437-461. doi:10.1515/IP.2007.023

Plummer, L., \& Koch-Hattem, A. (1986). Family stress and adjustment to divorce.

Family Relations, 35, 523-529. doi:10.2307/584513

Renick, M. J., Blumberg, S. L., \& Markman, H. J. (1992). The Prevention and Relationship Education Program (PREP): An empirically based preventative intervention program for couples. Family Relations, 41, 141-147. doi: $10.2307 / 584825$

Rodrigues, A. E., Hall, J. H., \& Fincham, F. D. (2006). What predicts divorce and relationship dissolution? In M. A. Fine \& J. H. Harvey (Eds.), Handbook of divorce and relationship dissolution. Routledge: New York, NY.

Rogge, R. D., Bradbury, T. N., Hahlweg, K. H., Engl, J., \& Thurmaier, F. (2006). Predicting marital distress and dissolution: Refining the two-factor hypothesis. Journal of Family Psychology, 20, 156-159. doi: 10.1037/0893-3200.20.1.156

Sbarra, D. A., \& Ferrer, E. (2006). The structure and process of emotional experience following nonmarital relationship dissolution: Dynamic factor analysis of love, anger, and sadness. Emotion, 6, 224-238. doi:10.1037/1528-3542.6.2.224

Scheerhorn, D. R. (1991). Politeness in decision-making. Research on Language and Social Interaction, 25, 253-273.

Schneider, C. S., \& Kenny, D. A. (2000). Cross-sex friends who were once romantic partners: Are they platonic friends now? Journal of Social and Personal Relationships, 17, 451-466. doi:10.1177/0265407500173007 
Schrodt, P., \& Afifi, T. D. (2007). Communication processes that predict young adults' feelings of being caught and their associations with mental health and family satisfaction. Communication Monographs, 74, 200-228.

Serewicz, M. C. (2006). Getting along with the in-laws: Relationships with parents-inlaw. In K. Floyd and M. T. Morman (Eds.), Widening the family circle: New research on family communication (pp. 101-116). Thousand Oaks, CA: Sage.

Shortt, J. W., Capaldi, D. M., Kim, H. K., \& Owen, L. D. (2006). Relationship separation for young, at-risk couples: Prediction from dyadic aggression. Journal of Family Psychology, 20, 624-631.

Sprecher, S. (1994). Two sides to the breakup of dating relationships. Personal Relationships, 1, 199-222. doi:10.1111/j.1475-6811.1994.tb00062.x

Sprecher, S., \& Felmlee, D. (1997). The balance of power in romantic heterosexual couples over time from "his" and "her" perspectives. Sex Roles, 37, 361-379. doi:10.1023/A:1025601423031

Stephen, T. (1987). Attribution and adjustment to relationship termination. Journal of Social and Personal Relationships, 4, 47-61. doi:10.1177/0265407587041004

Sutter, D. L., \& Martin, M. M. (1998). Verbal aggression during disengagement of dating relationships. Communication Research Reports, 15, 318-326.

Tashiro, T., \& Frazier, P. (2003). "I'll never be in a relationship like that again": Personal growth following romantic relationship breakups. Personal Relationships, 10, 113-128. doi:10.1111/1475-6811.00039

Terhell, E. L., Broese van Groenou, M. I., \& van Tilburg, T. (2004). Network dynamics in the long-term period after divorce. Journal of Social and Personal 
Relationships, 21, 719-738. doi:10.1177/0265407504047833

Teven, J. J., \& McCroskey, J. C. (1997). The relationship of perceived teacher caring with student learning and teacher evaluation. Communication Education, 46, 1-9. doi:10.1080/03634529709379069

The U.S. Department of Health and Human Services. (2002, July). Cohabitation, marriage, divorce, and remarriage in the United States. Retrieved July 15, 2008 from www.cdc.gov/nchs/data/series.

Trees, A. R., \& Manusov, V. (1998). Managing face concerns in criticism: Integrating nonverbal behaviors as a dimension of politeness in female friendship dyads. Human Communication Research, 24, 564-583. doi:10.1111/j.14682958.1998.tb00431.x

Tuccitto, D.E., Giacobbi Jr., P. R., \& Leite, W. L. (2010). The internal structure of positive and negative affect: A confirmatory factor analysis of the PANAS. Educational \& Psychological Measurement, 70, 125-141. doi:10.1177/0013164409344522.

U.S. Bureau of the Census (2008). America's families and living arrangements. Retrieved October 12, 2008 from http://www.census.gov/population/www/socdemo/hh$\underline{\text { fam.html. }}$

Vangelisti, A. L. (1994). Messages that hurt. In B. H. Spitzberg \& W. R. Cupach (Eds.), The dark side of interpersonal communication (pp. 53-82). Hillsdale, NJ; Lawrence Earlbaum Associates, Inc.

Wagoner, R., \& Waldron, V. R. (1999). How supervisors convey routine bad news: Facework at UPS. Southern Communication Journal, 64, 193-209. 
doi:10.1080/10417949909373134

Waller, W. (1937). The rating and dating complex. American Sociological Review, 2 , 727-734. doi:10.2307/2083825

Watson, D., Clark, L. A., \& Tellegen, A. (1988). Development and validation of brief measures of positive and negative affect: The PANAS scales. Journal of

Personality and Social Psychology, 54, 1063-1070. doi:10.1037/0022-3514.54.6.1063

Weber, A. L. (1998). Losing, leaving, and letting go: Coping with nonmarital breakups. In B. H. Spitzberg and W. R. Cupach (Eds.), The dark side of close relationships, (pp. 267-306). Mahwah, NJ: Lawrence Earlbaum Associates.

Weintraub, M., \& Wolf, B. M. (1983). Effects of stress and social supports on motherchild interactions in single and two-parent families. Child Development, 54, 12971311.

Weiss, R. S. (1975). Marital separation. New York: Basic Books.

Whitehurst, D. H., O’Keefe, S. L., \& Wilson, R. A. (2008). Divorced and separated parents in conflict: Results from a true experiment effect of a court mandated parenting education program. Journal of Divorce and Remarriage, 48, 127-144. doi:10.1300/J087v48n03_08

Wilmot, W. W., Carbaugh, D. A., \& Baxter, L. A. (1985). Communicative strategies used To terminate romantic relationships. The Western Journal of Speech Communication, 49, 204-216.

Young, S. L. (2010). Positive perceptions of hurtful communication: The packaging matters. Communication Research Reports, 27, 49-57.

doi:10.1080/0882409093526562 
Young, S. L., Paxman, C. G., Koehring, C. L., Anderson, C. A. (2008). The application of a facework model of disengagement to unrequited love. Communication Research Reports, 25, 56-66. doi:10.1080/08824090701831800

Zhang, S., \& Stafford, L. (2008). Perceived face threat of honest but hurtful evaluative messages in romantic relationships. Western Journal of Communication, 72, 1939. doi:10.1080/10570310701828628 
Appendix A

Perceived Face Threats (Cupach \& Carson, 2002)

Using the scale below, rate your level of agreement with each statement by placing the number that best indicates your feelings in the blank provided.

\section{Strongly Disagree}

1
2
3 $\begin{array}{lll}4 & 5 & 6\end{array}$
Strongly Agree
7

1. My former spouse's actions were polite.

2. My former spouse's actions showed disrespect toward me.

3. My former spouse's actions damaged the relationship between us.

4. My former spouse's actions took away some of my independence.

5. My former spouse's actions were rude.

6. My former spouse's actions invaded my privacy.

7. My former spouse's actions strengthened the relationship between us.

8. My former spouse's actions made me look bad in the eyes of others.

9. My former spouse's actions were rude.

10. My former spouse's actions were insensitive.

11. My former spouse's actions showed contempt toward me.

12. My former spouse's actions constrained my choices.

13. My former spouse's actions were tactful.

14. My former spouse's actions were justified.

15. My former spouse's actions made me feel obligated to comply.

16. My former spouse's action made me feel like I had no control.

No reverse coded items

Positive Face Threat items: 1, 2, 3, 5, 7, 9, 10, 11, 13, 14

Positive Face Threat Range: 10-70

Negative Face Threat items: 4, 6, 8, 12, 15, 16

Negative Face Threat Range: 6-42 
Appendix B

Revised Instructional Face Support Scale (Kerssen-Griep, Trees, \& Hess, 2008)

Consider the messages you received during the divorce process. Use the scale below to indicate the degree to which you agree with each statement.

1

\section{Not at all}

3

4

7
6

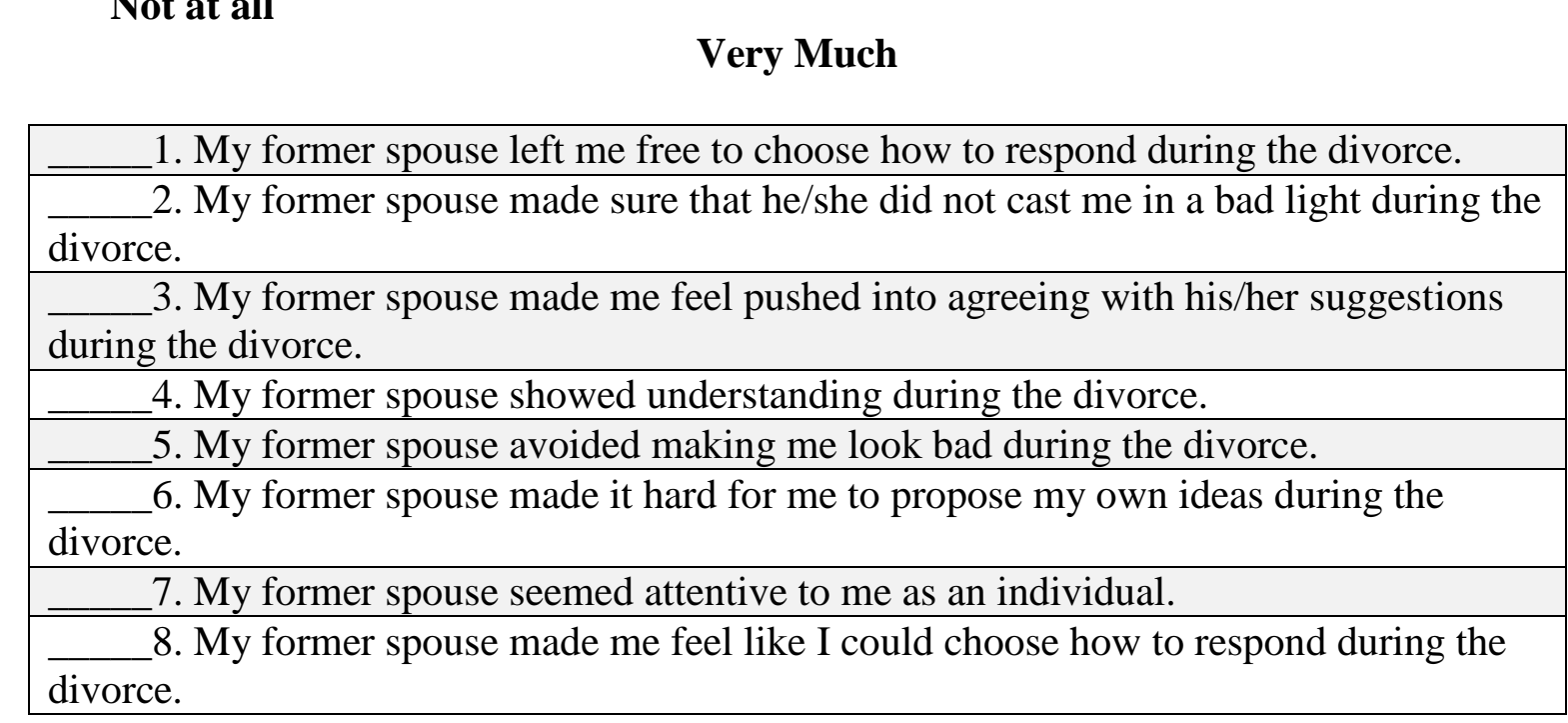

Reverse code: 3,6

Negative Face Support items: 1, 3, 6, 8

Negative Face Support Range: 4-28

Positive Face Support Items: 2, 4, 5, 7

Positive Face Support Range: 4-28 
Appendix C

Conflict (Brissette \& Cohen, 2002)

Please circle the number that best describes the severity or intensity of the conflicts you experience with your former spouse.

$\begin{array}{ccccc}1 & 2 & 3 & 4 & 5 \\ \text { Not } & & & & \text { Extremely } \\ \text { Intense } & & & & \text { Intense }\end{array}$




\section{Appendix D}

Source Credibility- Goodwill/Caring Dimension (McCroskey \& Teven, 1999)

Based on your impressions of your former spouse, evaluate your former spouse during the conversation that you described. Circle one number per set of adjectives, the closer the number is to one of the adjectives, the stronger your perception of your former spouse. If you feel both apply, or feel neutrally, circle the middle number. During the event, my former spouse:

\begin{tabular}{|lcccccccc|}
\hline Cared & 1 & 2 & 3 & 4 & 5 & 6 & 7 & Did not care \\
\hline Had my interests at heart & 1 & 2 & 3 & 4 & 5 & 6 & 7 & $\begin{array}{c}\text { Did not have my interests } \\
\text { at heart }\end{array}$ \\
\hline Was self-centered & 1 & 2 & 3 & 4 & 5 & 6 & 7 & Was not self-centered \\
\hline Was concerned with me & 1 & 2 & 3 & 4 & 5 & 6 & 7 Was unconcerned with me \\
\hline Was insensitive & 1 & 2 & 3 & 4 & 5 & 6 & 7 & Was sensitive \\
\hline Was not understanding & 1 & 2 & 3 & 4 & 5 & 6 & 7 & Was understanding \\
\hline
\end{tabular}

Reverse Code: $1,2,4$

Perceived former spouse caring range: 6-42 
Appendix E

Hurt (Zhang \& Stafford, 2008)

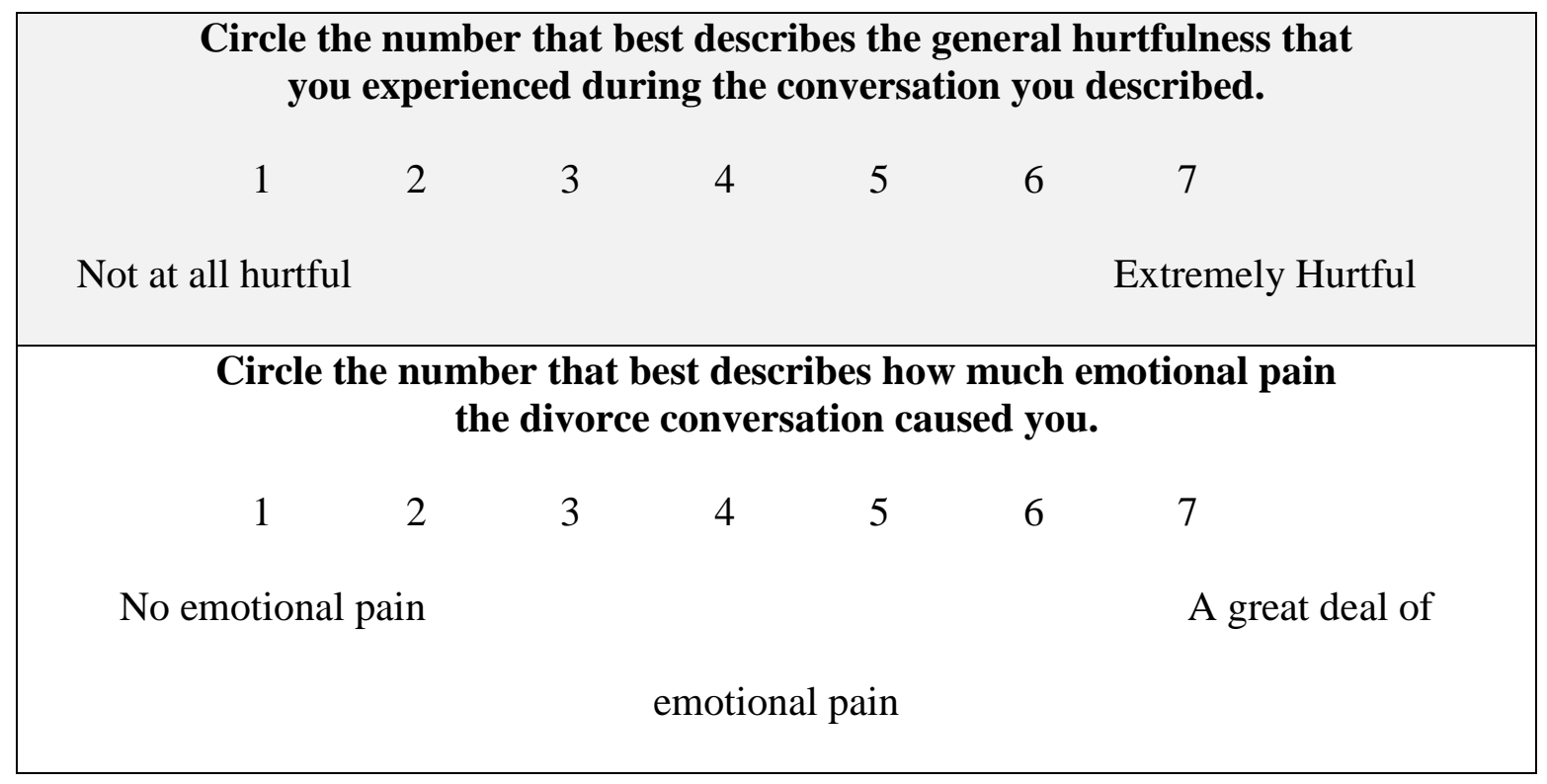




\section{Appendix F}

Positive and Negative Affect Schedule (Watson, Clark, \& Tellegren, 1988)

Using the scale below, indicate the extent to which each word describes how you felt during the conversation you recalled between you and your former spouse concerning the decision to divorce.

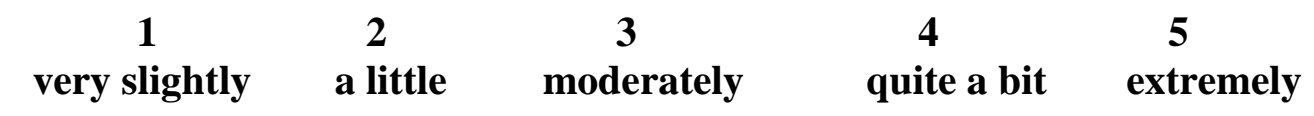

\begin{tabular}{|l|}
\hline 1. I felt interested \\
2. I felt irritable \\
\hline 3. I felt distressed \\
4. I felt alert \\
\hline 5. I felt excited \\
6. I felt strong \\
\hline 7. I felt inspired \\
\hline 8. I felt determined \\
9. I felt attentive \\
\hline 10. I felt active \\
\hline 11. I felt guilty \\
\hline 12. I felt nervous \\
\hline 13. I felt jittery \\
\hline 14. I felt hostile \\
\hline 15. I felt proud \\
\hline 16. I felt upset \\
17. I felt ashamed \\
\hline 18. I felt scared \\
\hline 19. I felt enthusiastic \\
20. I felt afraid \\
\hline 21. I felt love \\
\hline 22. I felt anger \\
\hline 23. I felt sadness \\
\hline
\end{tabular}

Positive Affect Items: 1, 4, 5, 6, 7, 8, 9, 10, 15, 19, 21

Positive Affect Range: 11-55

Negative Affect Items: 2, 3, 11, 12, 13, 14, 16, 17, 18, 20, 22, 23

Negative Affect Range: 12-60 


\section{Appendix G}

Perceived Stress Scale (Cohen, Kamarck, \& Mermelstein, 1983)

Please use the scale below to indicate how often each statement describes you.

$\begin{array}{ccccc}\text { Never }^{0} & 1 & 2 & 3 & 4 \\ \text { Very Often }\end{array}$

1. In the last month, how often have you been upset over something that happened unexpectedly?

2. In the last month, how often have you felt that you were unable to control the important things in your life?

3. In the last month, how often have you felt nervous and "stressed"?

4. In the last month, how often have you dealt successfully with irritating life hassles?

5. In the last month, how often have you felt that you were effectively coping with important changes that were occurring in your life?

6 . In the last month, how often have you felt confident about your ability to handle your personal problems?

7. In the last month, how often have you felt that things were going your way?

8. In the last month, how often have you found that you could not cope with all the things that you had to do?

9. In the last month, how often have you been able to handle irritations in your life?

10. In the last month, how often have you felt that you were on top of things?

11. In the last month, how often have you been angered because of the things that happened were outside of your control?

12. In the last month, how often have you found yourself thinking about things you have to accomplish?

13. In the last month, how often have you been able to control the way you spend your time?

14. In the last month, how often have you felt difficulties were piling up so high that you could not overcome them?

Reverse code: $4,5,6,7,9,10,13$

Stress Scale Range: 0-56 
Appendix $\mathrm{H}$

Attachment to Spouse Scale (Kitson (1982)

Using the scale below, please indicated the extent to which the statement describes your feelings.

$\begin{array}{ccccc}1 & 2 & 3 & 4 & 5 \\ \text { Not at all } & & & & \text { very much }\end{array}$

1. Everything I do seems like an effort.

2. I find myself spending a lot of time thinking about my ex-spouse.

3. I'm feeling like myself again since the divorce.

4. Sometimes I can't believe we got a divorce.

5. I find myself wondering what my ex-spouse is doing.

6. I have no interest in anything since the divorce.

7. I'm angry at my ex-spouse.

8. I do not feel any guilt about the divorce.

9. I feel I will never get over the divorce.

Reverse code: 3,8

Continuing Attachment to Spouse Range: 9-45 
Appendix I

Affective Learning Scale (Andersen, 1979)

Please circle the number that best indicates how you would rate your current relationship with your former spouse. Circle one number per set of adjectives, the closer the number is to one of the adjectives, the stronger your perception of your former spouse. If you feel both apply, or feel neutrally, circle the middle number. My overall relationship with my former spouse is:

\begin{tabular}{|llllllllr|}
\hline 1. Bad & 1 & 2 & 3 & 4 & 5 & 6 & 7 & Good \\
\hline 2. Valuable & 1 & 2 & 3 & 4 & 5 & 6 & 7 & Worthless \\
\hline 3. Unfair & 1 & 2 & 3 & 4 & 5 & 6 & 7 & Fair \\
\hline 4. Negative & 1 & 2 & 3 & 4 & 5 & 6 & 7 & Positive \\
\hline
\end{tabular}

Reverse code: 2

Overall affect toward former spouse range: 4-28 
Appendix J

Post-divorce Relationship Typology (1987)

How would you characterize your relationship with your former spouse (check the one that best applies)?

$\square$ we are good friends, we still discuss task and personal matters

$\square$ we are cooperative in task related matters, but have little personal interaction

$\square$ we are not friends but avoid conflict, we communicate due to necessity

$\square$ we are not friends, angry, and engage in frequent, serious conflict

$\square$ we have no contact with each other 
Appendix K

Positive Turning Points

**Note: The turning point descriptions are written in the participants' own words and may include grammar and spelling errors.

1

I feel that the most positive turning point after my divorce was when my car broke down and I had no one else to call but my ex. He came picked me up and was kind about the whole incident and the tension has been much less since that.

2

At our older son's wedding reception, he stopped me and said 'We did a good job, didn't we? It wasn't always perfect, but we did the best we could'. I said 'Yes, we did'. Then we hugged. That's when I knew that although we had our problems, we always had our childrens' best interest at heart.

3

After the divorce, when I ended my relationship with her ex best friend

4

My ex-husband and I were able to reconcile with each other and recognize that the relationship moved too fast and marriage came too quickly. We didn't know eachother as well as we thought we did. We talked at a family gathering and actually got along quite well, but we both kept our emotional distance. We were civilized.

\section{5}

There was not a positive relationship with my former spouse after the divorce. We went our separate ways and I have found happiness. He was not someone who I wanted to be in contact with after the divorce was final. To this day I see the relationship as a positive step to where I am and I do not regret it.

\section{6}

It would have to be when she told me she was going to start dating. We had always discussed that for the kids sake and so the other would not find out through the grapevine, we would be open with the each other regarding future relationships. It stung a little I have to say, but at the same time it was a relief, because now I feel I can go on with my life. Before I go into the details it should be stated that we have communicated on a daily basis since our initial seperation. We are friends but our life together was a rollercoaster and we were both ready for the ride to stop. She called me on a Saturday morning and said we needed to talk, I knew something was going on because she had been distant. She informed me she had met someone and was going to see him on a regular basis and that he was going to be spending time with her and the kids. This event was positive because it meant we would keep our word to one another as parents. 
Rejoicing together in our daughter's graduation from college

8

I just decided that our daughters deserved a better parental relationship that what my parents had after they got divorced. I shared that with her and she agreed. We've been cicil with each other ever since then.

9

We met for lunch at my work a few moths later. Yes it was based on business, but we both genuinely cared how the other one was doing and asked each other as much.

Incidentally, the divorce was not bitter, we still keep in contact to this day.

10

Feeling good about his life after he moved out.

11

After my divorce had end, my exwife and I never spoke until her grandmother had past away. This was a turning point in a positive direction, because she confided in me for emotional support.

12

Our middle son was in an accident and had to have surgery and we worked through this together. He had never been a very considerate person or have any feelings that were noticable. He actully had feelings and we seemed to bond through that.

13

About a year after the divorce was final our dog that we had died. I had kept the dog after the divorce but we both loved him. when he died, my ex came over and helped me dig a hole in the yard for the dog. It was small but $i$ defiantly knew that he cared and that he knew i did too. After this we began to talk normally. Like former friends.

14

Ex-husband came back to homestead (the house where we both lived together as a family and where I still resided) I had asked for his help in cleaning out storage items, I had rented a large container to dispose of any items either one of us needed. This was the first time we worked together, conversed together without any arguments since the divorce. We were able to talk about the past, the present and even a little about our futures as individuals.

15

When my ex-husband finally accepted that we were not getting back together and stopped trying to smother me with constant communication and contact. 
16

To make a decision to sale our house as prescribe by the judgement. I left my former wife in the house about 18 months prior to the divorce. We have two boys, 15 and 10 at that time. My former wife called me the evening of the divorce day to have my opinion about the house issue. From that time our relationship became better than the previous four years.

17

none

18

To be honest there are not many positive events. If there are any, they are quickly followed by a negative event which wipes away and positive feelings. My youngest daughter was recently injured in a sledding accident, fracturing her spine, and shattering a disk in her back. My ex and I were able to work together and do what was right for our daughter during her time in the hospital. My ex is a pediatric Nurse Practitioner and a very good one so I had a lot of trust in her decision making skills, etc. However, those positive feelings are completely gone as money rules the roost.

19

My daughter's wedding. We were able to act and behave like a normal family even though we were divorced. We were able to make agreeable decisions and were an actual couple at the ceremony and reception. When we were married, it seemed like everything ended in an argument. During this important time, we were civil to each other and enjoyed the wedding with family and friends.

20

After we had been divorced for about a year, my ex e-mailed me to say hi, and we ended up having a good conversation that I think gave us both some closure. I told him about how I felt bad about what had happened and that I had realized, that I was never really committed to the marriage and probably shouldn't have gotten married in the first place. He responded that he had had a feeling about that prior to our marriage and that he understood. We both agreed that we were better off divorced and that getting a divorce had been for the best because we were both thriving as people after it. He thanked me for the time we had spent together and for being his best friend for several years.

21

When he asked for help/advice with a financial situation. It was positive because it seemed he valued or recognized my opinions again.

22

Attending my daughter's first communion with my spouse and my ex-spouse and his wife was a nice moment, a time when I believed things were on a positive path toward cooperation and collaboration for the betterment of our daughter. Although the event was organized and coordinated by me (since my ex did not have the same faith), he was happy to participate and pleased to take part in the ceremony. I saw it as a foreshadowing 
of future events in my daughter's life in which we would all come together (e.g., graduations, perhaps her wedding).

23

We have always had strong communication and still speak, we got married WAY too young. A positive turning point I would have to say is being able to still speak and see each other.

24

I a not sure if there has been a positive turning point. My former spouse still is hopeful that we will get back together. We are friendly to each other but sometimes it makes it worse for him. He still does not fully accept that our marriage is over and it had problems, if being truly honest, right from the beginning.

25

About a year after the divorce became final, we realized that we needed to get along for the sake of the children. It was if a light bulb went off in our heads to make us understand that the past is in the past and we need to shape our childrens' future.

26

The reason we split was because $i$ cheated on my wife and we were young both in our early twenties and overseas in the NAVY. Might sound cliche but its true, that you dont know what you have till its gone. After I had told her I had cheated she filed for divorce and told me she never wanted to see or hear from me again. Two months went by when we didnt even talk after the divorce till one day she called and said that she wants me to know that if $i$ show her that $i$ have grown up and $i$ become person she knows i can be than to call her and she will give me a second chance. So prior to getting that call i never thought $\mathrm{i}$ would ever talk to her again. This gave me something to strive for. I just had to prove $\mathrm{i}$ was responsible done fooling around and ready to be an adult and in a grown up relationship

27

A postive turning point was when my daughter started college. It proved to us that despite the situation and the hardships the family suffered, our children were still strong, responsible adults.

28

the most prevalent event that i can recall was when my ex wife and i could come together to make sure that my son had a good life. we would work together on making sure that he had a suffiecent amount of tom not only with me his father but also the motherly support he needed.

29

We realized we had to become civil that later turned into a friendship for the kid's sake because of joint custody. We felt it was healthier for all involved if we remainded civil to one another. 
30

I would like to believe it was my continuing to provide legal help when needed for her and her side of the family when needed, free of charge and my agreeing to pay for all of my son's college expenses instead of requiring her to fulfill her required obligatory share of our son's college expenses.

31

Began sending corrospondance about my son without me asking for it (normally I have to ask many times for information). She sent drawings he had completed (he is 4 years old) without my request. It was a turning point because it was something that I didn't have to request whereas everything else I need to make multiple requests to receive information for the past few years.

32

There has not been any positive turning points with my ex-husband.

33

After going out for dinner for the first time, we both realized we were completely different from one another however it attracted us more than just appearance. We were very interested in learning about each others life style, one being from the country while one being from the city.

34

A positive turning point was when we decided to be civil with one another, and decided to become friends again, this was hard after a painful divorce.

35

After the divorce was final our friendship relationship was able to take the forefront. My grandmother had a heartattack and I called him to tell him what happened. We had been together for 9 years and our families were very important to us. During the discussion of my grandmother's condition I noted that he seemed to have finally realized that he would not get back with me and that he accepted we would be friends. The tone of voice and direction of conversation led me to this conclusion. About 8 months after the divorce was finalized we had our first real friend conversations where everything from the past was discussed. I believe that this was the true turning point for us that was precipitated from the conversation of my grandmother several months before.

36

My Ex wife and I were always able to talk to each other after the divorce, which made it easier when we no longer talked or saw each other again.

37

I really can't think of anything in particular that has been positive. We haven't reached that point 
About 2 years after the divorce, my ex husband started to spend time consistently with our daughter. We were then able to create a consistent schedule so that she knew when she would see him. It allowed them to develop that critical bond between father and daughter and also allowed them to get to know each other without other people's persuasion.

39

My former spouse remarried and moved to the state his new wife was from. This was positive because I felt free of him, no kids were involved so I had a chance to start over.

40

after the divorce was final we still talk on the phone 2 or 3 times a week just to talk about our daily live. see each other sometimes in the weekends with our friends and try to enjoy the the good times with friends all together

41

He reached a point after all of the hurt and pain he was feeling, when he realized that it was best to get along for our son.

42

My ex-husband and I absolutely did not get along at all until I was remarried, and my current husband told him that I was not single any more and he could not just treat me however he wanted, if he didn't respect me, he would have him to answer to. I was on the phone with my ex husband, about visiting our child, or possibly about the money he owes me, I am not sure which one. He (the x) got mouthy with me, as usual, and my husband took the phone from me and told the $\mathrm{x}$ he would no onger treat me like that. Up until about this point, I did not get along with his new wife, either. His new wife is also his X-wife before me.

43

There have been none.

44

I was watching a movie about a little girl who's parents were divorced and near the end of the movie, i was overwhelmed with emotions and sadness of seeing the child without both of her parents together and the child not understanding. I had been having feelings of still loving my ex and mising him, but this movie made my realize that I did not want my family like that. So i immediately called him and told him how I felt and much to my disbelief, he felt the same way. This took place 1 month after the divorce was final. I felt I had to divorce him b.c he had an affair and carried on a relationship with this woman for a year and a half. It seemed once the divorce was final, all the anger left and I was just left with love and missing my husband. I should have waited it out or tried harder instead of thinkning I had no other option since he had an affair. 
45

My former spouse \& I have been through many ups \& downs since our divorce. We have finally realized that we need to work together instead of against each other to raise our children. My ex-husband was with a very controlling partner that did not want him to help in anyway with the children \& did not want us to communicate about them. We would have to sneak to discuss them. I would say that when they split up it was the best thing for everyone. Now we can all be friends we can talk. Him \& my new husband are friends \& it makes life much easier for our children. That has to be the most positive event for us.

46

I needed a new vehicle. My ex-husband knew this and knew that I could not get approved by myself. He took it upon himself to put the car in his name so that I could have it. This was a positive step towards us remaining close friends and confidants.

47

The positive turning point for me was when we actually began to talk as civilized adults, rather than hot-headed kids.

48

We bumped into each other getting coffee. I would say this experience was positive. This provided a chance for us to talk and to check up with each other.

49

No response

50

We have had to pay for our son's college, and have worked amicably to do so. It has worked out so well, and has really helped our friendship grow. It is such a positive thing when two divorcees can come together for that sort of thing, especially when it comes to monetary issues.

51

One day my Mother threw him out of the back-yard she was always on his side. She finally saw the light

52

The birth or our first grandchild. It made the two of us realize that even though our relationship as husband and wife was over, our relationship as a family was still strong and would always remain.

53

When he told me he moved on, I helped him plan how to propose to his future wife. Satisfying to know that he is happy and really am over him. 


\section{4}

It would probably be a few weeks after finalizing the divorce. We decided to meet up at a concert just to see how each other was doing. Yeah, I know that did seem like a small time period, but the divorce itself went pretty well, considering that it was a divorce. Anyway, we simply went there as friends and both had a good time. We didn't bring up anything from the past. We didn't have any arguments. We were simply two people who enjoyed the concert together. I think it was a positive turning point because it was the first time after the whole process that we could just be ourselves again. Of course, we both knew that there was no way we'd get back together again, but we both knew that the other person was going to be OK. We knew we could speak to each other again without worrying about any problems arising.

\section{5}

Our divorce was a mutal agreement..although there were some negative feelings that occured through it all, we managed to remain adults throughout the proceedings. We went our separate ways, but he did always contact me when I had mail that was still being delivered to our old address that he thought was important and would make arrangements to take it somewhere where I could pick the mail up without contact with him. I appreciated this gesture because it limited the contact with him, deflecting for both us a possible uncomfortable encounter.

56

I really can not say that I had a positive turning point except for the fact that I had full custody of my son. My ex-husband moved out-of-state and did not show up for any aspect of our divorce.

\section{7}

A positive turning point after the divorce with my spouse was when he realized I was never coming back to him, so he stopped giving me a guilt trip and finally let me be at peace.

\section{8}

Contacting spouse after hearing his father had passed away and reaching out to him. He was cordial and thankful for my support and my family who were with him out of state for funeral services.

59

One of the main positve turning points was when our daughter was able to drive to meet her father. I did not have to worry about her not getting a ride home or that he refused to bring her back.

60

I have not had any positive turning points in my relationship with my former spouse. The most positive thing that has happened is that I moved 1000 miles away from him. After I moved away, the relationship has changed in several ways. He has not broken into my 
house, he has not come to the house in the middle of the night, he has not stolen anymore from me.

61

I can't recall a positive turning point. We remain distant and have as little communication or contact as possible. It was a bitter divorce, and it has been difficult to get past the hurt and abuse that was done to me.

62

The only thing positive about the finality of our divorce was he was no longer a part of my life. We don't speak to this day because he is abusive and cruel.

63

No response

64

I would say the turning point in the relationship after the divorce was our son Grayson's 4th birthday party- the first family event after the divorce was finalized. We both realized that we had to set our personal feelings aside and be parents. This made me see that though my relationship with Scott was over he would always be in my life as Grayson's dad, and I couldn't let my feelings about him interfere with our childrens' lives.

65

I believe that positive event in my relationship with my former spouse was when we could finally have a civil conversation that did not end in anger or tears. We could discuss how his weekend or my weekend with the children was without being sarcastic or discuss how each of us could attend our children's sporting events without it being awkward.

66

I have been going through my divorce for over a year and a half. I can't really say there has been a positive turning point as of yet. We are going through a custody battle so things still have a tendancie to get pretty heated.

67

The positive turning point for me was just knowing that everything was over and that i'm now able to live a stress free life.

68

There was no turning point. I have not spoken to him since I signed the papers.

69

No response 
70

The only positive thing is that once the divorce papers were signed we didn't have any further communication at all.

71

We were able to communicate better after he got a girlfriend. He stopped being so mad about our divorce and accepting of the situation when he had someone else to focus his attention on.

72

The reason for the divorce was because of him cheating. Once his relationship with her was over and I had moved on and began to date I felt our relationship improved. I was so satisfied that their relationship didn't last. Also, this is the point where he actually began to feel like what he did was wrong and wanted me back. Although this was difficult and hurtful it made me feel better about him because I knew he did love me despite what he did to me.

73

Attending my son's baseball game with my former spouse and her new husband. We were both newly remarried. All of us attending the game was a concern, but ended up being a pleasant evening. My son was especially pleased with the outcome.

74

I honestly feel there was no positive turning point after my divorce. she left me, took my son to $\mathrm{HI}$ and im still tying to find her. no contact after the divorce.

75

several months after our divorce was final I was approached by my boss, the principal of the school In which I teach. he wanted to let me know that he had been confronted by the parents of an unhappy student who was threatening to transfer to another school. When asked why the parents mentioned several circumstances and situations they were dissatisfied with. After each of those was dismissed and cleared up the parents also mentioned that they were friends of my ex-husband and felt their child might be uncomfortable with me in the building. I have never taught this student, and rarely even saw him in the school; so of course this shocked me as well as my principal. He informed these parents that I was not an issue of any kind for their child. I was very upset by this and confronted my ex about his friends attempt to place me in a difficult position. Instead of dismissing the incident and refusing to discuss it, as he does with most attempted conversations, he appologized for his friends. He assured me that he knew nothing of their unhappiness with the school, or my being there and wholeheartedly agreed with my principal. He promised me he would tell his friends to leave me alone.

76

i had no place to keep my dog until i got a house and he kept it for me for a couple of months 
77

I don't really recall a turning point, per se. My divorce was amicable from the beginning. Though the divorce was my idea, I was very open in communications with my former spouse. In turn, he was open in his communications with me. If I could pick a time when it was a true turning point, I would have to say it was when, after the divorce, I had a heart-to-heart conversation with him over the phone about our relationship and expressed to him that I was sorry the relationship did not work, but that I truly believed the split was necessary for both of our happiness. He, in turn, expressed that he was very hurt by the failure of the relationship, but that he was moving on. Since then, we continue with very open communications, primarily about our son with whom we have joint custody.

78

The turning point for me was when I envited my ex to our sons birthday party and relized that we could still be friends even though we could no longer live together.

79

we went to dinner together to catch up on our lives. we both paid for our meal seperately. we also talked about how we would continue our relationship in the future as friends so things wouldnt be awkward if we were to run into eachother.

80

When my ex and I started seeing other people. We were able to talk about it as if we were friends. Before our divorce there was so much fighting and arguing that we couldn't talk about anything. It was nice to have him as a friend and remember what I liked about him.

81

We finally accepted that for our son's sake we must get along. I accepted that he decision to end the marriage did not make him a bad father.

82

A positive turning point was about a year after the divorce I went to a mutual friends birthday dinner and she was there. We sat down and had a productive conversation, now we remain friends

83

Several months after our divorce was finalized my ex-wife and I went to a mutual friend's wedding reception and were able to have a normal conversation with one another. I felt like this was a positive turning point because it was the first time since the divorce that we both seemed to have things figured out.

84

after we divorce 2 days later we started talking again. 
85

I honestly don't know that there has been one. The divorce itself was the last really positive thing that ever occurred between us.

86

A discussion ensued about my ex wife's new boyfriend (now husband) and that he was moving in. She related to me that she was unfair in her treatment of me during our marriage and it gave me some closure.

87

I do not think I can help you with the survey. There have not been positive points. I have had to take her back to court for her violating my parenting rights.

88

Well my wife and I switch off with the kids every other weekend and I had them one weekend and the next I wanted to take them camping with me and she decided it was alright and let me take them two weeks in a row which i thought was pretty nice and positive 


\section{Appendix L}

\section{Negative Turning Points}

**Note: The turning point descriptions are written in the participants' own words and may include grammar and spelling errors.

1

I never had a neagative turning point after the divorce was final.

2

After the divorce was final we had issues surrounding our kids. We have two kids and the divorce was very difficult on our oldest son. He felt a lot of anger towards me because of how the divorce unfolded. There was not a specific "turning point", but I would say that my relationship with my son affected my relationship with my ex-husband in a negative way.

\section{3}

she cheated

4

so many, but unfortunately, I'm not a negative or begrudging person. Beat me down today, I'm still there tomorrow. My ex kept clothes from the children. Sent them with absolutely nothing. I had to purchase entire wardrobes to include winter coats and boots, gloves, everything.

\section{5}

Working out child care and visitation with my former spouse.

6

Well, my ex-husband and I still had to file taxes jointly for 2009 and we used his email for the confirmation. He is stationed in VA and I reside in WV so we had to do it online. When I was checking his email I saw a notification where he sent a girl flowers. I confronted him about it and it blew into a huge fight. This is coming from a guy who apologizes to me constantly about how he treated me but never tries to fix anything. Since hes been with this girl we havent really spoken at all. He calls me but I never answer anymore.

7

My wife came to me on a weekend in July and said she wanted a divorce. She told me she no longer loved me and that the spark was gone. 
8

He disappeared from my and our son's life. I helped him thru his drinking problems and geting his life back. Only to have him quit being a father. I do feel that was the biggest turning point after the divorce. The asbent father figure.

\section{9}

there has been no comunication after the divorce was final.i havent talked to her since the day of the divorce.if $i$ had to describe a negative turning point it would have to be the divorce hearing itself.she did not get everything she wanted and became very angry with me,we havent spoke since.

10

His little involvement with the children.

\section{1}

We started to argue alot before we actually called it guits. we argued about money, friends, clothes and it used to be worse when we would have a couple of beers on the weekend. Instead of talking things out we screamed at each other and even called each other names and in front of the children.

12

The father of my children (I like to refer to him this way as opposed to my ex) and I have tried very hard to have positive communication for the kids. However, we had a joint debt that he felt I was not taking care of quickly enough. I tried to explain and used a four-letter word to emphasize that you I was doing all I could do and that you "can't get blood from a *\&\%^ing turnip."

13

he was very jalse about me even between me and my cousen, and some time he don't lat me to do what $\mathrm{i}$ want to do it has to be he like or not to do it

14

After the divorce was final, our negative turning point was still fighting over our child.

15

She was sleeping with another man

16

a volatile arguement, which led to a domestic violence charge, in which jail time was involved.

17

I really dont have any negative points after our divorce was final. My ex and I mutually wanted a divorce to pursue different careers . 
18

A meeting to discuss jointly owned rental properties seemed to be a negative turning point.

19

Ex-husband starting running around with very unscrupulous women to whicn he just gave all his money away and also has a really bad gambling problem which takes away all his money we worked together to make. He was very tight with me when we were together.

20

When my ex stopped taking my children

21

While at church, the ex-wife dragged my son away from me and spat back at me, "It's because he likes me more than you!"

22

When I found out that she had begun to drink alcohol, something that she had never done before. I found this out from my ex in person.

23

After the divorce, my ex husband asked me not to sell the house but to let him live in it until our girls were out of high school and then we would sell it. One day prior to selling the house I was at the house helping him clean and get it ready to sell. He had let the house go, and it was a mess. Along the day I put a few things in the back seat of my cara trophy of my son's, a stuffed animal of my daughter's, some earrings and a calendar. My daughter borrowed my car several times that day to do errands, and at one point she stopped back by the house we were selling. He noticed the things in the back seat- and threw a fit in front of my daughter and her friend. He physically removed the items, embarassing her, and accused me of stealing things from the house. The next week I got a letter from his lawyer stating that if $i$ ever attempted to steal items from the house again I would be reported to the police. I was infuriated, at the thought of putting my kids in the middle of that situation, of it looking like a $i$ was stealing valubale items and $i$ realized i could not trust him to exagerate a situation to his advantage, so I never stepped foot in that house again. I raised my children there- we bought it together- and there were items of momento $i$ wanted. But $i$ knew $i$ would never get them and that was his way of getting to me. I was also very upset that my daughter took his side and told me i should have never taken the items- that $i$ was wrong. He delighted in making me look bad legally, in fron of family and friends, and i would no longer cooperate with him.

\section{4}

A few months after the divorce, my "ex" (Nicholas's father) found a new girlfriend and moved in with her. She had 2 children, both by different men and my "ex" chose to raise her children, not his own! Finding out he didn't care about his own child, but would raise someone else's, ripped me apart inside. I didn't care he was with her or her kids...I only cared that he wouldn't have anything to do with his own. The turning point for me was 
when I found out, after running into them as a family, at Walmart. It hurt me deeply to see that he really didn't care about his own son and I have spent my life trying to make-up for it. For years I wouldn't tell Nicholas who his father was...only that he was a "friend." I couldn't do that to Nicholas. I didn't want Nicholas to feel unwanted by his father or feel he had done something wrong. His father and I never speak and haven't in years, even though he lives within a 15 mile radius. The effects this had on Nicholas have left emotional and mental scars which he does a good job of hiding, but I can see them sometimes.

25

One negative point is when I first started dating, my ex made me feel like a bad parent when my daughter tried to call me and couldn't get ahold of me because my phone was out of service.

26

My divorce is not yet final, it will be final within five days. I first separated from my husband in April 08, after which he moved back in after several weeks after I had surgery to help with the children. He left the final time in Dec. 08 and we didn't live together after that. There was a lot of verbal, emotional, mental, and sometimes physical abuse towards me and towards the children by him. I felt that the relationship was past saving, and even though we still lived together after the first separation, the relationship was over. I started seeing another man in September, two months before he moved out in December. I carried on a relationship with this man for over a year. In August 09 I decided to file for divorce. My husband became increasingly desperate, and once when he was at the marital residence visiting with the kids, he ransacked through my papers and found a printed email between myself and the man I was seeing. From that point forward, he started to stalk and harass, and continues to do so to this day. He broke into my email, via guessing my security questions, and changed my password. He printed off several month's worth of email exchanges between me and my boyfriend before I found out the account was compromised. He told the children repeatedly on many occasions that I was a whore, bitch, slut, etc. and also spread rumors about me to all my friends, our mutual friends, and family. He obtained cell phone records from my phone and called every single number I had any exchange with for three years. He found out via the email account that my boyfriend was very strongly attached to his dogs. He found out where he lived, and mixed a large quantity of peanut butter and D-Con rodenticide and left it inside his fence, so his dogs subsequently ate it and were poisoned. He is facing criminal charges for the poisoning. He leaves me harassing voicemails filled with profanity, he violates the court order we have stating that he is not supposed to have any contact with me other than having to do with the children, he withholds child support, he deliberately will not work a job so that he only pays very little in support, he follows me when I am out in public, he stalks me when I am shopping, etc., he drives past my house repeatedly during the day and night, he comes to my house and leaves objects on my porch and comes into the back yard and leaves things there to let me know he's been there and that he's watching me. He leaves objects on my car when I am parked in other places to let me know he's watching. He does not exercise visitation with his children on the schedule set by the court, he only takes them sporadically about once a month at best. I have had 
very little luck with the courts so far. The only charge I have been able to place has been for phone harassment, and he was found not guilty, with the caveat that if he repeats it, he will automatically be found guilty. His behavior has cost me the relationship with my boyfriend. He has estranged his children from him with his behavior. It has been a nightmare.

27

After 5 and half years of marriage, my husband abrutly initiated a divorce that was completed within 61 days (the allowable time in out state). Immediately following our divorce, I maintained minimal contact with my former husband related to a few financial things (closing bank accounts, transfering car loans, etc), and I thought all of it was taken care of. However, about a year and a half later, he called accusing me of stealing about $\$ 10,000$ from his bank account--the one that I thought was closed because I had signed my forms to close it and he said he had done the same. When I first saw the phone call, I had a silly hope that he was finally calling to apologize for all of the pain he had caused for leaving me so abruptly. Needless to say, the fact that he called to accuse me of stealing money was the exact opposite of my expectation and it was that point when I fully realized that he really didn't care about my feelings and had been harboring false hopes for an apology. After this call, and a lot of tears, I finally came to terms with this dimension of our divorce. As it turns out, he hadn't actually closed the account, my name was on it, and had gone into this overdraft because the state took their taxes out of the account (he was deliquent in taxes for a small business). After we got this sorted out, I started to get calls from creditors. Some were looking for my ex-husband. Others were demanding that I make payments on a checking account that had been overdrafted. This began a long process of interactions between us in which I was reminding him to make payments on these accounts (and had to pay some money myself at times to avoid penalties). I was persistent because I wanted my record cleared, but I wanted him to pay for what he had done. During these interactions, he agreed to those principles, but he couldn't actually act on this because he had other debts that he was taking care of. Apparently, following our divorce, he had gotten into severe debt, mismanaged the business, and generally lived an irresponsible life. About a year after the first phone call, he initiated a phone call with me asking for the name of his first boss. My ex-husband wanted to get a full time job with this former employer. I fully supported this move because I wanted him to have income to pay the debts and supplied him with the information. A year after beginning this job, my ex-husband finally paid his debts (and even paid back my parents a large sum of money they had lent him for starting the business). Throughout the whole process, I believed him when he said this was his intent, I was just skeptical about his ability to see it through. I also noticed that in our interactions, he continued to seek my approval like he had during out marriage. I might have been a little mean for withholding it, but then again, I didn't approve of how he had gotten himself (and me) in a lot of financial difficulty. Furthermore, I was saddened to see the path that his life had taken because it was very different from the dreams and ambitions of the man I had married. I feel that the initial interaction was negative because, at the time, I believed that I due an apology for the divorce and instead was accused of theft. The following interactions were negative because I didn't want to have to deal with all of his financial problems, but was legally obligated. Once again I found 
myself having to be in a supportive role for him, even though he had left me. After this event, I trust my ex-husband even less. He has taken actions to try to disprove my trust and will concede that to him. But I don't ever intend to get into financial obligations with him again (this is made easy since we don't have any interactions now).

28

When I returned to my Maiden name, my ex husband was very upset.

29

when he stop helping with my son and took on the roll of helping someone else with there kids that pissed me off and I looked at him very different.

30

My ex wife decided to move 3+ hours away from where I live and where she had been living. My son had to leave the school and friends he loved as well as I could no longer coach his soccer team. He was and still is very upset about this, I realized that me ex really would never but the needs of our son before her own. She wanted to move to be close to her boyfriend and the boyfriend apparntetly is more important than our son.

31

The settlement stated that my ex-wife would be responsible for the majority of the accured debt, including credit cards, loans, etc. However, she filled bankruptcy and I ended up paying off her debt. By filing bankrupcy, she was protected from paying off her debt and because my name was on them, I became responsible and payed them off. This did not sit well with me, but moved on because we have a 7 year old son that we share jointly.

32

I received custody of the kids.

33

No response

34

I had to meet my ex spouse at the bank for him to pay me my alimony. When I arrived he had his mistress or what ever you call her with him. I had seen her before but with her being there I felt he was showing her off, not that she was a prize but I felt after all the time we were married,20 years he wouldnot be so cruel. We had just celebrated our aniversary of 20 years.

35

When my ex-husband met his new wife and tried to change things with our son that he and I had agreed upon and had been doing for quite a while.

36

There was no negativity after the divorce. 
37

The negative turning point is that he did not speak to the children anymore after the divorce and has nothing to do with them.

38

In my relationship the negative turning point was when he was not doing anything. Would not help with cleaning up or help to pay bills. I was working 16 hours a day 5 to 6 days a week to make the bills. It was negative because I felt like I was single in a marriage. Plus he was also trying to keep me from my family.

39

A major turning point after our divorce would have to be her unwillingness to compromise with the visitation of my children. She moved 300 miles away just so she could have total control over our sons.

40

the worst moment was when she indicated that if $i$ sought extended access to the children, she would accuse me of spousal abuse, there by preventing me from any access what so ever. As there had never been abuse, and it was used solely as an intimidation tactic, it was a very negative experience. She went so far as to indicate to her parents that I had assaulted her in the past. (to their credit, and to an extent mine, they did not believe her)

41

After I got custody of our son, my former spouse was extremely hostile toward me. He called me names and threatened me. He showed up at my house and demanded that he see his son, and I had to call the cops, but eventually he left.

42

He would not pay for anything for my kids. He buys only for himself and not my sons....now thats a turning point.

43

I believe the relationship changed for the worst after the divorce when I found out my ex was dating a mutual friend. It was negative because I tried having respect for him because of everything we went through but he couldn't go out and meet someone new and now I have to hear about them together all the time. Just disrespectful

44

Once the initial divorce was finalized, the ex wanted to start dating and immediately allow our 4 year old daughter to meet whoever he was dating. Our divorce hadnt even been finalized 6 days when this conversation occurred.

45

All of the negative turning points in my relationship occured prior to my divorce. Prior to the divorce I found out my exhusband had a 20 year relationship with another woman and 
had a son with her. We were married 30. Nothing shocked me after I found out this information.

46

When my son, Nick was about 5 years old and decided that one particular weekend visitation, he didn't want to go to his dads. He said they always did the same thing on that weekend and his dad asked him "don't you love daddy anymore" and I blew up.

47

When I realized that I had just spent the last several years commiting to a relationship that was over and that the stablization of a home for my son was over.

48

My former spouse would not help pay for the extra things the kids wanted to do.

49

There havent been any positive events since the divorce, but fighting for custody over our child was a terrible event. She took me to court because she did not want to have joint custody and she got full custody. It was negative because it caused more problems and she got my son.

50

The relationship between my former spouse and myself had deteroriated long before the divorce was final due to something that he did to his oldest two daughters.

51

When he was not willing to pay child support until it was in writing. He was not willing to take responsiblity until he was told to do so. It did not make anymore negative it just reinforced why I was going through this divorce.

52

My ex husband became more controling. It seemed I was unable to do much outside the relationship. At the most negitave point we were having a argument and he became physical an pushed me into a wall.

53

He moved in with his girlfriend and then threw our adult disabled daughter out when she complained about her. He just dropped her off at my house.

54

I don't recall any negative event after finalizing the divorce.

55

No response 
56

When moving my belongings out of the house I moved his motorcycle out of the way in the garage to enable me and my friends to move my boxes easier. He knew I was moving my items that day and despite that he had his own personal gear set up on the kitchen table, so I left the kitchen table alone. Later that day he called me to tell me that if I want the kitchen table and chairs I should get them because they are out on the front lawn waiting to get picked up by the garbage collectors. He said he was irritated that items were moved close to his motorcycle, so he retaliated by throwing the table and chairs into the drainage ditch, causing damage and scratches to the table and chairs. I felt that this was one final example of him jumping to conclusions and not seeing the big picture. $\mathrm{He}$ also knew when I was coming to pick up my stuff and what the stuff was that I was picking up, so he should have at least cleared off the table. For me, this was the point when I knew I had made the right decision since this was one final example of him losing his temper and only seeing things from his point of view.

57

After being divorced three years, I purchased a condo. The ex-spouse started making negative comments about "living in luxury" to the children. However, he is financially better off then I am, and could easily afford a nicer home than mine!

58

When I asked for Child Support and he didn't want to. Our agreement was that he didn't have to pay child support so that he could afford transportation to Texas to visit her regularly. He never came to visit, so I asked for the money. He thought it was unfair.

59

The children would go with their father on the weekend and come home with bags full of dirty clothes. It was as if he thought that he was babysitting my children. When I confronted him, he explained that he didn't have time to wash the clothes. I didn't think that it was necessary for the children to keep separate clothes at his house because they grow out of the clothes so quickly. It would be a waste of money.

60

She said i did not spend enough time with her.

61

interaction with former spouses's new wife; this occurred during the funeral for my ex inlaw

62

My ex-husband denied having a child with me from the day I found out about the pregnancy. We were divorced when my daughter was 4 months old and he denied to his entire family that she was his child, and demanded a paternity test. 
63

A time where I was meeting my ex to drop off clothes for our 3 year old and he would not even allow me to say hello to our son.

64

continued to aleniate emancipated children toward me.

65

problems with the kids after they had stayed with her under her supervision

66

My former spouse and I did not agree on sending our children to private vs public high school. I felt they would be better off in public high school she felt otherwise. I went o public high school she went to private.

67

Right after our divorce was final, my former spouse came to get some odds and ends he left at the apartment we had shared together. When he came he brought several of his friends, and he acted like I meant nothing to him and continued to talk about another woman. This was negative because it made me feel terrible about myself and the relationship I had with him.

68

I never actually saw my wife after it was final, but the one thing that changed our relationship was when her sister caught me in a threesome with a really fat girl and a guy I've never met. I'm completely serious.

69

My ex tried to continue with his controlling ways after the divorce. Even though we had a court order as to how much support he would give, he told me that he didn't have to pay as we were no longer in the state of FL and our decree was nul and void

70

The critical moment that changed our marriage was when my ex-husband became a police officer. I felt it was negative because it changed him as a person. He was a minister in the church, but after becoming an officer he no longer acted like a minister.

71

Take your pick. A major turning point after the divorce was when my former spouse filed a false domestive violence complaint against me. It was during a time when we were exchanging the kids for visitation and she was also sharing their report cards with me. I became upset that she would not let me review the report cards with the kids over the weekend. I reminded her that the parenting plan requires it. The next day after I had dropped the kids off police arrived at my door and took me in for processing because she complained that I physically threatened and intimidated her and forcefully lunged at her 
with my fists. Despite having witnesses to the contrary, the protective order remained in effect for one year.

72

No response

73

After the divorce was final, my ex and I were left to exchange the remaining items that each of us still had in our possessions of the other person's. We were communicating through email only, trying to set up a mutual time. I was working full-time and going to school full time, so my time was very limited. After several rounds of emails of not being able to settle on a mutually good time, my ex began to threaten me, both with threats of physical violence (i.e., if you don't cooperate I'll come to your house and beat your door down, and you'll be lucky if I don't beat you in the process), and also empty threats of intimidation (i.e., I'm going to show up with the Sheriff and have you arrested.) I tried explaining over email that he was proposing times that were not good for me - I was in class, I had a work commitment - and tried to propose alternative times, which he said did not work for him. He finally became so aggressive that I called the police myself, filed a complaint of harassment against him, got a restraining order, and ended up having to arrange for a 3rd party to make the exchange of goods for us. I obviously felt it was negative because I was being harassed and threatened. I will add though, that our divorce was very negative and contentious, so at this point, I already felt our relationship was changed for the negative.

74

My former spouse contacted me after the divorce was final and asked if we could get coffee to "tie up loose ends". I learned that he meant that although he did not want to be married, he still wanted to "date" me, which was very awkward and painful, seeing as I tried everything to make it work. I felt frustrated and confused to his intentions, also why he waited until the divorce was final to try to make amends.

75

No response

76

A negative turning point in our relationship with my ex-husband after the divorce was final was between me and him with him not complying with paying his child support. Payment almost always would come late if they ever came at all, when I asked him why he was not making his child support every month he told me that it was because he did not feel it right that he have to pay so much when I had the kids full time when I asked him if he would like to have the kids more often he responded with he didn't have the time.

77

We were never negative, per say, but the one and only comment that I made that was negative that ended all communication between us was one evening he texted me saying 
that he had been to the doctor because he was experiencing heart problems and the comment I texted back was maybe he should quit drinking.

78

We had a trustee account for both daughters. As part of the MSA we agreed to make my spouse(wife) the sole exexcuter of the accounts and that the funds were to be used only for the children's education. It also stipulated that the funds use could be used in another matter as long as both of us agreed in writing. The MSA also stipulated that if my spouse used the money without contacting me, then I would be legally named exector for all remaining funds. My wife on 2 occassions violated this agreement for amounts exceeding $\$ 15,000$. I sent her a letter and a copy of the signed MSA informing her I wanted to enforce this stipulation. She shared this with the children in such a manner that my daughters thought I was suing my spouse which was a complete twisting of the facts and both daughter expressed utter rejection towards me and told me they would never talk to me again. 